\title{
Hospital system design : creating supply flexibility to match demand variability
}

Citation for published version (APA):

Molema, J. J. W. (2009). Hospital system design : creating supply flexibility to match demand variability. [Doctoral Thesis, Maastricht University]. Datawyse / Universitaire Pers Maastricht.

https://doi.org/10.26481/dis.20091113jm

Document status and date:

Published: 01/01/2009

DOI:

10.26481/dis.20091113jm

Document Version:

Publisher's PDF, also known as Version of record

\section{Please check the document version of this publication:}

- A submitted manuscript is the version of the article upon submission and before peer-review. There can be important differences between the submitted version and the official published version of record.

People interested in the research are advised to contact the author for the final version of the publication, or visit the DOI to the publisher's website.

- The final author version and the galley proof are versions of the publication after peer review.

- The final published version features the final layout of the paper including the volume, issue and page numbers.

Link to publication

\footnotetext{
General rights rights.

- You may freely distribute the URL identifying the publication in the public portal. please follow below link for the End User Agreement:

www.umlib.nl/taverne-license

Take down policy

If you believe that this document breaches copyright please contact us at:

repository@maastrichtuniversity.nl

providing details and we will investigate your claim.
}

Copyright and moral rights for the publications made accessible in the public portal are retained by the authors and/or other copyright owners and it is a condition of accessing publications that users recognise and abide by the legal requirements associated with these

- Users may download and print one copy of any publication from the public portal for the purpose of private study or research.

- You may not further distribute the material or use it for any profit-making activity or commercial gain

If the publication is distributed under the terms of Article $25 \mathrm{fa}$ of the Dutch Copyright Act, indicated by the "Taverne" license above, 


\section{Hospital system design}

creating supply flexibility to match demand variability 
The research for this thesis was performed at the department of Health Organization, Policy and Economics, within the School for Public Health and Primary Care (CAPHRI), Faculty of Health Medicines and Lifesciences, Maastricht University.

Part of the research was performed with the financial support of the Netherlands Organization for Health Research and Development (ZonMw) and the Aravind Eye Care System.

Printing: Datawyse / Universitaire Pers Maastricht

Cover design: Leanne Bongers

Lay-out: J.J.W. Molema

ISBN 9789052788746

(C) J.J.W. Molema, Maastricht 2009 


\title{
Hospital system design
}

creating supply flexibility to match demand variability

\author{
DISSERTATION
}

to obtain the degree of Doctor at the Maastricht University, on the authority of the Rector Magnificus Prof. dr. G.P.M.F. Mols,

in accordance with the decision of the Board of Deans, to be defended in public

on Friday 13 November 2009, at 16.00 hours

by

Johanna Jacoba Wilhelmina Molema

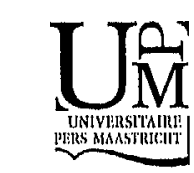




\section{Supervisor}

Prof. dr. G.G. van Merode

\section{Assessment Committee}

Prof. dr. C. Spreeuwenberg (chairman)

Prof. dr. J.A.M. Maarse

Prof. dr. A.C. Nieuwenhuijzen Kruseman

Prof. dr. ir. J.M.H. Vissers (Erasmus University Rotterdam)

Prof. dr. J. de Vries (University of Groningen) 
"So eine Arbeit wird eigentlich nie fertig; man muss sie für fertig erklären wenn man nach Zeit und Umstanden das Möglichste getan hat" J.W. von Goethe (1787)

Voor mijn ouders en Adriaan die altijd 'das Möglischste' voor mij doen 


\section{CONTENTS}

Chapter I Introduction 9

Chapter 2 Flexibility in hospitals through parttime working doctors 25

Chapter 3 Specialty labeling limits patient flow continuity 43

Chapter 4 Creating cross-functional wards in hospitals to improve 63 patient flow

Chapter 5 A vision on hospital system design: Aravind Eye Hospital

103

Chapter 6 Analyzing hospital system design - How supply flexibility 103 can improve performance

$\begin{array}{ll}\text { Chapter } 7 \text { General discussion and conclusions } & 127\end{array}$

Summary 146

$\begin{array}{ll}\text { Samenvalting } & 148\end{array}$

Acknowledgements 152

Curriculum Vitae $\quad 155$

$\begin{array}{ll}\text { List of publications } & 157\end{array}$ 


\section{CHAPTER 1}

Introduction 
When a patient goes to a hospital, he expects to receive the care he needs, at the moment he needs it [1]; yet, being a patient is almost intrinsically bound to waiting [2-4]. Patients are not just waiting on waiting lists to gain access to a hospital but, once inside, continuous flow is lacking and patients are likely confronted with (high) in-process waiting times [5-7]. Only few hospitals are designed to achieve optimal patient flow [4]. The design of most hospitals gets patients entangled in jumbled, stop-start flows that impede a lean progress of a treatment $[4,8,9]$. In such hospitals, patient appointments are cancelled or delayed and patients themselves are transferred back and forth between departments. Such outcomes incur hospital costs and can decrease the quality of care [10].

Most hospitals do not seem able to adequately match demand and supply. This can be derived from the fact that most hospitals are characterized by waiting lists and in-process waiting times as well as inefficient use of (human) resources. Due to the higher demands placed on healthcare by the ageing population as well as the increase of acute care services and co-morbidity and poly-morbidity, the need for a better match between supply and demand becomes even more evident $[4,11,12]$. This thesis aims to explicate opportunities for matching supply to demand in hospitals from the perspective of operations management.

\section{Current hospital systems}

Patient demand can be defined as the care and quality of care that patients ask for or need from a hospital system at a specific time and place. Hospital supply, in this respect, can be defined as the care and quality of care that is offered at a specific time and place and by the (human) resources that are elements of the hospital system. Previous studies have shown that the imbalance between demand and supply in hospitals can be explained with insights from operations management $[3,4,8$, 9, 13-16]. Operations management $(O M)$ is concerned with the design, operations, and improvement of production systems that create an organization's output $[17,18]$. OM has many dimensions, one of them being 'design and control' [19]. Through design and control, systems should match supply and demand, such that waiting times for customers are minimized and resource utilization is maximized [18].

In their strategy, hospitals lay down what services they want to offer and to whom. Many hospitals, additionally, express in their mission statement that 
they aim to serve their patients as well as possible and strive to deliver patient centered care. The way hospitals are designed and use resources determines what they supply to patients and how they can treat their patients. From the viewpoint of $O M$, a hospital delivers patient centered care when it designs its system to achieve continuous patient flows without cancellations and delays $[8]$.

Most hospitals are home to a variety of medical specialties and departments that each focus on their own patients, staff and non-human resource capacities $[9,14]$. The overall system is more a virtual organization and each department functions as an independent system, treating a range of more or less homogeneous patient groups [7]. As such, performance control at the departments focuses on local optimization and is not always aligned to what is optimal for patients [20]. For example, the focus on medical specialties means patients might have to wait, e.g., for a bed or for an operating room of specialty A to become available, while specialty B has several beds idle or operating time available. Also, as more than half of the patients demand care from more than one specialty, the tension between patient flow and local optimization is rising [20].

The local (sub)optimization is a result of the functional organization of hospitals [21]. That is, if hospitals are structured into specialty departments, more coordination is needed [20]. We could say that hospitals, with their functionalistic structure, are complex systems [9]. Complexity can address both the materials processed in a system and the processing itself. In hospitals, the materials processed are the patients and their demands. Patient demands can be complex in a sense that patients demand care from multiple medical specialties or that their disease is rare or highly medically complex [9] Demands can also be complex when one disease manifestation can have multiple causes or when the relation between cause and effect is ambiguous [20]. Complexity stemming from demand can also be the result of non deterministic arrival times of demand, which cause uncertainty about when service is required [22]. Processing in hospitals can be complex when a treatment process has many coordination and transfer points and/or when multiple specialties are involved [9]. Complexity can also result from nondeterministic treatment times, which make it difficult to coordinate the processing [22].

Maruster et al. assume that the more specialties or physicians involved in a treatment, the more complex the case is [20]. Ideally, from a patient's perspective, the complexity of processing should depend on the complexity of 


\section{G}

his demand. This is, however, not always the case. If we take the functionalistic structure of hospitals as an example, this structure and its processing complexities do not always have a relation with the medical complexity of demand. Patients that need some diagnostic tests, diagnostic imaging (e.g. an X-ray), and a visit to a doctor, currently need to make several appointments and need to come back several times [23]

Supply should not only match demand in terms of complexity, but also in terms of variability. Changes in demand often occur in hospitals and are the result of inherent non-uniformity, or variability $[5,18]$. This variability causes uncertainty for hospitals and can affect system performance [5, 18, 22]. By creating variety in its resources and generating options to do things differently if demand changes, hospital managers can create a system state needed to respond to variability and minimize its effects $[24,25]$. This requires the system to be flexible [26].

To minimize waiting for patients and maximize resource utilization, demand and supply should match. Hospitals can achieve this through structuring the system such that system complexity and flexibility are aligned to demand complexity and variability. In this thesis, demand complexity and variability are treated as a given, i.e. a constant factor, and it is studied how supply can be matched to demand. In the next paragraph, a conceptual basis is given for studies conducted within this thesis.

\section{System structure, planning and control}

A system is a collection of entities, e.g., people, machines, tasks, or subsystems, that act and interact together to accomplish objectives [27], System structure represents the relations amongst the entities in the system, whether and how elements are divided into subsystems, how coordination amongst the entities is achieved, and how the system functions [28-33]. To structure a system, planning and control decisions need to be taken [34].

\subsection{Planning and control}

Production control in a hospital concerns, within the boundaries set by evidence based medicine, the design, planning, implementation, and control of coordination mechanisms between patient flows and workflows. Hereby, production control aims to maximize output with available resources and minimize waiting times and costs, while ensuring delivery flexibility [7]. Planning and control decisions need to be made to manage supply on a daily 
base and structure the hospital as a whole in the long run [35]. Through the decisions, hospitals can trade-off between patient service levels and resource utilization. Service levels, expressed in e.g. patient waiting times, can be increased by making more resources available to patients. The latter decreases the probability of patients waiting for resources and thus increases service levels from an $O M$ perspective. In contrast, increasing the number of available resources can affect the resource utilization level and make the overall use of resources in a system less efficient.

The trade-off between patient service levels and resource utilization is made for the hospital as a whole as well as for each of the departments and patient groups the hospital aims to serve [7]. This implies that planning and control takes place on different levels. In fact, it varies from strategic planning, to medium-term planning, and day-to-day decisions $[25,30,34,36]$. The decisions made on the different levels serve different purposes. Table 1 displays a hierarchical framework of planning and control of hospital supply that encompasses both the planning levels and their purposes.

Based on the hospital's strategy, a group of patients is selected that will be serviced in the hospital. This group of patients has an inherent variability in terms of demand mix, volume and delivery (how many patients of what type will demand care when?). Next to that, the medical complexity of the cases is a given. To provide patient centered care and optimize service levels, supply in the hospital should be matched to this demand within the boundaries set by evidence based medicine. From an $O M$ viewpoint, the goal of matching supply and demand would be to minimize patient waiting times and unnecessary transfer points, while maximizing resource utilization. Following on $\mathrm{OM}$, this match can be strived for through planning and control. Hereto, hospitals can use the hierarchical planning framework in table 1.

The framework in table 1 can be used top-down, which means that first the long-term strategy and the patient mix are defined before medium-term decisions are made regarding the volume and skill mix of resources and the grouping of patients and resources into configurations. Finally, more short-term decisions are made to, e.g., define the daily allocation of resources to single patient groups. 
Table 1: Hierarchical planning and control framework $[25,36]$

\begin{tabular}{llll}
\hline & Purpose & Planning horizon & Scope \\
\hline $\begin{array}{l}\text { Strategic } \\
\text { planning }\end{array}$ & $\begin{array}{l}\text { Decide what services to offer } \\
\text { and in what form to offer them } \\
\text { (organizational archetype) }\end{array}$ & Long-term & Hospital as a whole \\
$\begin{array}{l}\text { Patient volume } \\
\text { planning \& } \\
\text { contral }\end{array}$ & $\begin{array}{l}\text { Trade-off between service level } \\
\text { and resource utilization; } \\
\text { decisions are made regarding } \\
\text { patient mix }\end{array}$ & $\begin{array}{l}\text { Medium-term } \\
\text { (production period) }\end{array}$ & Hospital as a whole \\
$\begin{array}{l}\text { Resource } \\
\text { planning \& } \\
\text { control }\end{array}$ & $\begin{array}{l}\text { Determine required resource } \\
\text { volume and skills }\end{array}$ & $\begin{array}{l}\text { Medium-term } \\
\text { (production period) }\end{array}$ & Each patient group \\
$\begin{array}{l}\text { All patient } \\
\text { groups }\end{array}$ & $\begin{array}{l}\text { Define market performance } \\
\text { objectives; acquisition of } \\
\text { resources; control of patient } \\
\text { flow; utilization }\end{array}$ & $\begin{array}{l}\text { Medium-term } \\
\text { (production period) }\end{array}$ & Each patient group \\
$\begin{array}{l}\text { Decouple production phases } \\
\text { ingle patient } \\
\text { group }\end{array}$ & $\begin{array}{l}\text { Shat deal with different levels } \\
\text { of uncertainty }\end{array}$ & $\begin{array}{l}\text { Shay) } \\
\text { darm (day-to- }\end{array}$ & $\begin{array}{l}\text { Processes used in } \\
\text { facilitating day-to- } \\
\text { day patient activities }\end{array}$ \\
\hline
\end{tabular}

\subsection{System structure}

Through planning and control of patient volume, resources, and patient groups hospital managers can structure the hospital and its departments. The structure that follows from the planning and control decisions determines the flow of both work and customers within the system and impinges on the required variety in resource skill levels within and between subsystems as well as on the interchangeability of resources and skills across subsystems [18].

First, patient volume planning applies to determining the aggregation level of demand for queues and the grouping of specific patient groups, like acute and elective. Next, resources have to be planned. Whom and what is needed to treat the specific patient mix that has been strategically chosen as target demand by the hospital management. Not just the volume in terms of number of workers and the hours they are available is important, but also the skills of each of the workers. The skills of the workers determine which demand mix can be treated and whether a changeover in the mix over time can be dealt with in the system. The third step in planning and control is the allocation of all these resources and their skills to the specific patient groups. After these three steps, the contours of the structure are fixed. If workers and resources are grouped based on medical specialty, a functionalistic structure has arisen; if they are grouped based on a specific treatment process, a process structure has arisen. Herewith, the processing complexity in the system is determined. The final set of planning and control decisions relates to the daily control of activities in the hospital. 
2.3 Implications for matching demand and supply

The state of a system describes that system at a particular time [27]. It describes the resources available, their skills, how they are allocated to processes and patient groups, etc. Whether demand and supply match, depends on the state of the system. If demand and supply do not match, the state should be altered. The decisions in the planning and control framework define, to a large extent, both the system state and the opportunities to manipulate the system state.

The top-down approach to planning and control has several consequences for the match that can be achieved between demand and supply. For one, the choice'for a certain product mix, resource skill mix, and/or resource aggregate in a system determines how fast and at which cost the system can move from one state to another. If, e.g., a product is added to the product mix, the available workers may need to be re-educated or new workers need to be hired. Both interventions cost money and time [18, 31]. Or, costs arise if work contracts are extended in a situation where the product volume increases and work contracts are not initially open to minimum-maximum work hour constructions and the work is too complex for temporary workers [18]. Costs and time can also be associated with adapting the layout of a building or using non-human resources in another way than originally intended [9]. For example, if for the production of a new product a machine has to be altered, this will cost money. Or, adding a product to the mix might require extending the system by adding an element.

Another consequence is that the long-term planning decisions determine the degrees of freedom for short-term planning and control. In fact, the choices on each level determine the ability for a system to respond to changes in demand on that level as well as on the lower levels in the framework. The responsiveness of a system can be defined as "the actions or behavior of a system using a set of capabilities to purposefully and timely address changes triggered by stimuli" [26]. A change in demand can be such a stimulus. For example, if there is an epidemic or when processing is innovated resource volume or resource skills need to be adapted. Also, daily fluctuations in demand can require short-term changes in resource volume or skills available [37]. The set of capabilities that enables the responsiveness of a system depends on flexibility in the system. 


\section{CHAPRE I}

\subsection{Conceptual model}

In literature, a collection of studies is described that study several relations between system structure, demand, and supply in hospitals, with the aim of achieving some match between them [e.g. 3, 4, 8, 9, 13-16]. Figure 1 aims to bundle the elements introduced in literature and provides insight into the relations between them, from an $O M$ perspective. The model displays that, depending on the planning and control decision and the system structure, a system can be characterized as complex and/or flexible. The complexity and flexibility of the system should match the complexity and variability of demand.

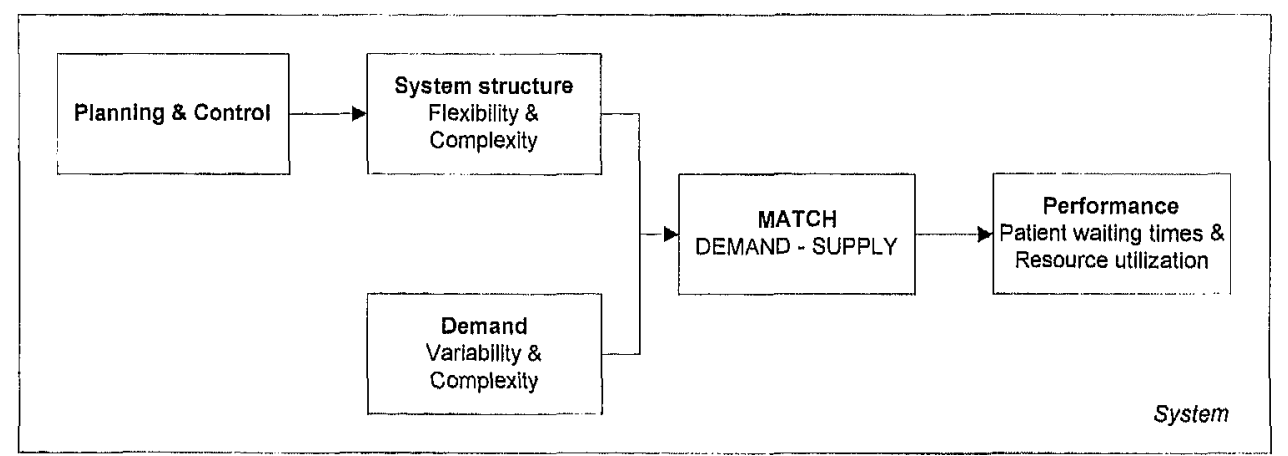

Figure 1: Conceptual model

Figure 1 was used to answer the central research question in the thesis, namely: "given the variability and complexity of demand in a hospital, how should planning and control be organized so that the system structure enables a match between supply and demand, resulting in low patient waiting times and high resource utilization?" The main assumption for the model is that flexibility in supply provides opportunities for matching supply to demand. To ground this assumption, the next paragraph will define supply flexibility and relate it to hospital systems.

\section{Flexibility}

The extent to which a system is able to create variety in the mix and/or volume of resources in a system, so that the system state can be changed without adding resources or fundamentally changing the resources, can be attributed as supply flexibility [26]. 
3.1 Supply flexibility - when and how?

Tachizawa \& Thomsen [38] argue that flexibility in supply is needed when uncertainty arises concerning the demand mix (what is needed?), demand volume (how much is needed?), and/or delivery (when is it needed?). Creating flexibility into resource volume or mix can enable a system to adequately respond to these drivers without having to acquire new resources or fundamentally change the ones available. In this respect, Gerwin [39], Schmenner \& Tatikonda [40], Purbey et al. [41], and Cousens et al. [42] introduce ways in which supply can be flexible:

- Mix: ability to produce different products at the same point in time;

- Changeover: ability to deal with changes in the product mix over time;

- Rerouting: ability to change the operating sequence through which the parts flow;

- Volume: ability to easily make changes in the aggregate production amount;

- Sequencing: ability to reorganize the procesing of different kinds of parts; How flexible a system is, i.e. how much variety can be generated, depends on characteristics of the system elements and their interrelations. For example, it will be easier to re-route products through the system when processes in the system are standardized [43] or when resources are grouped based on tasks and processes instead of based on function [18]. Skill levels of workers and the interchangeability of workers and skills across subsystems or departments also affect the supply flexibility $[18,39,41]$. Cousens et al., in this respect, state that flexibility in resource volume and mix can be enabled through employment policies and work contracts, cross-skilled staff and creating flexible resource aggregates [42].

3.2 Enabling flexibility through planning and control

Following from the described hierarchical planning framework, we might assume that the level of flexibility in a system depends on the planning freedom that remains after the long-term and medium-term planning decisions. The long-term and medium-term decisions to functionally structure a hospital limit the hospital's ability to respond to changes in demand in the short-term. If we retrospectively assess the example of the beds allocated to specialty $A$ and specialty $B$, we can say that the lack of an appropriate bed for patients is the result of the functionalistic structure. Because the decision to aggregate beds to specialties is a medium-term decision (see table 1), it can not be undone in the short-term and patients need to wait. Were beds not specialty labeled bu 


\section{CHAPTERT}

aggregated on a higher level, the probability that a patients needs to wait would decrease. Also, grouping resources on a level other than that of medical specialties may result in less patient transfers. Structuring the hospital differently can thus create flexibility to respond to changes in patients' demands.

For example, MRI capacity in hospitals is often split up in time slots, which are allocated to different medical specialties or patient types. If a patient arrives at a time the specific medical specialty does not have the MRI at its disposal, this patient needs to wait; sometimes days or weeks. Were the MRI capacity not allocated to types of specialties or patients but used on a first in - first out basis, the patient might not have to wait this long. Another example relates to hospitals in which nurses are mono-skilled. Each nurse can perform a limited set of tasks, most often within a specific medical specialty. When the nurse is busy, patients in need of these tasks need to wait as nobody else can perform them. Would the medical specialty of the hospital deploy a group of multiskilled nurses, these nurses could be assigned to the process where they are most needed.

The attractiveness of a particular structure depends on the hospital's strategy [44]. For example, if the aim is to offer integrated care to chronic patients, a configuration would fit that in its structure integrates the resources that patients require. This could be a structure that groups together staff members of different medical specialties that can coherently perform multiple tasks. On the other hand, if the aim is to offer a specific fast-track surgery service, a configuration would fit that in its structure supports this specific task and medical specialty. To make the flow of patients from this configuration to, for example, after care in a nursing home continuous, both configurations need to attune their admission and discharge policies. The choice for a structure thus also determines the aggregation level of demand or supply in a system, i.e. how different demands and resources are collected into groups with the same aggregate label, task or function [18]. Next, the skill level of resources should correspond to the structure of the configuration. In a functional structure, specialized resources are grouped together $[9,21]$. In a process oriented structure, the skills required to complete the process should be grouped together, which may require grouping different types of resources, of different specialties. The more cross-skilled resources are, the more flexible they can be used amongst configurations [18, 22]. 


\section{Thesis outline}

By studying several questions in the various chapters of this thesis, opportunities for better matching supply to demand in hospitals are studied, under the assumption that supply flexibility provides opportunities for this match.

\subsection{Sub-questions and chapters}

The following questions were studied

- How can flexibility in resource volume be created and what are its effects on patient waiting times and resource utilization?

- How can flexibility in resource mix be created in hospitals and what are its effects on patient waiting times and resource utilization?

- What are the relations between planning and control, system structure, and supply flexibility at an excellent hospital?

Chapter 2, 3 and 4 study how supply flexibility in resource volume and mix can be created in Dutch hospitals. In chapter 2, the relations between system structure in terms of employment policies and work contracts and supply flexibility were studied. Having a pool of flexible employees can benefit an organization and limit discontinuity in flows [9, 42, 45]. We studied how creating parttime jobs for doctors could enable flexibility and how the design of these jobs is interrelated to the design of the system. Chapter 3 discusses how increasing the aggregation level of resources can increase supply flexibility. In this chapter, it is assumed that discontinuity in patient flows can be the result of capacity labeling [4, 37]. Labeling capacity per specialty creates functional aggregates that can serve only a limited set of patients and, herewith, can impede continuous flow. We studied how increasing the aggregation level of beds in a hospital creates opportunities for patient flow management resulting in substantial performance and flow improvement. In chapter 4 , the issue of resource aggregation was further studied. Here, a closer look was taken at achieving a match between supply and demand over multiple departments in a hospital. A model was used to measure the effects that different resource aggregates in the hospital had on the utilization of these resources as well as on the waiting times for patients to be served by these resources.

Chapters 5 and 6 study the relations between system structure and system design in an excellent hospital, i.e. one of the Aravind Eye Hospitals. Aravind Eye Hospitals lead the field by achieving operational excellence by responding to the demands of millions of patients [46]. In chapters 5 and 6 , it 


\section{CMAPTERI}

is analyzed to what extent the Aravind structure provides evidence for the conceptual model of this thesis. In chapter 5 the relations between the structure of a system, supply flexibility and output are studied from the perspective of the Aravind Eye Hospitals. To, subsequently, analyze if the planning and control decisions that Aravind takes lead to the most excellent results or that other decisions lead to at least comparable results, chapter 6 introduces a simulation study. In this study, planning and control at the outpatient department of one of the Aravind Eye Hospitals is studied in detail, and the relations between supply flexibility and system structure are quantified.

This thesis is concluded by a general discussion about what the studies in this thesis contribute to the knowledge about the relations among planning and control, flexibility, and system performance in hospitals. Also, the practical implications of the findings for hospital managers are discussed.

\subsection{Method}

In the various chapters of this thesis, case studies servers as the vehicle for building evidence for the conceptual model in figure 1 as well as identifying gaps or flaws in the model. All studies performed in this thesis were case studies in which the system design of one or more hospital departments were analyzed

Each case under study was modeled. Modeling is a technique often used within $O M$ to gain some understanding of how a corresponding real-world system behaves [27]. Models can be descriptive and/or quantitative. Also, models can be used to explore a system or to optimize a system. Here, both descriptive models and quantitative models were used to explore different situations in which supply flexibility might improve the outcome of the system.

All models were structured as simple queuing models. To study the relations between system structure and output, like customer waiting times and resource utilization, $O M$ applies queuing theory [18]. To understand as well as improve hospital system design and decrease patient waiting times insights from queuing theory can be applied [5]. A queuing model consists of one or more servers that provide service of some kind to customers. Customers who arrive to find all servers busy (generally) join a queve (or line); hence, the name queuing model [27]. Input into the queuing model is the arrival process, which describes how customers arrive in the system (the probability distribution of interarrival times and the corresponding arrival rate). To serve the customers, a service process should be defined which specifies the number of servers, whether each server is preceded by its own queve or there is one queve 
feeding all servers, and the probability distribution of customer service times. Finally, the rules the system uses to choose the next customer from the queve when a server completes the service to the current customer are called queve disciplines. The performance measured in a queuing model is often the number of customers treated per time period, the time customers spend in queves, and the utilization of the servers.

For populating the various models in this thesis, input data were gathered through interviews, observations, and from historic patient daiabases in the hospitals under study. Interviews were always held with a variety of staff members in the hospital, such as doctors, nurses, managers, technicians, and support staff. For the simulation models, especially, quantitative data regarding patient arrival times and service times were needed to characterize the queuing models' basic variables. As far as possible, these numbers were based on extensive data sets. However, not all hospitals have a sound registration system for such data. In these cases, input data were estimaled by a representative group of staff members involved in the modeled process. 


\section{GMAPTR T}

\section{References}

1. Bergeson SC, Dean JD. A Systems Approach to Patient-Centered Care. JAMA. 2006 December 20, 2006;296(23):2848-51.

2. Murray $M$, Berwick DM. Advanced Access: Reducing Waiting and Delays in Primary Care. JAMA. 2003;289(8):1035-40

3. Womack JP, Jones DT. Lean Thinking - Banish waste and create wealth in your corporation. Revised and Updated. New York: Free Press; 2003.

4. Institute for Healthcare Improvement. Optimizing Patient Flow: Moving Patients Smoothly Through Acute Care Settings. Boston: $\mathrm{IHI} ; 2003$,

5. Noon CE, Hankins $C T$, Cote MJ. Understanding the impact of variation in the delivery of healthcare services. Journal of Healthcare Management. 2003;48(2):82.

6. Van Merode GG, Groothuis S. Hospitals as complexes of queuing systems. In: Anderson JG, Katzper M, editors. Health Sciences Simulation 2003; 2003 January 19-23, 2003; Orlando FL: Sociely for Modeling and Simulation International (SCS); 2003. p. 39-44

7. De Vries G, Bertrand JWM, Vissers JMH. Design requirements for health care production control systems. Production Planning \& Control. 1999;10(6):559-69.

8. Walley P. Designing the accident and emergency system: lessons from manufacturing. Emerg Med J. 2003;20(2):126-30

9. Van Merode GG, Molema H, Goldschmidt H. GUM and six sigma approaches positioned as deterministic tools in quality target engineering. Accreditation and Quality Assurance. 2004; 10(1-2):32-6

10. Hendrich AL, Lee N. Intra-unit patient transports: Time, motion, and cost impact on hospital efficiency. Nurs Econ. 2005;23(4):157-64

11. van Bussel B, Pijpers E, Ferreira I, Castermans P, Nieuwenhuijzen-Kruseman A. Polymorbidity in diabetes in older people: consequences for care and vocational training. Postgrad Med J. 2007;83(986):763-7.

12. Nieuwenhuijzen-Kruseman AC, Mulder WJ, Piipers E. Ageing and polymorbidity: is there o mismatch between the training of internists and the need? The Netherlands Journal of Medicine. 2007 365;65(10):636.

13. Molema JJW, Van Merode GG. Case mix and acule care system design. Proceedings of the 2008 Spring simulation multiconference. OHtawa, Canada: ACM; 2008.

14. Parnaby J, Denis TR. Seamless healthcare delivery systems. International Journal of Health Care Quality Assurance. 2008;21(3):249.73

15. Young $T$, Brailsford $S$, Connell $C$, Davies R, Harper P, Klein JH. Using industrial processes to improve patient care. BM. 2004;328(7432):162-4

16. Walley P, Silvester K, Steyn R. Managing Variation in Demand: Lessons from the UK National Health Service. Journal of Healthcare Management. 2006;51(5):309-20.

17. Chase RB, Aquilano NJ. Production and operations management: manufacturing services. 7 th ed. USA: Richard D. Irwin, Inc; 1995.

18. Krajewski LJ, Ritzman LP. Operations Management. 6th Edition ed. Upper Saddle River, NJ: Prentice Hall; 2002.

19. Pilkington A, Fitzgerald R. Operations management themes, concepts and relationships: a forward retrospective of IJOPM. International Journal of Operations \& Production Management. 2006;26(1 1):1255-75.

20. Maruster L, Weijters T, de Vries G, van den Bosch A, Daelemans W. Logistic-based patient grouping for multi-disciplinary treatment. Artificial Infelligence in Medicine. 2002;26(1-2):87. 107. 
21. Van Merode GG. A prelude to the 2004 Antwerp Quality Conference: Targets and target values - integrating quality management and costing. Accreditation and Quality Assurance. 2004:9: 168-71.

22. Hopp WJ, Spearman ML. Factory Physics: foundations of manufacturing management. Second ed. New York: Irwin/McGraw-Hill; 2001.

23. Molema JJW, Kleinschiphorst M, Groothuis S, Pavlova MI, Groot WNJ, Van Merode GG. De effecten van bedriffstijdverlenging in ziekenhuizen. Maastricht: Universiteit Maastricht; 2004.

24. Berwick DM. A primer on leading the improvement of systems. BMJ. 1996;312(7031):619. 22

25. Vissers JMH, Bertrand JWM, De Vries G. A framework for production control in health care organizations. Production Planning \& Control. 2001;12(6):591-604.

26. Santos Bernardes E, Hanna MD. A theoretical review of flexibility, agility and responsiveness in the operations management literature: toward a conceptual definition of customer responsiveness. Infernational Journal of Operations \& Production Management. 2009;29(1):30-53

27. Law AM, Kelton WD. Simulation Modeling and Analysis. Third ed. New York, USA: Tata McGraw-Hill; 2003.

28. Silvestro R. Positioning services along the volume-variety diagonal - The contingencies of service design, control and improvement. International Journal of Operations \& Production Management. 1999; 19(4):399-420.

29. Silvestro R, Fitzgerald L, Johnston R, Voss C. Towards a classification of service processes. International Journal of Service Industry Management. 1992;3(3):62.75.

30. Armistead CG. Service operations strategy: framework for matching the service operations task and the service delivery system. International Journal of Service Industry Management. 1990; 1(2):6-16.

31. Galbraith JR. Designing organizations: an executive guide to strategy, structure and process. New and Revised ed. San Fransico, USA: Jossey-Bass; 2002.

32. Tummers GER, van Merode GG, Landeweerd JA. Organizational Characteristics as Predictors of Nurses' Psychological Work Reactions. Organization Studies. 2006;27(4):559-84.

33. Mintzberg $\mathrm{H}$. The structuring of organizations. Engelwood Cliffs, N.J.: Prentice-Hall, Inc.; 1979.

34. Anthony RN. Planning and control systems - a framework for analysis. Boston, Massachusetts: Division of Research, Graduate School of Business Administration, Harvard University; 1965.

35. Hax AC, Candea D. Production and inventory management. Englewood Cliffs, New Jersey: Prentice-Hall, Inc.; 1984.

36. Van Merode GG, Groothuis S, Hasman A. Enterprise resource planning for hospitals. International Journal of Medical Informatics. 2004;73(6):493-501.

37. Bagust A, Place $M$, Posnett JW. Dynamics of bed use in accommodating emergency admissions: stochastic simulation model. BMJ. 1999;319(7203):155-8.

38. Tachizawa EM, Thomsen CG. Drivers and sources flexibility: an exploratory study. International Journal of Operations \& Production Management. 2007;27(9.10):1115-36.

39. Gerwin $D$. An agenda for research on the flexibility of manufacturing processes. International Journal of Operations \& Production Management. 2005;25(12):1171.82.

40. Schmenner RW, Tatikonda MV. Manufacturing process flexibility revisited. International Journal of Operations \& Production Management. 2005;25(12):1183-9.

41. Purbey S, Mukherjee K, Bhar C. Performance measurement system for healthcare processes. International Journal of Productivily and Performance Management. 2007;56(3):241-51. 


\section{CHAPTER}

42. Cousens $A$, Szwejczewski $M$, Sweeney $M$. A process for managing manufacturing flexibility. International Journal of Operations \& Production Management. 2009;29(4):357-85.

43. Liker JK. The Toyota Way. New York: McGraw-Hill; 2004.

44. Hyer NL, Brown KA, Zimmerman S. A sociotechnical systems approach to cell design: case study and analysis. Journal of Operations Management. 1999;17(2):179-203.

45. Hamilton $S$, Wilson R, Butcher $A$. Hospital trusts' views on flexible career grades. BMJ Career Focus. 2000;320(7226):Suppl: 2-3.

46. Prahalad CK. The Aravind Eye Care System: delivering the most precious gift. In: Prahalad CK, editor. The fortune at the bottom of the pyramid. Upper Saddle River, NJ: Pearson Eduation, Inc.; 2005. p. 265.86. 


\section{CHAPTER 2}

\section{Flexibility in hospirts through pourthime working doctors}

This chapter is based on:

Molema JJW, Groothuis S, Baars IJ, Kleinschiphorst M, Leers EGE, Hasman A, Van Merode, GG. Healthcare system design and partitime working doctors. Health Care Management Science. 2007;10(4):365-71. 


\section{Abstract}

Most hospitals are faced with variability and uncertainty in patient demands. As a result, not all activities can take place according to a plan and hospifals need to be able to react to changes. This requires flexibility. Sources of flexibility in system design in hospitals have not before been searched in the structure of jobs. We studied how creating parttime jobs for medical doctors could be enabled from a system design perspective. A theoretical analysis was performed, illustrated by two case studies.

We conclude that introducing parttime jobs increases flexibility in the system which can improve performance. This encourages altering system design such that reactive decisions regarding staff allocation can be better made.

From the case studies it seems that work redesign can enable partime work, and at the same time improve system performance. Better managing variability in the system contributed to this. The case studies results also showed that systems characterized by different levels of variability fit with different work contracts.

\section{Acknowledgements}

We would like to thank the Netherlands Organization for Health Research and Development, ZonMw, for funding this research project. Also, we greatly acknowledge the department of Surgery of the university hospital Maastricht, the Netherlands, and the Endoscopy department and the department of Internal Medicine of the Catharina hospital Eindhoven, the Netherlands, for their cooperation in this research. 


\section{Introduction}

More and more physicians would like to work parttime [1-4]. In addition, the number of female specialists is expected to keep rising in the next years, which will further increase the demand for more flexible, parttime jobs [1-7]. To accommodate this demand for flexibility in working hours, (more) opportunities for working partime and/or sharing jobs should be created. Such opportunities can make the profession more alluring, which is important, considering the expected shortage of physicians $[3,8]$.

Currently, relatively few partime jobs for physicians exist in healthcare. For example, in the Netherlands, only six percent of the surgeons in university hospitals work partime, while fifty-four percent would like to [9]. The Netherlands Organization for Health Research and Development, affiliated to the Dutch government, funded a research program to explore opportunities for working parttime in healthcare: 'Parttime work among medical specialists'. The study discussed in the present chapter was part of this program and focused on parttime work from a logistical viewpoint. That is, a hospital can be considered a production system consisting of, amongst others, people, patients, tasks, and subsystems that act and interact together to accomplish objectives [10]. The structure of a hospital represents the relations amongst these entities, how coordination amongst them is achieved, and what performance of the system is [1 1-16]. To structure a hospital and coordinate activities, planning and control decisions need to be taken [17]. One such decision is introducing parttime work contracts for employees.

Parttime work contracts can create variety in workforce volume and/or work hours over days and weeks [18]. The extent to whether a system is able to create variety in the mix and/or volume of resources in a system, like doctors in a hospital, so that the system state can be changed is called flexibility [19]. How flexible a system is in terms of part time work contracts, i.e. how much variety can be generated, depends on the interchangeability of workers and tasks across subsystems or departments and the variety worker skills, worker specialization, and job design $[20,21]$. [22-24]. Being flexible can enable an organization to respond to changes in demand volume, demand mix, and demand arrival $[22,25]$. This can be essential to most hospitals, where demand tends to fluctuate over time $[26,27]$.

Increasingly, research is being performed on the effects of physicians working partime in healthcare $[4-9,28-30]$. Several of these studies reported no differences between parttime and fulltime physicians in terms of (quality) performance $[29,30]$. Also, a system with flexible, partime employees at its 


\section{CHAPT 2}

disposal can design its process differently [31]. Having a flexible pool, for example, could enable a better reaction to fluctuations in demand per week, day or even per hour [32]. Such issues related to applicability and effects of parttime work may, according to Parkerton et al. [29] and Murray et al. [30], interact with the structure of the system in which the parttime work is performed. However, no studies on parttime work from the viewpoint of fitting the system structure with the structure of work contracts and fluctuations in demand are known to the authors.

Therefore, we explored the nature of the relations between system structure and parttime work. Our central research question was: "What is required for enabling working parttime in healthcare organizations?" Our study focused on enabling working partime from a system's perspective; not a financial or human resource perspective.

Redesigning work to enable partime work may change the organization of care processes and, consequently, could affect system design and performance. We will first elaborate on these relations. Subsequently, for illustration, two cases are introduced which represent two different hospital production systems. In both cases, computer simulation was applied to gain insight into enabling partime work [33]. The simulation study is described and its results are discussed. Finally, we conclude on how an organization can enable work redesign challenges like parttime work.

\section{Healthcare system design}

A system is the means by which a process occurs, i.e. it provides the structure for a process to function in [34]. A production process is any activity or group of activities undertaken to transform input into output [24, 35]. Flows, i.e. the movements of resources [24], exist both within and between processes.

Healthcare production systems contain various flows, such as patient, resource, information, and material. Through their production systems, healthcare organizations aim to offer value adding activities for patients and secure efficient, high quality patient care [33, 36-39]. To do so, production system design should enable continuous patient flow and efficient performance [40]. However, in many hospitals discontinuity characterizes patient flows, in the form of series of queues from one activity to the next [41]. Discontinuity can cause variability in the service process as well as system performance and can make a system difficult to manage $[20,41]$. 
2.1 Discontinuity

System characteristics causing discontinuity in flow can be grouped into three categories: 1) uncertainty, 2) inflexibility, and 3) complexity of coordination [41]. Uncertainty relates to the extent of information being either unavailable or available but unused. This information can concern demand, supply, or the service process itself. Inflexibility determines the degree of adaptability of the production system to changes in demand. Adaptability can be restricted due to technical, economic, or staff inflexibility. Coordination complexity concerns the number of transactions and transfers. Coordination is complex in processes and subsystems that share resources. Sharing leads to transfers of information, capacity, personnel, materials, etc. Since most processes and systems in healthcare share resources, flows are interdependent.

Variability, either inherent or preventive, affects the efficiency attainable in a system, system performance, and quality of patient care [20, 24, 26, 41, 42]. In healthcare a lot of variability is present, e.g., random or non-uniform arrival rates, service times, outcomes, but also a variety of treatment options for one diagnosis $[20,26,42]$. Managing variability to predict flow and to improve performance is one of the main objectives in operations management [26, 41]. In Lean Thinking variability is managed, among other things, through work design. An example of such work design is standardizing processes' and systems' designs by using standardized documentation according to which the workers must perform [43]. This can reduce waste as well as uncertainty, staff inflexibility, and complexity of coordination $[24,32,47-46]$.

2.2 Managing discontinuity through parttime work

Work contracts specify the duties to be fulfilled by a worker. The organization that employs the worker has jobs designed to fulfill these duties. In healthcare, job designs determine which tasks a physician should fulfill, when and how to fulfill them and how much time is available for this. Thus, through the design of jobs, work contracts may directly affect system design and performance. Moreover, as job design may influence the continuity of flow, work contracts are an important element of system design. This means that if a certain system is characterized by some level of variability and discontinuity, also the work contract should be evaluated [30,47,48]. Let us carry a comparison to working partime.

Introducing parttime work in a system may require changing the design of work and tasks. Creating parttime work in a system could imply a re-allocation of personnel to activities as well as changes in tasks and responsibilities [44]. 


\section{CHAPIER}

In fact, creating parttime work in a system is a type work redesign. Hackman [49] defines work redesign as "any activities that involve the alteration of specific jobs with the intent of increasing both the quality of the employees' work experience and their on-the-job productivity".

Redesigning work via parttime jobs may be used as a management instrument. Having a pool of flexible employees can benefit an organization and restrict discontinuity in flows $[31,41]$. It could help standardize processes and reduce variability. For example, to flexibly respond to changes in demand, a system requires flexible staff in terms of availability and capabilities. Often, parttime workers can provide this flexibility. There may, however, be constraints to introducing parttime work [30]. For example, a system in which many resources are shared may not benefit from introducing parttime workers, since this may further increase the number of transactions. Also, if a parttime worker demands to work only morning shifts, the system in which he works must facilitate a low variation in shift durations. If this is not the case, the demanded contract should not be implemented or the system redesigned.

Different contracts for parttime work exist [31]. Contract types differ on the bases of several variables. A first distinction in contract types stems from deciding on the number of hours to work per day and week and on how to assign these. A partime contract with fixed work hours and days can be called a day-based contract [50]. Minimum/maximum contracts are more flexible parttime contracts. They specify the minimum work hours per week which can be extended to a specified maximum, if necessary [50]. The second distinction in contract types is how the parttime physician organizes his work. He can either share or split a fulltime job $[1,31]$. Job sharing implies two physicians equally sharing all tasks of one job. The whole job is the couple's responsibility. This requires finding a suitable partner; something, that may be difficult and therefore can impede parttime work [2]. Job splitting implies splitting up a whole job or single tasks into smaller parts. Each physician is responsible for his own part. This solves the problem of finding a partner. At the same time, splitting a job can make that job less attractive because it can affect skill variety if the new job no longer comprises the full range of responsibilities and skills.

The various contracts were studied further in a simulation study carried out for two cases, each characterized by a different system design. 


\section{Case studies}

We used a multiple case study to explore how partime contracts and system design interact. Also, we studied how this interaction affects discontinuity in the system, measured in in-process variability and performance. Two cases were selected and described using process mapping [51]. Next, we developed simulation models in MedModel $(8$ [52], a discrete event simulation program. To this end, we used the flow charts complemented with historic patient data over one year. After validating and simulating the models of current situations in both cases, scenarios in which partime contracts were enabled were set up and evaluated.

\section{1 Case descriptions}

Case 1 concerned the work process of surgeons specialized in care for elective patients with intestinal problems in the surgery department of a Dutch university hospital. Of their total work time, the surgeons spent $40 \%$ of their time on this process. Case 2 concerned work processes of the three gastroenterologists working in the endoscopy department in a Dutch general hospital. The study focused on patients receiving gastroscopy, colonscopy or sigmoidoscopy. The gastroenterologists spent $50-60 \%$ of their total working time at the department. Figure 1 displays patient flow at the surgery department and figure 2 at the endoscopy department.

Overall, the surgeons' work process in case 1 resembled a job-shop design and the overall system design could be characterized as an "Archipelago" [41]. Additionally, the treatment process for the patients was multidisciplinary. This made flow coordination complex. So did the fact that capacities in the process were shared with others. Also affecting the complexity of coordination was that the surgeon who operated on the patient had to visit the patient. These visits took place at the ward preoperatively, one day before surgery, and postoperatively, the evening after surgery as well as several days later at the outpatient clinic. Besides, task times varied greatly as did times between activities. Overall patient throughput times were days to weeks. All this resulted in many transfer points and jumbled patient flows.

Work design in the monodisciplinary endoscopic process in case 2 resembled a product-line and overall system design could be characterized as a "Procedure based factory" [41]. Coordination was not complex because no capacity was shared and patients mef the gastroenterologist only in the endoscopy room. Also, since most patients were outpatients and thus not transferred to and from wards, transfer points were few. 


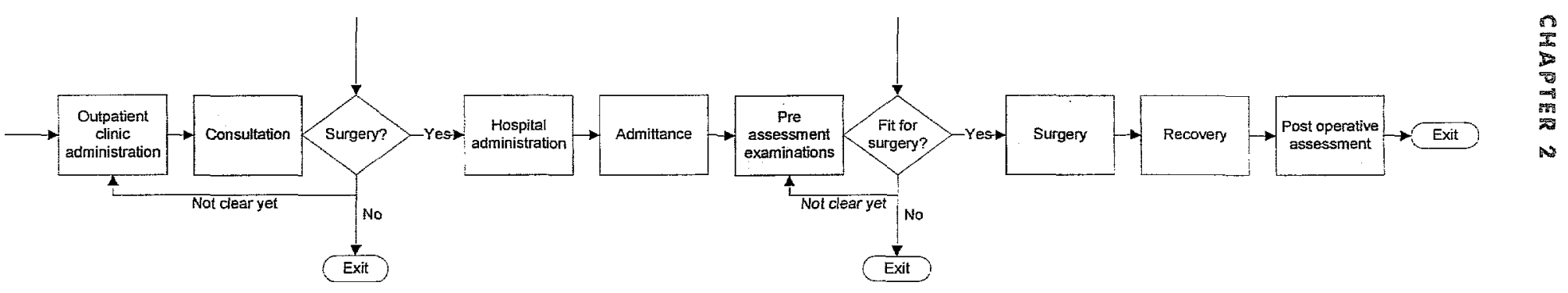

Figure 1: patient flow at surgery department (all shaded squares represent activities in which surgeons perform tasks)

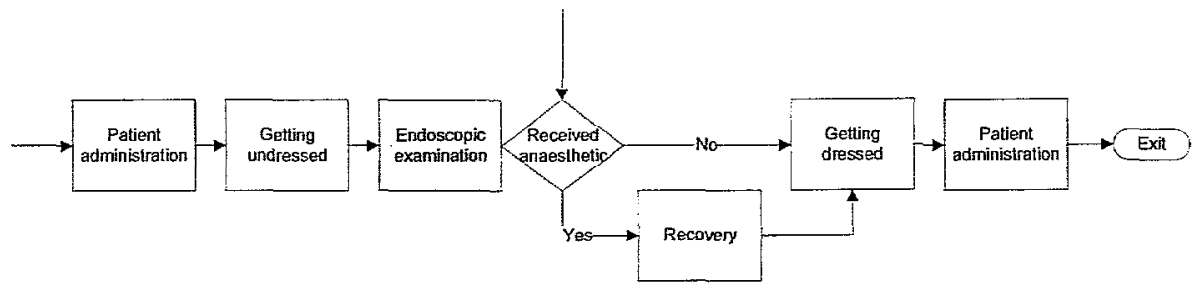

Figure 2: patient flow at endoscopy department (all shaded squares represent activities in which gastroenterologists perform tasks) 
FLEXIBILTTY THROUGH PARTTIRE WORKING DOCTORS

Table 1: Current situation in the surgery department and endoscopy department

\begin{tabular}{lrrrrr}
\hline Surgery department & \multicolumn{5}{c}{ Endoscopy deparment } \\
\hline Throughput time (in days) & \multicolumn{3}{l}{ Throughput time (in min) } \\
& Avg. & 36 & & Avg. & 35 \\
& Median & 34 & & Median & 34 \\
& Std. dev. & 7 & & Std. Dev. & 3 \\
Shift exceeded (in min) & & & Morning shift (in min) & & \\
& Avg. & 93 & & Avg. & 203 \\
& Median & 87 & & Median & 201 \\
& Std. Dev. & 146 & & Std. Dev. & 9 \\
Room utilization (in \%) & & & Workday (in min) & & \\
& Avg. & 63 & & Avg. & 443 \\
& Median & 62 & Median & 441 \\
& Std. Dev. & 9 & & Std. Dev. & 9 \\
\hline
\end{tabular}

The focus in the endoscopy process was on the medical intervention (the endoscopy) and not on continuous patient flow. Task times were uncertain and patient flow was discontinuous at times, because patients waited at some points in the process. Patient throughput time was somewhat over 30 minutes.

3.2 Comparing the cases

Overall, both work and system designs were less standard in the surgery department (case 1) than in the endoscopy department (case 2). Case 1 was characterized by more uncertainty and required more complex coordination. The differences between the cases may be (partly) explained by the patient mix. In case 1, patients were more medically complex and needed a multidisciplinary process delivered at several locations. Further, during a shift the surgeons in case 1 were not solely allocated to the selected patient group, whereas the gastroenterologists in case 2 were. Patient throughput times in case 1 far exceeded throughput times in case 2. These differences were expected to influence the possibilities for partlime work per case.

Table 1 displays the results of simulating the current situations. It shows that both cases contained variability (expressed in the standard deviations). However, case 1 more than case 2. Taking into account this variability in both cases, we set up scenarios to explore the possibilities for enabling partime contracts and restricting discontinuity in flow as much as possible. 


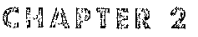

\subsection{Simulation scenarios}

As described in part 2.1, discontinuity in flow can be caused by complexity of coordination, staff inflexibility, and uncertainty. These three factors were used to define variables for setting up the simulation scenarios. Additionally, two strategies for enabling partime work in a system were applied for setting up the scenarios. The first strategy implied selecting a contract to directly enable partime work. By doing so, we aimed to create a flexible system design, reduce variability, and optimize flow. The second strategy meanf indirectly enabling parttime work. Following this strategy, we reduced variability first to manipulate system design and to make system design better fit the parttime work contract.

In the surgery department, we applied both strategies to the three variability related factors. Firstly, parttime work was directly enabled through decoupling the complex doctor-patient relationship. For this scenario, the surgeon who performed surgery on a patient no longer had to visit that patient preoperatively and postoperatively. This could now also be a different surgeon, which enabled, for example, working according to a day-based contract. Secondly, parttime work was directly enabled for the surgeons by decreasing staff inflexibility and splitting their tasks at the outpatient clinic and transferring some of them to a nurse specialist. Thirdly, partime work was indirectly enabled. Uncertainty in service times was reduced to study the effect of this decrease in variability on process performance, especially duration of the workday. No longer were patients scheduled using general average operation durations, characterized by large standard deviations. Instead, for this scenario, the patient population was split up into subgroups, each characterized by a more homogeneous average operation duration and smaller standard deviation [53].

Since current performance in the endoscopy department was such, that neither a complex doctor-patient relationship nor opportunities for task transfer existed, the scenarios focused on indirectly enabling parttime work through reducing uncertainty in service times. For all scenarios, the uncertainty in service times was manipulated (more and less uncertainty) and the effects on performance were measured.

\subsection{Results scenarios}

In case 1, decoupling the surgeon-patient relationship at the operating theatre decreased throughput time and increased production (table 2). However, in practice, this requires extra information transfers which can raise complexity. 


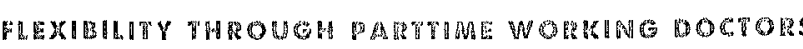
Table 2: Reducing staff inflexibility and complexity at surgery department (250 replications)

\begin{tabular}{rccc}
\hline $\begin{array}{c}\text { Scenario } \\
\text { Performance indicator }\end{array}$ & Current situation & $\begin{array}{c}\text { Decoupling doctor- } \\
\text { patient relationship }\end{array}$ & Transferring tasks \\
\hline Throughput time (in days) & & & \\
Avg & 36 & $33^{*}$ & 36 \\
Median & 34 & 31 & 34 \\
Std. dev. & 7 & 7 & 7 \\
\hline
\end{tabular}

* Significant difference $p<0.05$

Table 3: Reducing uncertainty in patient scheduling at surgery department (500 replications)

\begin{tabular}{rcc}
\hline $\begin{array}{c}\text { Scenario } \\
\text { Performance indicator }\end{array}$ & Current situation & Creating subgroups \\
\hline Shift exceeded (in min) & 93 & $21^{*}$ \\
Avg & 87 & 11 \\
Std. Dev. & 146 & 97 \\
Avg & 63 & $62^{*}$ \\
Median & 62 & 62 \\
Soom utilization (in \%) & 9 & 6 \\
\hline * Dev. & &
\end{tabular}

* Significant difference $0<0.05$

In the second scenario, adding a nurse specialist to take over surgeon tasks at the outpatient clinic did not significantly influence throughput time. This could be expected, since no differences were assumed between the surgeons and the nurses regarding consultation time [54].

Table 3 shows that reducing uncertainty in service times in the surgery department improved performance. The predictability of shift duration and utilization of operating capacity improved. However, planned shift time was still exceeded, although, much less frequent.

Simulation results of the scenarios in the endoscopy department made clear that decreasing uncertainty in service times improved process predictability and performance. Not only was the process predictability increased by this decrease in supply variability. Also, patients flowed more continuously. Vice versa, the simulations showed that more variability resulted in increased patient throughput time, caused by increased queuing. Besides, uncertainty regarding patient throughput time increased and the predictability of shift endpoints decreased. 


\section{CHAPTER 2}

Table 4: Reducing and increasing uncertainty in demand and supply in the endoscopy department (250 replications)

\begin{tabular}{|c|c|c|c|c|c|}
\hline \multirow{2}{*}{$\begin{array}{c}\text { Experiment } \\
\text { Performance indicator }\end{array}$} & \multirow{2}{*}{$\begin{array}{c}\text { Current } \\
\text { situation }\end{array}$} & \multicolumn{2}{|c|}{$\downarrow$ uncertainty in task times } & \multicolumn{2}{|c|}{$\uparrow$ uncertainty in task times } \\
\hline & & $-20 \%$ & $-30 \%$ & $+20 \%$ & $+30 \%$ \\
\hline \multicolumn{6}{|l|}{ Throughput time (in min) } \\
\hline Avg & 35 & $34^{*}$ & $34 *$ & $36^{*}$ & $37^{*}$ \\
\hline Median & 34 & 33 & 33 & 35 & 36 \\
\hline Std. Dev. & 3 & 2 & 2 & 4 & 5 \\
\hline \multicolumn{6}{|l|}{ Morning shiff (in min) } \\
\hline Avg & 203 & 202 & 202 & 203 & 204 \\
\hline Median & 201 & 202 & 202 & 200 & 203 \\
\hline Std. Dev. & 9 & 6 & 5 & 11 & 12 \\
\hline \multicolumn{6}{|l|}{ Workday (in min) } \\
\hline Avg & 443 & $441^{*}$ & $440^{*}$ & $445^{*}$ & $447^{*}$ \\
\hline Median & 441 & 441 & 442 & 442 & 445 \\
\hline Std. Dev. & 9.3 & 5 & 5 & 15 & 18 \\
\hline
\end{tabular}

* Significant difference $p<0.05$

\section{Discussion}

The results of the case study underpin that different systems, i.e. different system designs, lend themselves for different parttime contracts. In case 1, the high level of uncertainty about shift endpoints will conflict with fixed day-based contracts. Case 1 demands more flexible minimum-maximum contracts. Also, job splitting is possible in case 1 by splitting tasks at the outpatient clinic from surgery tasks. Job sharing can be applied in case 1 if the two surgeons that make up the couple operate as one and perform one full job together. However, if both surgeons work on more than a $50 \%$ basis, more than one job needs to be coordinated which makes the system more complex. And since process coordination is already complex in case 1, job sharing seems less suitable.

The production system in case 2 contains less uncertainty, so a day-based contract may be applicable, despite the somewhat uncertain task times. Job splitting is not possible in case 2 , since the gastroenterologists only perform one task in the system. Job sharing is possible and will not increase complexity, since the process already takes place in two clearly defined shifts (morning, afternoon) that the couple can share. This also makes job sharing attractive if the two physicians making up a couple want to work on more than a $50 \%$ basis. 
The simulation scenarios mainly focused on variability management to optimize patient flow. The results made clear that directly enabling parttime work can reduce in-process variability. This way, partime work can favor patient throughput times as well as the probability that scheduled work hours and shift endpoints can be upheld. Reducing uncertainty first leads not only directly to improved performance, but also makes it possible to better implement partime jobs.

Of course, all production systems in healthcare should manage variability and standardize patient processes to the extent possible [41]. However, process standardization may imply job inflexibility and reduced quality of jobs and work perception [49]. Therefore, an organization should continuously make a tradeoff between process standardization and employee flexibility. Adler, Goldoflas, and Levine [47] mention two job-related structures that can increase the attractiveness of standardized processes while upholding an efficient system design: 1) job enrichment (enables workers to become more innovative and flexible in the course of routine tasks) and 2) job switching (differentiates roles for dealing with two kinds of tasks). These structures could be interwoven with parttime work contracts.

In our study we focused on the relation between partime work and system design. It should be clear that for deciding on implementing parttime work more factors should be taken into account. For example, in our study we did not pursue the matter of costs associated with parttime work. Neither did we address the issue of working parttime and quality of care, in terms of ensuring continuity of care [2]. This continuity may be harmed if more physicians perform tasks within the same system. Also, no attention was paid to the human resource strategy necessary to attract enough staff to truly enable parttime work. A government, like the Dutch, should not only proclaim to implement partime jobs in healthcare and to limit work hours per staff member. Also, it should facilitate both creating partime educations programs and securing enough places in the medical education programs as well as the specialization training programs $[1,5]$. Hospitals themselves should become environments that value partime workers and provide the opportunities for employing them $[5,8]$. 


\section{Conclusions}

The study discussed in this chapter adds to the current knowledge about working parttime in healthcare. It shows that, from a logistical viewpoint, creating opportunities for working parttime seems very much possible. Enabling parttime work successfully requires insight into the structure of the hospital production system as well as an understanding of how the planning and control of employees can be done more flexibly through introducing flexible work contracts. The study underlines that a partime contract is an intermediate variable between work design, system efficiency, variability, and quality of work. Based on the results of the simulation studies, we can conclude that offering partime jobs can introduce flexibility in system design and can improve the care delivery process, patient flow, and performance. Thus, parttime work can be attractive for both physicians and patients.

Regarding the method applied, we can say that the case studies presented examples from practice and clarified the relations among system structure, variability, work design, and performance. Variability can be a characteristic of system structure. Variability in service times can be the result of variations in the skill and experience level of doctors but also be related to the use of strict treatment protocols. The case studies results showed that systems of different structure, resulting in different levels of service time variability, fit with different work contracts. This leads to the conclusions that variability resulting from system structure is a factor to be reckoned with in choosing work contracts arid designing jobs. Also, it shows that when designing a system, the effect planning and control decisions have on the variability in the structure should be taken into account. Both managers and doctors should take note of this when they choose to select parttime work contracts. In some systems, parttime work contracts might simply not fit, if the system structure is results in too much variability on other aspects than the work contracts.

The comparability of the two cases discussed in this chapter may be limited, since both had a clinically very different setting. Also, generalizability is limited since only two cases were studied. Further research could focus on comparing departments with the same dinical function, the same patient mix, but with a different structure. Additionally, if would be interesting to apply the proposed approach to an entire hospital. 


\section{References}

1. Mather HM. Specialist registrars' plans for working part time as consultants in medical specialfies: questionnaire study. BMJ. 2001;322(7302):1578-9.

2. Ramsay R. Working part time as a consultant. BMJ Career Focus. 2000;321(7272):2-3.

3. Gibson H. Are part time doctors better doctors? BMJ. 1997;315(7113):(suppl)2-3.

4. de Jong J, Heiligers $P$, Groenewegen $P$, Hingstman L. Part-time and full-time medica specialists, are there differences in allocation of time? BMC Health Services Research 2006;6(1):26.

5. Evans J, Goldacre MJ, Lambert TW. Views of UK medical graduates about flexible and part time working in medicine: a qualitative study. Medical Education. 2000;34(5):355-62.

6. Kermode-Scott B. Changes in Canada's medical workforce could affect access to care. BMJ. 2004;329(7474):1064-b.

7. Cull WL, Mulvey HJ, O'Connor KG, Sowell DR, Berkowitz CD, Britton CV. Pediatrician Working Part-Time: Past, Present, and Future. Pediatrics. 2002;109(6): 1015-20.

8. McMurray JE, Heiligers PJM, Shugerman RP, Douglas JA, Gangnon RE, Voss $C$, et al. Part-time medical practice: Where is it headed? American Journal of Medicine. 2005;1 18(1):87-92.

9. Van der Vange $N$, Vriend $M$, Slootman KCP, Heiligers P. Working flexibly (in Dutch). Medisch Contact. 2003;58(15).

10. Law AM, Kelton WD. Simulation Modeling and Analysis. Third ed. New York, USA: Tato McGraw-Hill; 2003

11. Silvestro R. Positioning services along the volume-variety diagonal. The contingencies of service design, control and improvement. International Journal of Operations \& Production Management. 1999;19(4):399-420

12. Silvestro R, Fitzgerald $L$, Johnston R, Voss $C$. Towards a classification of service processes, International Journal of Service Industry Management. 1992;3(3):62-75

13. Armistead CG. Service operations strategy: framework for matching the service operations ask and the service delivery system. International Journal of Service Industry Management. 1990; 1(2):6-16.

14. Galbraith JR. Designing organizations: an executive guide to strategy, structure and process New and Revised ed. San Fransico, USA: Jossey-Bass; 2002.

15. Tummers GER, van Merode GG, Landeweerd JA. Organizational Characteristics as Predictors of Nurses' Psychological Work 'Reactions. Organization Studies. 2006;27(4):559-84

16. Mintzberg H. The structuring of organizations. Engelwood Cliffs, N.J.: Prentice-Hall, Inc.; 1979

17. Vissers JMH, Bertrand JWM, De Vries G. A framework for production control in health care organizations. Production Planning \& Control. 2001;12(6):591-604.

18. Cousens $A$, Szwejczewskil $M$, Sweeney $M$. A process for managing manufacturing flexibility International Journal of Operations \& Production Management. 2009;29(4):357-85.

19. Santos Bernardes E, Hanna MD. A theoretical review of flexibility, agility and responsiveness in the operations management literature: toward a conceptual definition of customer responsiveness. International Journal of Operations \& Production Management. 2009:29(1):30-53

20. Hopp WJ, Spearman ML. Factory Physics: foundations of manufacturing management. Second ed. New York: Irwin/McGraw.Hill; 2001.

21. Van Merode GG, Molema H, Goldschmidt H. GUM and six sigma approaches positioned as deterministic tools in quality target engineering. Accreditation and Quality Assurance. 2004 Dec; 10(1-2):32-6. 


\section{CHA 2}

22. Gerwin D. An agenda for research on the flexibility of manufacturing processes. International Journal of Operations \& Production Management. 2005-25(12):1171-82.

23. Purbey S, Mukheriee K, Bhar C Performance measurement system for healthcare processes. International Journal of Productivity and Performance Management. 2007;56(3):241-51.

24. Krajewski L, Ritzman LP. Operations Management. 6th Edition ed. Upper Saddle River, NJ: Prentice Hall; 2002

25. Tachizawa EM, Thomsen CG Drivers and sources flexibility: an exploratory study. International Journal of Operations \& Production Management. 2007;27(9-10):1115.36.

26. Noon CE, Hankins CT, Cote MJ. Understanding the impact of variation in the delivery of healthcare services. Journal of Healthcare Management. 2003;48(2):82

27. Walley P, Silvester K, Steyn R. Managing Variation in Demand: Lessons from the UK National Health Service. Journal of Healthcare Management. 2006;51(5):309-20.

28. Lugtenberg $M$, Heiligers $P$, de Jong J, Hingstman L. Internal medicine specialists' attitudes towards working part-time: a comparison between 1996 and 2004. BMC Health Services Research. 2006;6(1):126.

29. Parkerton PH, Wagner EH, Smith DG, Straley HL. Effect of Part-time Practice on Patient Outcomes. Journal of General Internal Medicine. 2003; 18(9):717-24

30. Murray A, Safran DG, Rogers WH, Inui $T$, Chang H, Montgomery JE. Part-time Physicians: Physician Workload and Patient-Based Assessments of Primary Care Performance. Arch Fam Med. 2000 April 1, 2000;9(4):327-32.

31. Hamilton S, Wilson R, Butcher A. Hospital trusts' views on flexible career grades. BMJ Career Focus. 2000;320(7226): Suppl: 2-3.

32. Liker JK. The Toyota Way. New York: MeGraw-Hill; 2004

33. Young T, Brailsford S, Connell C, Davies R, Harper $P$, Klein JH. Using industrial processes to improve patient care. BMJ. 2004;328(7432): 162-4.

34. Anthony RN. Planning and control systems - a framework for analysis. Boston, Massachusetts: Division of Research, Graduate School of Business Administration, Harvard University; 1965.

35. Chase RB, Aquilano NJ. Production and operations management: manufacturing services. 7 th ed. USA: Richard D. Irwin, Inc; 1995

36. Porter ME, Teisberg EO. Redefining health care: creating value-based competition on results. Boston, Massachusetts: Harvard Business School Press; 2006

37. Herzlinger RE. Consumer Driven Healthcare: implications for providers, payers, and policymakers. San Francisco: Jossey-Bass; 2004

38. Van Merode GG. A prelude to the 2004 Antwerp Quality Conference: Targets and target values - integrating quality management and costing. Accreditation and Quality Assurance. 2004;9:168-71.

39. Young T. An agenda for healthcare and information simulation. Health Care Management Science. 2005; 8:189-96

40. Donaldson L. Design Structure to fit Strategy. In: Locke EA, editor. The Blackwell Handbook of Principles of Organizational Behavior. Oxford: Blackwell Publishers Lid.; 2000.

41. Van Merode F, Molema H, Goldschmidt H. GUM and six sigma approaches positioned as deterministic tools in quality target engineering. Accreditation and Quality Assurance. 2004; $10(1-2): 32-6$.

42. Mclaughlin CP. Why variation reduction is not everything: a new paradigm for service operations, International Journal of service management, 1996;7(9):17-30.

43. De Treville S, Antonakis J. Could lean production job design be intrinsically motivating? Contextual, configurational, and levels-of-analysis issues. Journal of Operations Management. $2006 ; 24(2): 99-123$ 
44. Becker C, Scholl A. A survey on problems and methods in generalized assembly line balancing. European Journal of Operational Research. 2006;168(3):694-715.

45. Womack JP, Jones DT. Lean Thinking - Banish waste and create wealth in your corporation Revised and Updated. New York: Free Press; 2003.

46. Ballé $M$, Régnier $A$. Lean as a learning system in a hospital ward. Leadership in Health Services. 2007;20(1):33-41

47. Adler PS, Goldoflas B, Levine DI. Flexibility versus efficiency? A case study of mode changeovers in the Toyota Production System. Organization Science. 1999;10(1):43-68.

48. Tummers GER, Landeweerd JA, Van Merode GG. Work organisation, work characteristic and the psychological effects on nurses in the Netherlands. International Journal of Stress Management. 2002;9(3):183-206.

49. Hackman JR. Work design. In: Hackman JR, Suttle JL, editors. Improving life at work: behavioral science approaches to organizational change. Santa Monica, CA: Goodyear: 1977. p. 96-162.

50. Heiligers P. Working Part-time; only few people choose the best opportunity (in Dutch). Medisch Contact. 2001;56(47):1739-41.

51. Okrent MD, Vokurka RJ. Process mapping in successful ERP implementations. Industria Management and Dala systems. 2004;104(8):637-43.

52. MedModel ${ }^{\circledR}$. [Accessed on: 01-07-2007]; Available from: hitp://www.promodel.com

53. Van Merode GG, Groothuis S, Hasmon A. Enterprise resource planning for hospitals. International Journal of Medical Informatics. 2004;73(6):493-501.

54. Vriihoef HJ, Diederiks JP, Spreeuwenberg C, Wolffenbuttel BH, van Wilderen iJ. The nurse specialist as main care-provider for patients with type 2 diabetes in a primary care setting: effecls on patient outcomes. International Journal of Nursing studies. 2002;39(4):441-51. 


\title{
CHAPTER 3
}

\author{
Specially labeling limits

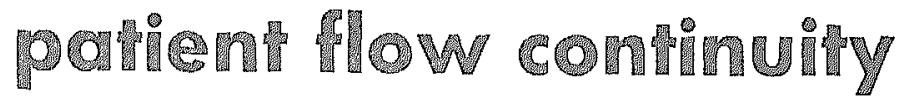

Molema JJW, Groothuis S, Van Merode, GG.

Submitted for publication 
CHAPIER B

\section{Abstract}

Most patient flows in hospitals are currently discontinuous. This can be considered a problem related to system structure. Structure represents the planning and control decisions made. Often structures in hospitals represent functional segmentation amongst departments, stemming from a focus on medical specialties. Resources, both human and non-human, are labeled to these specialties.

Beds are a major resource in hospitals. Most beds are labeled to a medical specialty. As such, the level of aggregation of beds is low and many different types of beds exist, each for a different patient type. Following queuing theory, we hypothesize that deciding to increase the aggregation level of beds in a hospital by removing specialty labels can create a structure with new opportunities for patient flow management resulting in substantial performance and flow improvement. To study this hypothesis, we analyzed a large Dutch hospital. Through simulation, the emergency system of the hospital was studied in particular.

The results found supported the hypothesis. The number of queues diminishes as soon as bed aggregation levels are increased. Further, setting up an acute medical admission department can improve the flow of emergency patients. The performance achieved depends on how the admission unit is organized. The simulation research is limited as only the acute medical admission unit was analyzed. 
SPECAATY LABELING IIMITS PATEANT FLOW CONTINUITY

\section{Introduction}

Even though most hospitals aim to deliver high quality care in systems with continuous flow of patients, "in healthcare, you usually sit and wait; 'patient' is clearly the right word" $[1$, p.50]. One of the main reason for this is the current focus on local optimization at specialty departments and not on overall patient flow [2-4]. As a result, patients who demand care from multiple specialties need to go from one specialty department to another, from one activity to another, without a clear structure and fit between the departments and activities [2].

Patient flow discontinuity is a frequent occurring problem that inevitably leads to patients not being able to access care at the time they express their need for it $[5,6]$. In this chapter, patient flow discontinuity is studied from a queuing theory perspective. Queuing theory offers insights into the relations between system input (patient demands), throughput (organization of servers, e.g. beds, operating rooms, doctors, nurses, diagnostic facilities), and output (patient waiting times). In hospitals, servers are often grouped based on medical specialty and labeled accordingly. Servers with a specialty label can only treat patients of that specialty. Servers that are more generally labeled because they encompass e.g. doctors of a different specialty or beds that can be used by different specialties, can treat more types of patients.

This chapter studies how exactly the level of server specialization in hospitals can affect patient flow discontinuity. Hereto, first a better insight into discontinuity and system structure is given from the queuing theory perspective. Second, opportunities for removing specialty labels from resources in hospitals are explored. In this section, the planning and control of one of the main resources in a hospital is subject of discussion: beds. In section 3 of the chapter, a case study is introduced. In the case study, we further explore the hypothesis that increasing the aggregation level of beds in a hospital creates opportunities for better management of patient flows resulting in substantial performance and flow improvement. The chapter ends with a discussion on the opportunities and possible effects of removing resource specialty labels in hospitals.

\section{Discontinuity and system design}

Figure 1 schematically depicts a typical hospital as a network of flows. Patient demands in queves are represented by arrows and resources providing service are represented as bullets. Each series of arrows and bullets displays a process 


\section{CHA}

through which patients flow. If figure 1 were an orthopedics department containing several processes, the following observations could be made. In one process, e.g., patients can undergo hip replacements and in the other knee surgery. The first bullet can represent a visit to the outpatient clinic where the patient is consulted by a doctor, followed by admittance to a hospital ward, a surgery, recovery at a ward, and then discharge. Doctors, materials, information and/or patients can be transferred between processes.

Figure 1 shows that the burden of coordinating many transfers of patients between servers in a hospital or department can be very high, making it difficult to secure efficient and highly-standardized patient and resource transfers and flows [2]. Insufficient coordination of transfers can result in nonvalue adding patient transportations, discontinuity in flows, and variability in performance $[2,6]$. Following on this, we assume that patient flows are currently discontinuous because of the complexity of system design $[6,7]$.

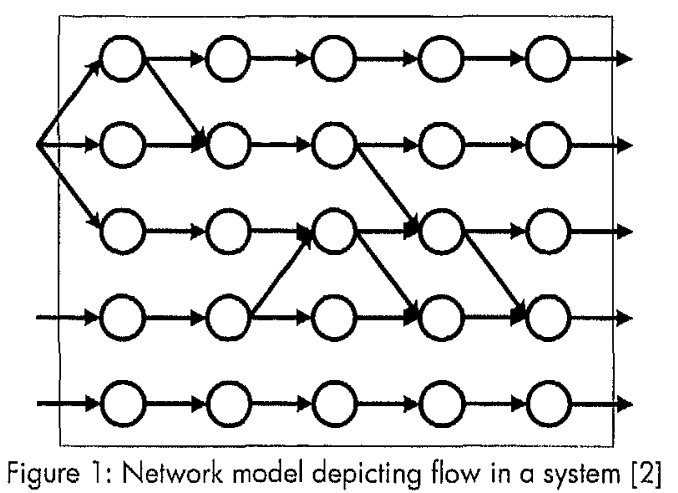

2.1 Queving theory and system design

A hospital or hospital department can be abstracted into a queuing model [8]. Queuing models make discontinuity measurable and can provide insight into system structure and patient flow management with a view for improvement [5, 6 , 9]. A simple queuing model comprises the flows of customers through a system, quantifying arrival, service, and queues [8]. A symptom of discontinuity in a system is a series of queves from one server to the next, resulting in unnecessary interruptions in customer flows [10].

Basically, queuing theory explains that queves and discontinuity exist if the system is characterized by at least one of the following $[5,6]$ :

i) Demand for capacity exceeds supply;

ii) Demand is uncertain;

iii) Service is uncertain. 
SPECIALTY LABELNG LMMTS PATENT HOOW CONTNUITY

Solving discontinuity in a system where demand for capacity exceeds supply would be simple; just add resources. Yet, in most systems, financial means are limited. Moreover, uncertainty about the arrival times of demand, the demand mix, and the demand volume exist. Also, service can be uncertain, due to random and controllable variability [1]]. Womack \& Jones attribute discontinuity in flows and production systems to a form of controllable variability they call waste, i.e. unnecessary activities that add no value [1]. Like waste, queuing and discontinuity lead to variability in process performance $[1,11,12]$. In healthcare, they can also affect the quality of the care process $[5,9,13]$.

Resources are labeled as part of the planning and control process [14, 15]. In a queuing system, servers of the same or different type that are grouped together form a configuration [16, 17]. The level of resource clustering in a group with the same aggregate label determines the aggregated supply leve of the configuration $[11,18]$. Labeling can be inferpreted as a form of waste. For example, specialty labeling causes patients in need of care from different medical specialties to be transported from one configuration to another [2, 19]. Such transfers have no added value yet they make coordination complex, cost time and money, and can increase uncertainty by increasing the risk for information loss and medical errors [1, 2, 19]. Furthermore, using specialty labels for resources assumes that management knows what the type and volume of customer demand will be as well as the time of arrival. Most hospitals, however, are characterized by variability in demand [5]. Specialty labels for resources do not take this variability into account. Additionally, because of specialty labels, customers might need to wait for resources to become available in one department, while at another department resources are idle.

To increase continuity in patient flows, we might want to think over current hospital system design as displayed in figure 1, specialty labeling of resources especially $[6,20,21]$. Changing the focus to labeling according to patient flows that exhibit similar service characteristics and group resources accordingly may result in an improved system design and reduced outcome variations [6].

2.2 Removing specialty labels

Aggregating resources on a higher level than medical specialty increases the volume of a resource aggregate and creates more general resources that are available to different types of customers. This increases the probability of 


\section{CHAPTER}

having a resource available when a new customer arrives and resources can be kept uniformly busy; both are less easily performed in case of multiple queues assigned to different types of servers [6].

Often, aggregating demand into a single queve presupposes an assignment of production processes to departments in such a way that the variations in aggregated demand are smaller than the sum of variations of the demand for each individual process [22]. As such, aggregation can enable system managers to obtain more accurate forecasts of demand [11]. However, increasing the resource aggregation level may require joining different queves that were previously connected to specific dedicated resources. If such a single queve leads to high in-process variation, the benefits of resource aggregation are counteracted [6]. For example, creating a single queue by clustering demand into a mix with much uncertainty in arrival rates and or service rates can create in-process variation $[11,23]$. Not clustering demand can remove the effect of uncertainty in demand mix. However, this can be counteracted by a lack of volume per queve or by a high level of server aggregation [6]. Still, having multiple queves with more disaggregated demand can be useful. For example, when different servers provide a limited and different set of services [11]. Servers that provide such services can be considered specialized. A specialized server in a system can be useful if products or clients require very specific service. In comparison, more aggregated servers can provide service for different demands/queves.

For healthcare, we can experiment with removing specialty labels for one of healthcare's principal type of servers, beds. The organization of beds in hospitals is a constantly recurring theme ("who or what gets which beds for what patients and why?") [21, 24]. Figure 2 displays a model derived from figure 1; however, in figure 2 the bullets are beds and two general bed aggregates are created, grouped by the dotted lines. As a result of the aggregation, the number of queves is substantially reduced in comparison to figure 1. Figure 2 shows the potential impact of aggregating beds within a network. It additionally illustrates that the decision whether or not to label beds and how to label them affects hospital design substantially. 


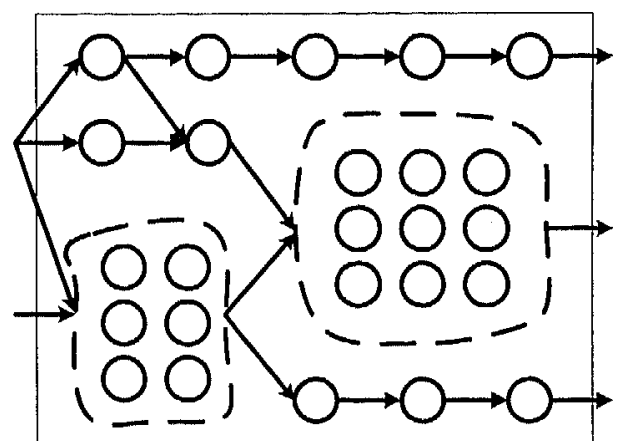

Figure 2: Level of server aggregation in network - dotted lines encircle cluster of servers

\section{Redesigning emergency care}

The current organization of emergency care in many hospitals is taken as an example of how the specialty labels can affect patient flow continuity is. In the Netherlands, most general hospitals have an emergency department (ED) to triage emergency patients. After this screening and an initial diagnosis, patients requiring admission are transferred to a ward bed that is very often specialty labeled. Each ward mostly represents one or a few medical specialties.

In fact, the distinction between emergent and elective patients can be interpreted as a consequence of a low level of bed aggregation and the subsequent inability of hospitals or specialty departments to absorb fluciuations in demand [25]. Increasing the level of bed aggregation can increase flexibility to respond to demand fluctuations [19]. A rising trend in emergency care is aggregating emergency labeled beds within a hospital into one department [21, 24-27]. Such an 'acute medical admissions unit' (AMAU) would admit all emergency patients coming from the ED who require hospitalization [26]. Despite that the designation of such an AMAU throughout literature leaves some unclarity as to the use of 'emergency' or 'acute' [21, 24" 27], most provide similar services to a variety of acute and/or emergency patients. To elaborate on the potential benefit of such a department, a case is now introduced of a large ( $>500$ beds) Dutch general hospital.

In the hospital under study, all beds were located at wards where they were labeled and clustered per specialty. Almost all specialties distinguished between elective and emergency beds. For the elective beds, admittance was planned as opposed to the emergency beds, which were kept available to emergency patients. 


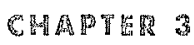

\begin{tabular}{lrr} 
Table 1: Current emergency patient transfers in hospital & \\
\hline Number of transfers & Frequency & $\%$ \\
\hline 2 & 1406 & 62.8 \\
3 & 579 & 25.9 \\
4 & 148 & 6.6 \\
5 & 63 & 2.8 \\
6 & 24 & 1.1 \\
7 & 8 & 0.4 \\
8 & 5 & 0.2 \\
9 & 2 & 0.1 \\
10 & 3 & 0.1 \\
15 & 1 & 0.0 \\
Total & 2239 & 100.0 \\
\hline
\end{tabular}

The clusters of specialty-labeled beds were all preceded by specialty labeled queves. Both elective and emergency flows were discontinuous. The latter disturbed the former because admittance of emergency patients was given priority over elective patients. Sometimes elective admissions were cancelled last minute because of this scheduling rule. Emergency flows were discontinuous because emergency patients were transferred between beds (see table 1), stemming from either a lack of bed capacity at the 'right' department or incomplete diagnostic information after the patient was transferred from the ED.

To overcome these discontinuities issues, management and staff agreed upon setting up the AMAU. The function of the AMAU was to diagnose patients and set up a treatment plan (see figure 3). Based on the treatment at the AMAU, some patients will be able to leave the hospital after the AMAU while others still need a transfer to a ward.

Next to the AMAU, the level of bed aggregation in the overall hospital was changed. Currently, 22 specialty labels were used in the hospital. For the new structure, instead of specialty labels, management would label beds for surgery (S) or non-surgery (B) patients, both for daycare (D) patients, and for acute patients $(A)$, and elective patients $(K)$. Also, a distinction was made between less complex patients $(Z)$ and more complex patients $(C)$. The hospital decided to put together seven groups: DB, DS, ABC, ASC, KBC, KSC, and KZ. A special eighth group, MK, was added by the hospital that comprised all mother-child related patients. 
SPEGIALTY LARELNG WMITS PATIENT FLOW GONUINUTY

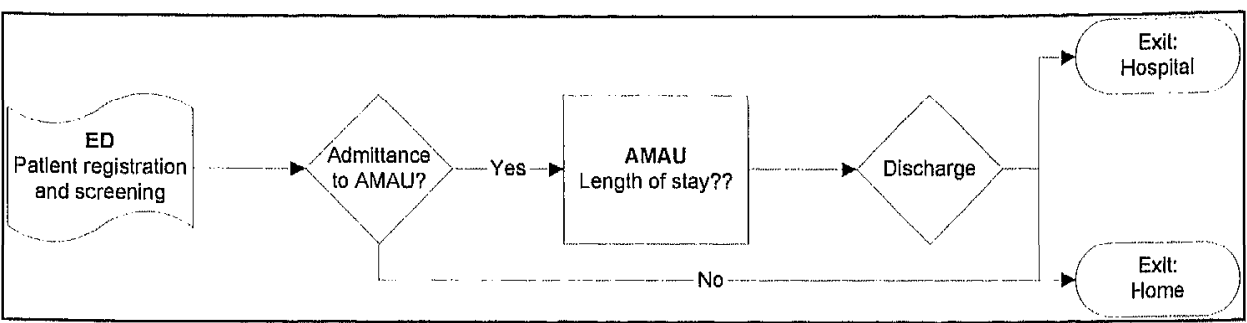

Figure 3: AMAU flow chart

\section{Case study}

The objective of reorganizing bed aggregation levels throughout the hospital was to improve access to beds. These plans were analyzed, the results of which are discussed below. Subsequently, to give hospital management insight into the effects of some decisions about the AMAU structure on performance, a simulation model was developed.

4. 1 Patient flow analysis

To gain insight into how the new system structure would affect bed utilization, historic patient data over three months in 2003 were collected and analyzed. In this period, during which no major holiday occurred, 9802 patients entered the hospital.

Table 2 displays the use of beds in the current situation and table 3 displays the use of beds in the new situation. Both tables, hereto, display the average number of beds used per day at each of the aggregate labels, the standard deviation, the median, and the coefficient of variation $\mathrm{CCV}=$ standard deviation divided by the mean). For the daycare patients in the new situations two calculations were made in table 3 ; one for the whole of bed use registrations and one excluding the weekends. The latter was done because the daycare wards are always closed during weekends. Additionally, graphs 1 to 8 display how bed use evolves over time in the new situation.

It needs to be noted here that, for both table 2 and the graphs, not all historic data over the three months were used. A period of 14 days was taken into account to correct for beds in use by patients who were admitted before the data collection started. 
CHAPTER 3

\begin{tabular}{lrrrr}
\multicolumn{5}{c}{ Table 2: Average numbers of beds used per specially label in the current situatio } \\
\hline Bedlabel & Mean & St. Dev & CV & Median \\
\hline spec1 & 3.0 & 3.0 & 1.0 & 3.0 \\
spec2 & 0.0 & 0.2 & 6.5 & 0.0 \\
spec6 & 51.6 & 6.8 & 0.1 & 52.0 \\
spec10 & 84.6 & 12.4 & 0.1 & 86.0 \\
spec17 & 6.0 & 5.3 & 0.9 & 4.0 \\
spec13 & 15.8 & 4.7 & 0.3 & 17.0 \\
Spec74 & 13.4 & 4.1 & 0.3 & 13.0 \\
spec78 & 0.0 & 0.2 & 6.5 & 0.0 \\
spec25 & 54.5 & 11.5 & 0.2 & 55.0 \\
spec26 & 20.9 & 5.9 & 0.3 & 21.0 \\
spec30 & 5.4 & 3.5 & 0.7 & 6.0 \\
spec38 & 1.1 & 1.2 & 1.2 & 1.0 \\
spec39 & 37.7 & 6.2 & 0.2 & 39.0 \\
spec42 & 0.1 & 0.3 & 2.6 & 0.0 \\
spec43 & 0.1 & 0.3 & 3.4 & 0.0 \\
spec47 & 64.8 & 7.6 & 0.1 & 65.0 \\
spec50 & 14.1 & 2.6 & 0.2 & 14.0 \\
spec52 & 35.3 & 6.0 & 0.2 & 35.0 \\
spec63 & 3.0 & 4.9 & 1.6 & 0.0 \\
spec64 & 3.2 & 5.8 & 1.8 & 0.0 \\
spec66 & 28.2 & 8.4 & 0.3 & 28.0 \\
spec74 & 8.3 & 2.6 & 0.3 & 9.0 \\
spec77 & 1.7 & 1.7 & 1.0 & 2.0 \\
spec85 & 1.7 & 2.2 & 1.3 & 1.0 \\
spec89 & 23.7 & 4.5 & 0.2 & 24.0
\end{tabular}

Table 3: Average numbers of beds used per aggregate label in the new situation

\begin{tabular}{lcccc}
\hline Bed label & Mean & St. Dev & CV & Median \\
\hline ABC & 153.0 & 13.7 & 0.1 & 155 \\
ASC & 49.5 & 5.8 & 0.1 & 50 \\
KBC & 43.9 & 5.7 & 0.1 & 44 \\
KSC & 45.0 & 5.4 & 0.1 & 46 \\
KZ & 92.0 & 24.3 & 0.3 & 97 \\
MK & 54.7 & 10.4 & 0.2 & 57 \\
DB & 19.9 & 13.6 & 0.7 & 25 \\
DS & 21.6 & 16.0 & 0.7 & 28 \\
DB (excl weekend) & 28.2 & 4.9 & 0.2 & 27 \\
DS (excl weekend) & 30.6 & 9.1 & 0.3 & 32.5 \\
\hline
\end{tabular}

Table 3 shows that bed use is much more consistent in the new situation; the graphs of the new situation underpin this. Consistency in bed use is displayed in the CVs that are lower in the new situation in table 3 than in the current situation in table 2. CVs in the new situation range from 0.1 to 0.3 , whereas in the current situation $\mathrm{CV}_{s}$ are often greater than 1. A CV of 1 and higher implies that the variation in output is high. In practice this means that in the 
current situation the number of beds occupied within an aggregate fluctuates much more than in the new situation.

Graphs 1 to 8 display the fluctuations in the number of beds occupied in the new aggregates. For the day care departments, it is clear that during the weekends, all beds are cleared. In the 'KZ' aggregate, where less-complex regular hospitalized patients are admitted, beds use is also less during the weekends; however, a substantial part of the beds remains occupied.

In the other departments that admit the more complex patients and the acute patients, bed use is less influenced by weekend discharges, as patients have a longer length of stay. In the 'MK' group, that represents the mother-child related patients, like deliveries and neo-natal care, there is a rather steep decline in the number of beds occupied after 40 days, for which there is no practical explanation (like a seasonal trend).

4.2 Simulation analysis of the AMAU

For the new AMAU, hospital management needed to decide on the allowed length of stay (LOS) of patients, discharge policy, and bed capacity. To be able to study the effects of these three decisions, a simulation model was set up. Simulation is a tool that can aid in decision making regarding system design through studying change scenarios in a low risk and relatively low cost environment $[8,9,28]$

Regarding the first decision, management considered two scenarios: one with a minimum LOS of 6 hours, a maximum of 72 hours, and with a specified average of 33.4 hours; and one with a minimum LOS of 6 hours, a maximum of 48 hours, and a specified average of 36 hours. For both scenarios the number of patients that could be discharged home after the AMAU was estimated by hospital management. With $72 \mathrm{hrs}$ as maximum LOS, $26 \%$ of the emergency patients could be discharged home; with 48 hrs as maximum LOS, $20 \%$ of the patients could be discharged home.

Regarding the second decision, management aimed to overcome disturbances related to emergency patient transfers at the regular wards, during the night (when staffing is low) or ward peak hours (approximately from 10am until $1 \mathrm{pm}$, i.e. when most non-emergency patients were admitted) especially. To achieve this, the AMAU should use discharge slots to define the discharge and transfer of patients to wards. Management wanted insight into the effect of discharge slots, compared to not having discharge slots. 
GHADTE 3
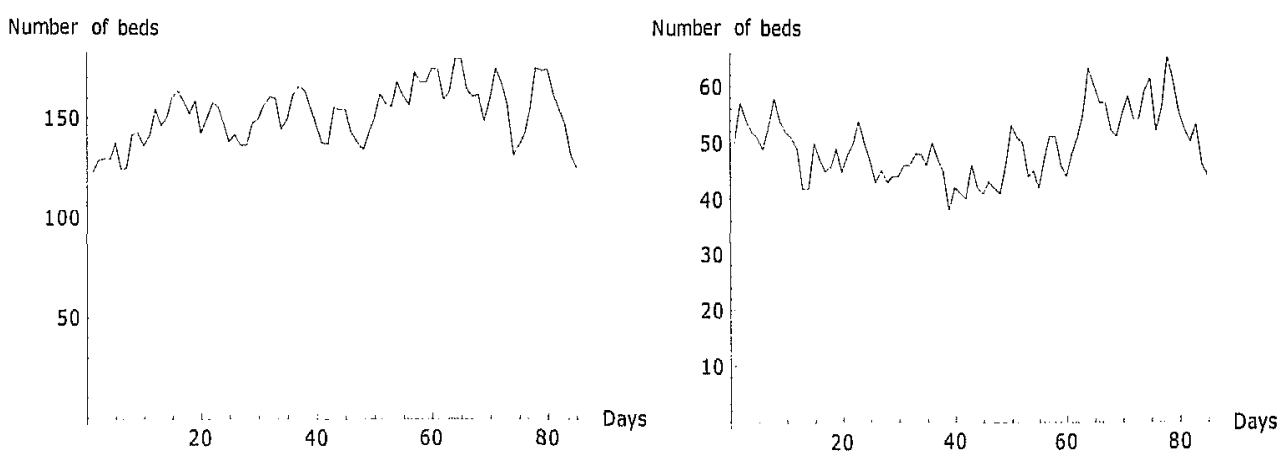

Graph 1: Number of beds occupied by ABC patients Graph 2: Number of beds occupied by ASC patients Number of beds
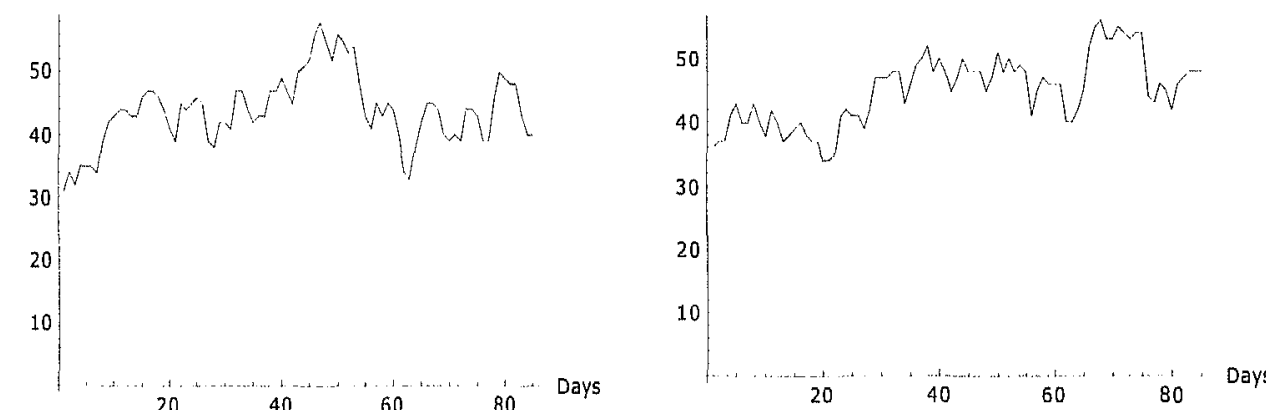

Graph 3: Number of beds occupied by KBC patients Graph 4: Number of beds occupied by KSC patients Number of beds

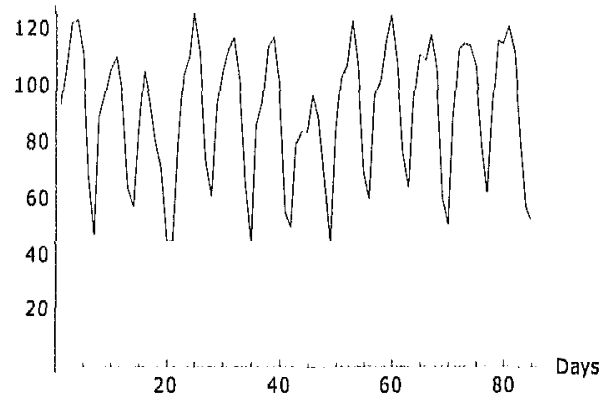

Graph 5: Number of beds occupied by KZ patients Number of beds
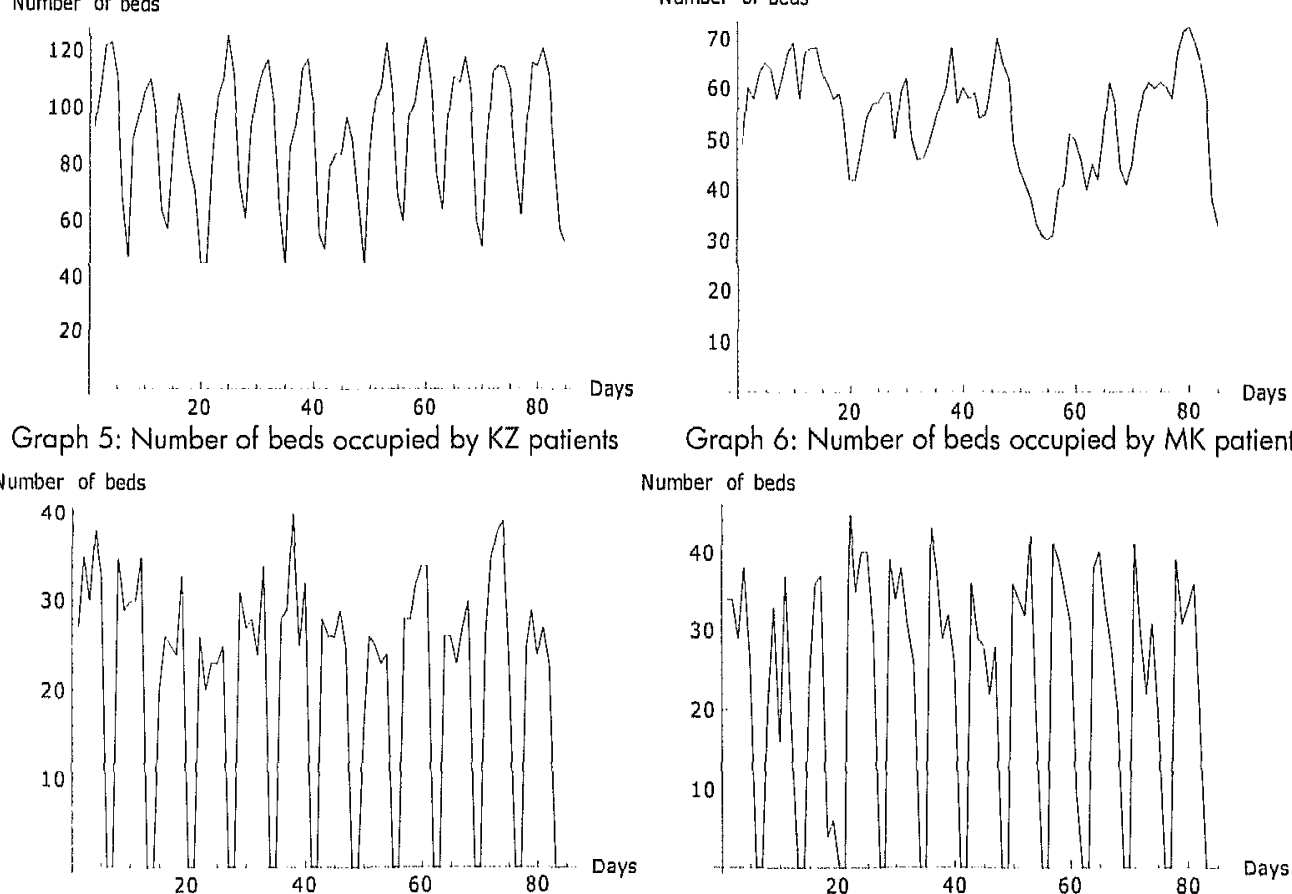

Graph 7: Number of beds occupied by DB patients

Number of beds

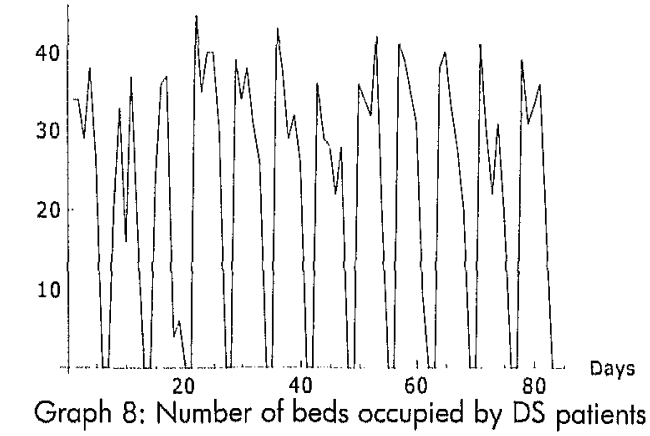




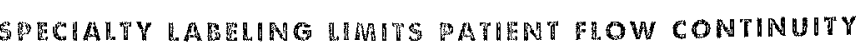

Table 4a: values of the independent experimental variables

\begin{tabular}{|c|c|c|c|c|c|}
\hline & Value $\# 7$ & Value $\# 2$ & Value $\# 3$ & Value \#4 & Value \#5 \\
\hline Bed capacity & 40 & 38 & 36 & 42 & 44 \\
\hline LOS (hrs) & $\begin{array}{l}\operatorname{avg} .33 .4 ; \\
\max .72\end{array}$ & $\begin{array}{l}\operatorname{avg} .36 .0 ; \\
\max .48\end{array}$ & & & \\
\hline Discharge slots & None & $8 \mathrm{am}-8 \mathrm{pm}$ & & & \\
\hline
\end{tabular}

Table 4b: Experimental design

\begin{tabular}{lccc}
\hline Experiment & Bed capacity & LOS & Discharge slots \\
\hline 1 & 1 & 1 & 1 \\
2 & 1 & 2 & 1 \\
3 & 1 & 1 & 2 \\
4 & 1 & 2 & 2 \\
5 & 2 & 1 & 1 \\
6 & 2 & 2 & 1 \\
7 & 2 & 1 & 2 \\
8 & 2 & 2 & 2 \\
9 & 3 & 1 & 1 \\
10 & 3 & 2 & 1 \\
17 & 3 & 1 & 2 \\
12 & 3 & 2 & 2 \\
13 & 4 & 1 & 1 \\
74 & 4 & 2 & 1 \\
15 & 4 & 1 & 2 \\
16 & 4 & 2 & 2 \\
17 & 5 & 1 & 1 \\
18 & 5 & 2 & 1 \\
19 & 5 & 1 & 2 \\
20 & 5 & 2 & 2 \\
\hline
\end{tabular}

Regarding the third decision, management assumed both the decisions on LOS and discharge policy to affect the number of beds necessary at the AMAU. As for AMAU bed capacity, management initially reserved 40 beds. These were beds that were previously specialty labeled at the wards. Management was, however, not sure how sensitive AMAU performance was in terms of possible interactions between the decisions on LOS and discharge policy and the number of beds available.

To study these issues, a simulation model was developed in Mathematica $\mathbb{R}$ [29], based on figure 3 and the historic patient data. The initial model represented an AMAU with 40 beds, no discharge slots, and a maximum LOS of 72 hours and an average LOS of 33 hours. For each of these independent variables alternative values were defined to experiment with them (see table $4 a)$. 


\section{CHAPTER 3}

In various experiments, different combinations of decisions were simulated based on an experimental design [8] (see table 4b). For each experiment, 365 days (1 year) were simulated. The performance indicators studied in the various experiments were patient waiting time for admittance to AMAU, patient waiting time they for discharge, and AMAU bed utilization. The latter was measured by dividing, per simulated day (24hrs), the number of hours al available beds were occupied by the total number hours beds were available that day.

The results of the experiments are displayed in table 5. The results of the experiments were compared via ANOVA analysis and Bonferroni Post Tests $(a=0.01)$ and evaluated against the objectives of implementing an AMAU. The ANOVA results are displayed in table 6 .

The results of the simulation study are in congruence with queving theory and do not cause a great deal of controversy. As can be expected, with fewer beds, discharge slots and a longer LOS patient admittance was hampered and patients spent more time waiting. The results of the ANOVA analyses in table 6 show which factors significantly influenced the outcomes of the simulation model. It differentiates between the factor with the most influence on outcome and the other factors that also significantly contributed to any differences in outcome. The ANOVA analyses showed that the variable most influencing the time spent in the queve preceding the AMAU was AMAU service time. The time patients waited in an AMAU bed before discharge was influenced most by the discharge policy. Regarding the number of beds available at the AMAU, Bonferroni post tests showed that all levels significantly differed from each other. Next to the main effects, interaction effects were measured. Al interaction effects had significant impact on the results, although less impact than the main effects.

At the AMAU, patient LOS was influenced most by the maximum allowed service time of either 48 or 72 hours. Further, LOS was influenced by the use of discharge slots. Having discharge slots of course increased LOS, as patients needed to wait to be discharged until it was time. Bed utilization, finally, was influenced by all three main factors, where the allowed service time had the most effect. It needs to be noted that the reported bed utilization included the time patients waited discharge at the AMAU. During this time, they were using the bed. However, this use of bed can be considered a waste. At the same time, having discharge slots prevents for nightly disturbances at the wards. So it is a tradeoff between efficiency at the wards and efficiency at the AMAU 
SPRCIALTY RABEHNG LMMUTS PATIENT FLOW CONTINUITY

\begin{tabular}{|c|c|c|c|c|}
\hline Exp. & $\begin{array}{l}\text { Wait time } \\
\text { admission }\end{array}$ & LOS & $\begin{array}{l}\text { Wait time } \\
\text { discharge }\end{array}$ & Bed utilization \\
\hline 1 & $0.1(+/-0.7)$ & $31.7(+/-18.6)$ & $0.0(+/ \cdot 0.0)$ & $0.7(+/ \cdot 0.1)$ \\
\hline 2 & $0.6(+/-1.9)$ & $35.9(t /-11.1)$ & $0.0(+/ \cdot 0.0)$ & $0.8(+1 /-0.1)$ \\
\hline 3 & $0.2(+/-1.1)$ & $33.1(+/ .18 .4)$ & $1.7(+/-2.3)$ & $0.7(+/ \cdot 0.1)$ \\
\hline 4 & $1.4(+/-3.3)$ & $38.3(+1 \cdot 10.9)$ & $1.9(+/-2.4)$ & $0.9(+/-0.2)$ \\
\hline 5 & $0.2(+/-1.1)$ & $31.8(t /-18.4)$ & $0.0(+/-0.0)$ & $0.7(+/-0.1)$ \\
\hline 6 & $1.4(+/-2.9)$ & $36.3(+/ \cdot 10.8)$ & $0.0(+/ \cdot-0.0)$ & $0.8(+/ \cdot 0.1)$ \\
\hline 7 & $0.4(+/-1.5)$ & $33.4(+/-18.5)$ & $1.7(+/-2.4)$ & $0.8(+/ \cdot 0.1)$ \\
\hline 8 & $3.2(+/ .5 .4)$ & $38.1(+/ .11 .0)$ & $1.9(+/-2.3)$ & $0.9(+/ \cdot 0.2)$ \\
\hline 9 & $0.5(+/-1.7)$ & $31.2(+/ \cdot 18.2)$ & $0.0(+/ \cdot 0.0)$ & $0.8(+/ .0 .2)$ \\
\hline 10 & $2.6(+/-4.3)$ & $36.1(+/ \cdot 10.9)$ & $0.0(+/-0.0)$ & $0.9(+/ \cdot 0.1)$ \\
\hline 11 & $0.9(+/-2.7)$ & $33.3(+/ .18 .4)$ & $1.7(+/-2.3)$ & $0.8(+/ .0 .2)$ \\
\hline 12 & $8.8(t /-11.0)$ & $37.9(+/ .11 .3)$ & $1.9(+/ \cdot 2.3)$ & $0.9(+/ .0 .1)$ \\
\hline 13 & $0.1(+/-0.5)$ & $31.8(t / \cdot 18.3)$ & $0.0(t / \cdot 0.0)$ & $0.7(+/ \cdot 0.1)$ \\
\hline 14 & $0.3(+/-1.3)$ & $36.1(+/-10.9)$ & $0.0(+/ .0 .0)$ & $0.8(+/-0.1)$ \\
\hline 15 & $0.1(+/-0.6)$ & $33.1(+/ \cdot 18.4)$ & $1.7(+/ \cdot 2.3)$ & $0.7(+/-0.1)$ \\
\hline 16 & $0.7(+/-2.4)$ & $38.4(+/ .11 .0)$ & $1.9(+/-2.4)$ & $0.8(+/ \cdot 0.1)$ \\
\hline 17 & $0.0(+/-0.2)$ & $31.7(+/ .18 .2)$ & $0.0(t /-0.0)$ & $0.6(+/-0.1)$ \\
\hline 18 & $0.1(+/ \cdot 0.8)$ & $36.0(+/ .11 .0)$ & $0.0(t /-0.0)$ & $0.7(+/ \cdot 0.1)$ \\
\hline 19 & $0.1(+/-0.6)$ & $33.4(+/-18.3)$ & $1.7(+/-2.3)$ & $0.7(+/ .0 .1)$ \\
\hline 20 & $0.3(+/ .7 .3)$ & $38.1(+/-11.2)$ & $1.9(+/ .2 .4)$ & $0.8(+/ \cdot 0.1)$ \\
\hline
\end{tabular}

Table 6: Results ANOVA analysis per performance indicator $(a=0.01)$

\begin{tabular}{|c|c|c|}
\hline & Most impact on performance $\ddagger$ & Impact on performance \\
\hline $\begin{array}{l}\text { Wait time } \\
\text { admission }\end{array}$ & Service time & $\begin{array}{l}\text { Number of beds } \\
\text { Discharge slots } \\
\text { Service fime* discharge slots } \\
\text { Service time* number of beds } \\
\text { Discharge slots"number of beds } \\
\text { Service time* discharge slots*number of } \\
\text { beds }\end{array}$ \\
\hline los & Service time & $\begin{array}{l}\text { Discharge slots } \\
\text { Interaction service time*discharge slots }\end{array}$ \\
\hline $\begin{array}{l}\text { Wait time } \\
\text { discharge }\end{array}$ & Discharge slots & $\begin{array}{l}\text { Service time } \\
\text { Interaction service time* discharge slots }\end{array}$ \\
\hline Bed utilization & Service time & $\begin{array}{l}\text { Number of beds } \\
\text { Discharge slots }\end{array}$ \\
\hline
\end{tabular}

¥ Most impact on performance implies highest $F$ ratio reported in ANOVA analysis 


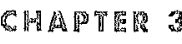

\section{Discussion and conclusions}

Because of the current complex organization of emergency care, with beds scattered around throughout a hospital, elective patients are often cancelled and their flow is hindered by emergent disturbances [4]. Additionally, the complexity related to labeling beds to specialists instead of groups of patients, causes queues for emergency patients as well as elective patients.

In this chapter, we showed that there is a huge opportunity to reduce the number of queves and increase opportunities for patient flow improvement by redefining the level of resource aggregation. By setting aside specialty labels of beds and creating an AMAU to streamline the flow of emergency patients, the numbers of queves within a hospital network can be substantially reduced. Moreover, the increased beds aggregates have a more predictable bed use with less variation over time. Further, aggregating beds by removing some specialty labels not only for emergency patients but also elective patients in a hospital decreases the number of patient transfers in the system, which can increase the level of service quality. Additionally, on the level of the wards, staff can benefit from more predictable flow patterns of patients. This applies to the flows of both emergency patients and elective patients. The simulation model showed that the structure of the $A M A U$, based on planning and control decisions, substantially affects performance, the average time patients stay at AMAU especially.

The hospital under study decided to implement the AMAU. When implementing the AMAU and the higher level of bed aggregation throughout the hospital, management should keep a focus not only on the separate departments but also on 'suppliers' of patients to the departments, like other departments and hospitals, general practitioners, and ambulances and on 'consumers' of patients treated at the departments, like general wards, rehabilitation centers or nursing homes. A target engineering approach could be adopted to optimally attune the different systems and design the whole care chain [30].

Further, patients and beds might still need to be divided into some subcategories and queues, like ICU [25]. Such labels can differentiate between highly specialized auxiliary functionalities for highly specialized, and expensive, treatments. ICU Not having labeled ICU beds would require that all beds in a hospital are equipped such that they are suitable for ICU care as well as medium and regular care. This would increase costs and demand a different nursing care model [19].

Also, the level of bed aggregation has direct relations with the job design and the allocation of staff to the beds and bed aggregates. Skill levels of staff 
should be aligned with the level of bed aggregation. For example, nurses working in a department with specialty labeled beds can be more mono-skilled for the specific specialty, whereas cross-skillfulness is requires in crossfunctional departments. With regard to the latter, there is obviously a limit. The level of cross-skillfulness should always be balanced to the quality of skills as well as the quality of work.

Due to the complexity of hospitals, patient flow discontinuity requires to be viewed upon from a systems perspective, i.e. as a problem in the context of a system of interacting subsystems [31]. Up to now, such a perspective is not appreciated enough in healthcare, which leads to sub-optimization of the various system components at expense of the whole system and at the expense of the flows of patients that require care from more than one medical specialty $[19,32]$. More and more patients express a demand for care from more than one medical specialty or discipline [33]. If systems are not redesigned to better fit these demands as well as the inherent fluctuations in demand resulting from random variability, the as-is situation with queves everywhere will remain.

\section{Study limitations}

The limitations of this study are fourfold. The first concerns the data set used as input for the simulation model. It did not include data of patients considered non-eligible for a stay at the AMAU. There is therefore no information on these patients. Also, at the time the selection was made, the hospital had had no experience with an AMAU. So, the selection criteria and their effects on performance could not be tested. The selection criteria chosen may therefore be adapted after the AMAU is implemented.

The second limitation applies to the element of 'model robustness', or 'whether the model reaches the same results when case mix changes'. In our model, we assumed no radical changes in the case mix. We would recommend further research by experimenting with the stochastic distributions within the model, especially with the arrival and service rates.

Thirdly, the simulation model based on the case study was simple. Even though the model was simple, experimenting with it provided good insights into the consequences of specific design choices. Following Burton and Obel [34], the computational validity of a model is a balance of the question studied, the experimental design and the computational model.

The fourth limitation concerns the fact that only the AMAU design was studied and not the entire hospital. This will be needed, since there is reciprocity 
CHAPTE 3

between departments, like the AMAU and the 'rest of the hospital'. For example, patients can only leave AMAU in practice, when a ward bed is available. If the process at the wards are so designed that this flow is hampered, AMAU performance will decrease. 


\section{References}

1. Womack JP, Jones DT. Lean Thinking - Banish waste and create wealth in your corporation. Revised and Updated. New York: Free Press; 2003.

2. Van Merode GG, Molema H, Goldschmidt H. GUM and six sigma approaches positioned as deterministic tools in quality target engineering. Accreditation and Quality Assurance. 2004; 10(1-2):32-6.

3. De Bruin A, Van Rossum A, Visser M, Koole G. Modeling the emergency cardiac in-patient flow: an application of queuing theory. Health Care Management Science. 2007;10(2):12537.

4. Institule for Healthcare Improvement. Optimizing Patient Flow: Moving Patients Smoothly Through Acute Care Settings. Boston: IHI; 2003

5. Noon CE, Hankins CT, Cote MJ. Understanding the impact of variation in the delivery of healthcare services. Journal of Healthcare Management. 2003;48(2):82.

6. Walley P, Silvester K, Steyn R. Managing Variation in Demand: Lessons from the UK National Health Service. Journal of Healthcare Management. 2006;51(5):309-20.

7. Kenis $P$. Waiting lists in Dutch health care: An analysis from an organization theoretical perspective. Journal of Health Organisation and Management. 2006;20(4):294-308.

8. Law AM, Kelton WD. Simulation Modeling and Analysis. Third ed. New York, USA: Tala McGraw-Hill; 2003.

9. Young $T$, Brailsford S, Connell C, Davies R, Harper P, Klein JH. Using industrial processes to improve patient care. BMJ. 2004;328(7432):162-4.

10. Van Merode GG, Groothuis S. Hospitals as complexes of queuing systems. In: Anderson JG, Katzper M, editors. Health Sciences Simulation 2003; 2003 January 19-23, 2003; Orlando FL: Sociely for Modeling and Simulation International (SCS); 2003. p. 39-44.

11. Krajewski LJ, Ritzman LP. Operations Management. 6th Edition ed. Upper Saddle River, NJ: Prentice Hall; 2002.

12. Liker JK. The Toyota Way. New York: McGraw.Hill; 2004.

13. Ballé $M$, Régnier $A$. Lean as a learning system in a hospital ward. Leadership in Health Services. 2007;20(1):33-41.

14. Van Merode GG, Groothuis S, Hasman A. Enterprise resource planning for hospitals. International Journal of Medical Informatics. 2004;73(6):493-501.

15. Vissers JMH, Bertrand JWM, De Vries G. A framework for production control in health care organizations. Production Planning \& Conlrol. 2001;12(6):591-604.

16. Van Merode GG, Hasman A, Derks J, Goldschmidt HMJ, Schoenmaker B, Oosten M. Decision support for clinical laboratory capacity planning. International Journal of Bio-Medical Computing. 1995;38(1):75.87.

17. Van Merode GG, Hasman A, Derks J, Schoenmaker B, Goldschmidt HWJ. Advanced management facilities for clinical laboratories. Computer Methods and Programs in Biomedicine. 1996;50(2):195-205

18. Becker C, Scholl A. A survey on problems and methods in generalized assembly line balancing. European Journal of Operational Research. 2006;168(3):694-715.

19. Hendrich AL, Lee N. Intra-unit patient transports: Time, motion, and cost impact on hospital efficiency. Nurs Econ. 2005;23(4): 157-64.

20. VanBerkel $P$, Blake J. A comprehensive simulation for wait time reduction and capacity planning applied in general surgery. Health Care Management Science. 2007;10(4):373-85.

21. Bagust $A$, Place $M$, Posnett JW. Dynamics of bed use in accommodating emergency admissions: stochastic simulation model. BMJ. 1999;319(7203):155-8. 


\section{CHADTE}

22. Van Merode GG, Oosten M, Vrieze OJ, Derks J, Hasman A. Optimisation of the structure of the clinical laboratory. European Journal of Operational Research. 1998;105(2):308-16.

23. Arnold D, Furmans K. Materialfluss in Logistiksystemen. Berlin Heidelberg: Springer-Verlag; 2007.

24. Proudlove NC, Gordon K, Boaden R. Can good bed management solve the overcrowding in accident and emergency departments? Emergency Medicine Journal. 2003;20(2): 149-55.

25. Walley P. Designing the accident and emergency system: lessons from manufacturing. Emerg Med J. 2003;20(2):126-30

26. Moloney ED, Bennett K, Silke B. Effect of an acute medical admission unit on key quality indicators assessed by funnel plots. Postgrad Med J. 2007;83(984):659-63.

27. Lammy D. Reforming emergency care; for patients. Emergency Medicine Journal. 2003;20(2):112.

28. Anderson J, Van Merode G. Special issue on health care simulation - Preface. Health Care Management Science. 2007;10(4):309-10.

29. Wolfram Research Mathematica. [Accessed on: 01.03-2007]; Available from: hitp://www.wolfram.com

30. Van Merode GG. A prelude to the 2004 Antwerp Quality Conference: Targets and target values - integrating quality management and costing. Accreditation and Quality Assurance. 2004;9:168-71

31. Hopp WJ, Spearman ML. Factory Physics: foundations of manufacturing management. Second ed. New York: Irwin/McGraw-Hill; 2001

32. Berwick DM, Nolan TW, Whittington J. The Triple Aim: Care, Health, And Cost. Health Aff, 2008;27(3):759-69.

33. van Bussel B, Pijpers E, Ferreira I, Castermans P, Nieuwenhuijzen-Kruseman A. Polymorbidity in diabetes in older people: consequences for care and vocational training. Postgrad Med J. 2007;83(986):763-7.

34. Burton RM, Obel B. The validity of computational models in organization science: From model realism to purpose of the model. Computational \& Mathematical Organization Theory. 1995; 1(1):57.71 


\title{
CHAPTER 4
}

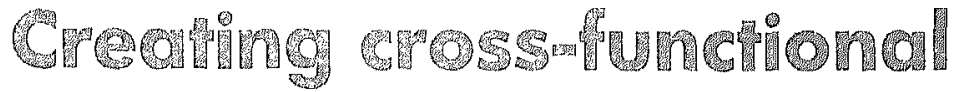

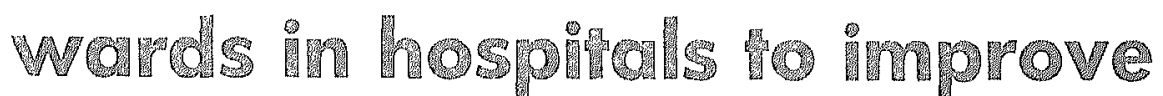 \\ pontenth mow
}

Molema IJW, Van Merode, GG

Submitted for publication 


\section{CHAPTER A}

\section{Abstract}

Acute Medical Admission Units (AMAU) are increasingly implemented in hospitals to streamline acute patient flows. These units group together acute beds that were previously specialty labeled and scattered in the hospital. Until now, however, there has not been a study focused on the relations between such a unit and the organization of regular ward beds.

Often, acute patients require additional 'regular' care after a stay at the AMAU, where they are diagnosed and treated initially. In such a case, patients are transferred to regular wards that also admit elective patients. The present research focused on the effect of the structure of regular wards on the flow of acute and elective patients as well as on utilization of beds. A simulation study was performed.

The results show that the configuration of beds into different aggregates of different labels affects output as well as the overall bed capacity. As long bed capacity is abundant, the configuration is of less to none effect. However, as beds are limited in most hospitals, changing the configuration of beds seems to provide the most opportunities for performance improvement. In this respect, the results show that the flow and throughput of patients is more sensitive to changes and disturbances in a hospital with many different bed labels. Moreover, when regular ward beds are aggregated on higher level then medical specialty, elective patients are less likely to face waiting times for admission.

Overall, the results infer that breaking down some of the functional barriers in hospitals can improve performance, without having to draw on limited budgets and bed pools. This holds true especially for the organization of care elective patients, as soon as an AMAU is introduced. 
CREATING CROSS-FUNCTIONAL WARDS IN HOSPITALS

\section{Introduction}

Hospitals contain many subsystems, i.e., medical specialties, which feed each other patients, information, materials, workers, etc [1]. Despite these subsystems depending largely on each other in terms of patient inflow and outflow, the overall flow of patients through a hospital seems difficult to control $[2,3]$. In general, many inconsistencies exist between departments that impede both the departments and the overall hospital to create direct access to patients' demands [4]. In fact, most hospitals are characterized by high patient waiting times for admission as well as in-process waiting times [5]. Overall, the healthcare supply chain in hospitals is characterized by wastes like overproduction, waiting, and overcapacity as well as process variability $[3,5$ 8].

To overcome some of the wastes, coordination issues, and problems related to scale amongst departments, a rising trend in hospital management is the introduction of cross-functional acute care units or acute medical admission units (AMAU) [9-13]. These units are set up to improve access and in-process transfers for acute patients and reduce the pressure on beds within existing resources [1 1]. AMAUs can function as fully fledged acute wards where acute patients remain throughout their stay in the hospital or they can function as a short stay ward where acute patients are diagnosed and receive only partial treatment. In case of the latter, most of the acute patients will require a transfer to a 'regular' ward and bed after a stay at the AMAU. Unclear is how these regular beds should be organized to ensure efficient transfers of AMAU patients to ward beds as well as direct access to the ward beds for elective patients. Therefore, this chapter studies the research question "How can an increased aggregation level of acute care beds as well as regular ward beds increase flexibility and improve output?"

To study the research question, this chapter introduces a case of a Dutch general hospital where plans were made to set up an AMAU following the short stay function. The question for the hospital was how the regular wards were to be organized to ensure a fit between the AMAU and the wards and how the relations between the AMAU and the wards would affect the service levels for both acute and elective patients as well as the resource utilization of beds in the hospital. To explore opportunities for the structure of the hospital beds, a simulation study was set up in which different scenarios for this were studied. 


\section{Hospital system structure}

A system is a collection of entities, e.g., people, machines, tasks, or subsystems, that act and interact together to accomplish objectives [14]. System structure represents the relations amongst the entities in the system, if and how elements are divided into subsystems, how coordination amongst the entities is achieved, and how the system functions [15-20]. A structure emerges from planning and control decisions [21]. Production control in a hospital concerns, within the boundaries set by evidence based medicine, the design, planning, implementation, and control of coordination mechanisms between patient flows and workflows, to maximize output with available resources and minimize waiting times and costs, while ensuring delivery flexibility [22].

Beds are a primary server in hospitals and are located in wards. The structure of a hospital in terms of the wards represents how beds are grouped into subsystems, how they are labeled, and how coordination is achieved among the subsystems. When designing the structure of beds in a hospital, it is just a matter of quantity and ward size, but also a matter of the configuration of beds within the wards [1].

\subsection{Traditional ward planning and control}

Traditionally, hospitals and their wards are functionally structured, i.e., departments and wards are grouped on the basis of medical specialties [23]. Because of this functional structure, more coordination is needed when patients require services from different specialties or when resources, like diagnostic equipment, need to be shared amongst specialties [24]. Coordination can make treatments and patient flows complex $[5,24]$. In a functionalistic structure an optimal flow for patients who demand care from multiple specialties is difficult to achieve [9]. Additionally, transferring patients can affect the qualify of care and also costs time and money [25].

Resulting from the functionalistic structure in hospitals are smaller groups of specialty labeled beds, each preceded by a specialty type patient queve. Because of the specialty labeling, smaller groups of beds exist that are allocated (part of) a ward. The scale of a subgroup of specialty labeled beds affects the probability of patients waiting for that bed type. That is, at an average bed utilization of $80 \%$, patients have a higher probability of waiting for a smaller group of beds than for a larger group of beds [8]. For patients in a hospital with a functionalistic structure this implies that the likelihood of both waiting times to be admitted to a bed as well as in-process waiting times related to bed-type transfers rise. 
Next to having beds labeled to specialties, hospitals and the medical specialties that control the use of the beds often make a further distinction in bed types related to the sense of urgency of the patients' demands. This results in beds labeled for acute patients and beds for elective patients. Whereas admitting elective patients is scheduled, admitting acute patients is not and takes precedence over the scheduled elective patients as acute patients' demands have a higher sense of urgency. For elective patients it implies that their admission can be cancelled, even at the very last minute, when the bed planned for this patient's admission is allocated to an acute patient. But even acute patients are faced with full wards. When this happens, they either have to wait some time for admission or, when this is not possible due to demand severity, they are transferred to another hospital or are temporarily admitted to a bed of another specialty within the hospital until a bed of the 'right' speciality is available.

\subsection{Cross-functional wards}

Variability concerning acute and elective patient demands for beds can make coordination of beds and patient flows difficult [1]. That is, variability in the aggregated demand and performance of a hospital depends on covariations between demands and flows in subsystems [26]. Hospitals characterized by demand variability need to be aware of how flows at one subsystem affect other subsystems and how the overall structure of specialty departments affects performance [27]. As the functional structure in wards can impede patient flow continuity and impair variability in aggregated demand and performance it needs to be evaluated. We propose that cross-functional integration of beds can take place by breaking down the functional barriers between wards and creating cross-functional teams. This can increase the responsiveness of systems in case of variability and improve performance in the system $[27,28]$.

An AMAU is an example of a cross-functional unit. Selting up an AMAU requires a change in the structure of a hospital, as acute care beds that were previously labeled to specialties and wards are now grouped together, without specific specialty labels [12]. We, however, assumed that it requires more than simply forming the AMAU to streamline the flow of acute as well as elective patients.

In a hospital where the wards are functionally structured, patients that need an available bed at a ward after the AMAU, might still face a likelihood of inprocess waiting times. And despite of the AMAU creating the opportunity for acute patients for reduced access time for admission, for elective patients, the 


\section{CHAPTER A}

probability of waiting to be admitted to the hospital remains if the functionalistic structure of the wards is not changed. To overcome these issues, next to introducing the AMAU, we proposed that the structure of how the 'regular' wards are organized should be redesigned. Like the beds in the AMAU, elective beds might also be aggregated on a higher level into crossfunctional wards. If this is done, bed aggregates of a larger scale are created. This could ensure a higher probability for direct admission for elective patients.

\subsection{Conceptual model}

For this chapter, we introduce a conceptual model for the planning and control of beds in a hospital. In this model displayed in figure 1, patient demand for beds, both acute and elective, is a given. The structure of the wards is not and is assumed to depend on two planning and control decisions: the mix of beds per aggregate and the volume of each aggregate. If beds are aggregated on a higher level than medical specialty, the mix of beds within a label is more diverse and more patient types can be admitted within the aggregate. This will be especially important for elective patients, who are admitted to a bed only if his bed is not needed for acute patients. Second, the size of the bed aggregate is expected to influence the flow of patients. If more beds are available, patients are less likely to be faced with waiting times for admissions or transfers. Increasing the size of the aggregates is also expected to affect resource utilization. Having more beds available is expected to decrease resource utilization.

Overall, increasing bed volume and creating a different mix of beds that share a label is assumed to create flexibility in bed supply. This flexibility is needed to react to demands of both acute and elective patients. More flexibility in resource volume and mix enables a better response to demand variability as well as complexity [29, 30].

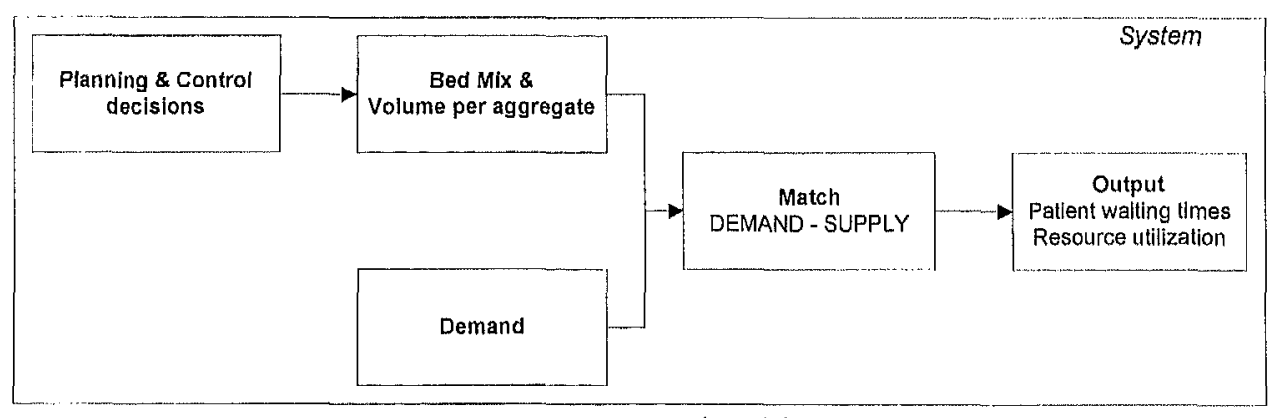

Figure 1: Conceptual model 


\section{Case study}

A simulation study was performed to study the assumed relations and effects between bed volume and mix per aggregate and performance. The model was based on the conceptual model in figure 1. The goal of the simulation study was to build evidence for the conceptual model and explore opportunities for improving system performance in a specific case by not only introducing an AMAU but also redesigning the organization of the non-acute beds. Before the design of the simulation study is described, the case is introduced.

\subsection{Case description}

The case of a large Dutch hospital was studied that, simultaneously, wanted to set up an AMAU to level the inflow of emergency patients and a new configuration of ward beds to level the inflow of elective patients. The AMAU was to function in between the emergency deparfment (ED) and the wards. By, additionally, reorganizing the aggregation level of beds of the wards, hospital management wanted to remove specialty labels and increase supply flexibility at the wards.

At the AMAU, patients that require care additional to the emergency department are to be further diagnosed and, if possible, treated. Those patients that require care additional to the AMAU are again transferred, this time to a regular ward bed. The other patients that are ready affer the treatment at the AMAU are discharged home. The AMAU was set up with specific discharge slots.

Most hospitals use discharge slots to coordinate the transfer and discharge process of patients. Patients are discharged often either in de morning or the evening, after rounds. Once the bed is cleared, a new patient can be admitted, either directly or via a transfer. Discharge slots enable staff to reserve a specific time slot during which they will be occupied with patient discharge. Using discharge slots, however, assumes that all patients are fit to go home or to another department at the same time, while some patients might be ready earlier. This can cause 'wrong' or inappropriate use of beds and impede the direct admission of new patients to the bed that is 'wrongfully' occupied by a patient awaiting discharge. Despite of this, the hospital wanted discharge slots for the AMAU, to overcome disturbances at wards at night and prevent from nightly discharges of patients that could go home. For the wards, discharge slots also existed, just as they always had.

The AMAU was to offer place to 40 beds. Hospital management wanted to extract these beds needed from the current bed pools at the wards. However, 


\section{CMAPBR}

there was no clear overview of the current number of acute beds available to each specialty labeled bed group at the wards. Each ward had a certain capacity for beds. Yet, how many beds were actually staffed and as such 'available' differed from day to day due to variations in staffing and workforce availability. To gain insight into the relations between bed aggregation mix and size and system performance, a simulation model was set up, making several assumptions and testing various scenarios for size and mix.

\subsection{Simulation model}

Fixed input to the simulation model were patients' demands for beds. Demand was specified as to arrival time, the medical speciaity needed for treatment and whether demand was acute or elective. Outputs measured were patient waiting times for admission to an AMAU bed and/or ward bed, wrong bed use resulting from patients waiting for a transfer or discharge, and bed utilization at the AMAU and the wards. We assumed the outputs to depend on the structure of the wards, i.e. the mix of beds within aggregates and the size of each aggregate.

For the model input, historic hospital information was used, as the AMAU was not yet implemented. The data set encompassed three months of data covering all admissions and discharges from the hospital during that period, of both acute and elective patients. The patients were characterized and grouped by hospital professionals and management. From the three-month data set $(N=9802)$ the 'daycare patients' $(N=3843)$ and patients characterized as 'mother-child' ( $N=1032)$ related were excluded from the model as the flows of these patients did not interact with the flow of the AMAU patients and the other elective patients. The remaining sample $(\mathrm{N}=4927)$ included 2101 acute patients, 2825 elective patients, and 1 patients for whom no group was registered. This latter patient was also excluded from the dataset. Of the 4926 patients that remained, the registered arrival times and stay times were used as input for the model.

In the current situation, patients were admitted to a bed labeled to a medical specialty. From the historic data set, the average number of patients admitted per day per specialty could be derived. Table 1 shows these numbers, which were used to determine the initial volume of each specialty bed aggregate in the simulation model. 
CREATING CROSS-FUNCTIONAL WARDS IN HOSPITALS

Table 1: Input data per patient group

\begin{tabular}{lcccccc}
\hline Specialty & Patients & $\begin{array}{c}\text { Avg. bed's } \\
\text { in use }\end{array}$ & $\begin{array}{c}\text { Acute } \\
\text { patients }\end{array}$ & $\begin{array}{c}\text { Avg. acute } \\
\text { beds in } \\
\text { use }\end{array}$ & $\begin{array}{c}\text { Weighted } \\
\text { beds } \\
\text { AMAU }\end{array}$ & $\begin{array}{c}\text { Size of } \\
\text { aggregate }\end{array}$ \\
\hline Spec1 & 2 & 0 & 0 & 0 & 0 & 1 \\
Spec2 & 862 & 52 & 487 & 41 & 8 & 44 \\
Spec3 & 1038 & 80 & 372 & 34 & 6 & 74 \\
Spec4 & 106 & 4 & 0 & 0 & 0 & 4 \\
Spec5 & 194 & 12 & 6 & 1 & 0 & 12 \\
Spec6 & 1 & 0 & 1 & 0 & 0 & 1 \\
Spec7 & 470 & 44 & 335 & 33 & 6 & 38 \\
Spec8 & 209 & 18 & 104 & 10 & 2 & 16 \\
Spec9 & 131 & 4 & 9 & 0 & 0 & 4 \\
Spec10 & 2 & 0 & 0 & 0 & 0 & 1 \\
Spec17 & 1 & 0 & 0 & 0 & 0 & 1 \\
Spec12 & 1 & 0 & 1 & 0 & 0 & 1 \\
Spec13 & 559 & 62 & 314 & 43 & 9 & 53 \\
Spec14 & 158 & 12 & 5 & 0 & 0 & 12 \\
Spec15 & 365 & 35 & 290 & 28 & 6 & 29 \\
Spec16 & 11 & 0 & 0 & 0 & 0 & 1 \\
Spec17 & 4 & 0 & 1 & 0 & 0 & 1 \\
Spec18 & 342 & 27 & 114 & 12 & 2 & 25 \\
Spec19 & 43 & 7 & 2 & 0 & 0 & 7 \\
Spec20 & 40 & 2 & 1 & 0 & 0 & 2 \\
Spec21 & 31 & 1 & 0 & 0 & 0 & 1 \\
Spec22 & 356 & 22 & 59 & 4 & 1 & 21 \\
Total & 4926 & 382 & 2101 & 205 & 40 & 349 \\
\hline & & & & & & \\
\hline
\end{tabular}

Based on the registered admissions and stay times per specialty, the average number of beds in use per specialty was determined. This was used in the simulation model as the volume of each specialty aggregate. To extract the planned $40 \mathrm{AMAU}$ beds from the regular wards, a weighted number of beds was subtracted from the bed total of each specialty, based on the number of acute patients and their stay time per specialty (see table 1).

As historic data were used, the data in table 1 represent information about the number of patients actually admitted. In this situation, there was no AMAU. Data related to the AMAU, therefore, had to be derived from the historic data and estimations. Acute admission data in the historic data set were used to determine the arrival of patients at the AMAU. Additionally, patient stay time at the AMAU was estimated by hospital management. Related to the short stay function of the AMAU, management estimated patients to stay at the AMAU 36 hours on average, with a minimum of 6 hours and a maximum of 48 hours. Next, they set a policy that, after 40 hours at the AMAU, it needs to be 


\section{CMAPTER \&}

evaluated for a patient if a transfer to a regular ward bed is necessary. If so, the patient is then transferred, if not, the patient is discharged within 8 hours. Both at the AMAU and wards, the hospital's regular discharge policy was simulated. For the AMAU, hospital wanted patient transfers to the wards and patient discharges home to take place between $8 \mathrm{am}$ and $8 \mathrm{pm}$. At the wards, discharge in the model took place at fixed times, at 10am and 6pm. These times correspond to daily practice in hospitals, were patients are discharged after morning or evening rounds of the staff.

Admittance of patients to wards took place on a 'first in first out' (FIFO) basis; however, acute patients were given priority. These patients flowed from their AMAU bed into a ward bed, as soon as they could be transferred from the AMAU and a ward bed was available. Elective patient stay time at the wards was based on the historic registrations. The same was done for acute patients that still needed treatment in a regular ward bed after the AMAU. Their stay time there was similar to the registered stay times in the data set, however, with the stay time at the AMAU subtracted.

For the model it was assumed that in the new situation, with an AMAU, the behavior of staff regarding the admittance of patients would not change, neither that the stay time of patients would change due to the AMAU. Next, in the model, patients are either transferred from the AMAU or discharged. Deaths at the AMAU or the wards are not taken into account. For the wards, it was assumed, in accordance to the assumptions of the hospital, that patients were no longer transferred from one ward bed to another as all medical specialty labels were removed.

\subsection{Experimental design}

The planning and control decisions expected to influence the performance in the hospital were the mix and volume of the bed aggregates. These decisions were included in an experimental design. Next to the current scenario with specialty labeled beds and volume based on the average number of beds occupied per specialty, scenarios were set up for regrouping the available beds into different aggregates and different aggregate volumes.

With respect to creating cross-functional wards by mixing the specialty beds, the hospital under study decided to differentiate between acute and elective patients, surgery and internal medicine patients (non-surgery) and complex (longer stay time and more transfers) and non-complex patients (shorter stay and less transfers). Hospital management labeled all 4926 patients in the sample according to these tags. For the simulation scenarios of ward 
configurations, different combinations of tags were used (see table 2). Each combination represents an aggregate of previously specialty labeled beds. For each aggregate that emerged from combining patient types, the number of beds available was computed based on the historic data registration. Again weighted numbers of beds were subtracted from the aggregates to compose the forty-bed AMAU. Table 2 displays the three scenarios that each represents a ward configuration (omitting the scenario with the 22 specialties that represents the current situation in the hospital and is displayed in table 1).

In table 2, the overall bed volume in the hospital is 389 beds, where 40 beds are allocated to the new AMAU. As historic registered data were used, it was unclear, whether the hospital in reality had had the 389 beds available every day, or whether more beds had been available to prevent for a risk of bed shortages. Most hospitals strive for an average bed utilization rate of less then $100 \%$, to minimize the risk of bed shortages. Bagust et al. [10] suggest that at an average utilization rate of $85 \%$ the risk of bed shortages is minimal. To simulate this situation, the size of each bed aggregate within a ward configuration was re-calculated by multiplying the capacity of each aggregate by 100/85 (see tables 3a-3d). A scenario for ward size was added where not $85 \%$ but $90 \%$ bed utilization was simulated. For this scenario, the size of each bed aggregate was multiplied by 100/90 (also see tables 3a-3d). In both scenarios, the number of beds in the AMAU was kept constant at 40 .

To be able to study the effects of different scenarios, including possible interaction effects between bed aggregation mix and volume, the computer simulation study was set up following an experimental design and the results of the experiments were compared using ANOVA analyses and Bonferroni post tests $(a=0.01)$. In total 12 experiments were simulated (see table 4). All experiments simulated the flow of patients through the hospital during 3 months. In the experiments, random numbers were used from the same pseudo. random number streams [14]. As a result, in all 12 experiments identical patients arrive in the same sequence. Herewith, it is possible to compare single runs of each experiment and study the effects of changing the input value of the experimental variables. 
CHATER 4

Table 2: Scenarios for bed aggregation

( $A=$ acule; $E=$ =elective; $S=$ surgical; $B=$ non-surgical; $C=$ complex; $Z=$ non-complex)

\begin{tabular}{lrlrlr}
\hline \multicolumn{2}{c}{ Scenario l } & \multicolumn{2}{c}{ Scenario II } & \multicolumn{2}{c}{ Scenario III } \\
\hline Bed aggregate & Size & Bed aggregate & Size & Bed aggregate & Size \\
AMAU & 40 & AMAU & 40 & AMAU & 40 \\
ABC & 122 & CB & 166 & A & 163 \\
ASC & 41 & CS & 87 & E & 186 \\
KBC & 44 & E & 96 & & \\
KSC & 46 & & & & \\
KZ & 96 & & 389 & Total & 389 \\
Total & 389 & Total & 389 &
\end{tabular}

Table 3a: Scenarios for size of bed aggregates in ward configuration (i=100\%; $i i=90 \% ; i i i=85 \%)$

\begin{tabular}{lrrr}
\hline Scenario l & & & \\
Bed aggregate & $i$ & $i i$ & iii \\
\hline AMAU & 40 & 40 & 40 \\
ABC & 122 & 135 & 144 \\
ASC & 41 & 45 & 48 \\
KBC & 44 & 49 & 51 \\
KSC & 46 & 51 & 54 \\
KZ & 96 & 105 & 112 \\
Total & 389 & 425 & 449 \\
\hline
\end{tabular}

Table 3b: Scenarios for size of bed aggregates in ward configuration II (i=100\%; ii $=90 \%$; iii=85\%)

\begin{tabular}{lrrr}
\hline Scenario II & & & \\
Bed aggregate & $i$ & $i i$ & $i i$ \\
\hline AMAU & 40 & - & - \\
CB & 166 & 184 & 195 \\
CS & 87 & 96 & 102 \\
E & 96 & 105 & 112 \\
Total & 389 & 425 & 449 \\
\hline
\end{tabular}

Table 3c: Scenarios for size of bed aggregates in ward configuration II (i=100\%; $i \mathrm{i}=90 \% ; i i i=85 \%$ )

\begin{tabular}{lrrr}
$(i=100 \% ; i i=90 \% ; i i=85 \%)$ & & & \\
\hline Scenario III & $i$ & $i i$ & $i i$ \\
Bed aggregate & 40 & 40 & 40 \\
\hline AMAU & 163 & 180 & 192 \\
A & 186 & 205 & 217 \\
E & 389 & 425 & 449 \\
\hline
\end{tabular}


CREATINO CROSS-FUNCTIONAL WARLS IN HOSPITALS

Table 3d: Scenarios for size of bed aggregates in ward configuration IV

\begin{tabular}{|c|c|c|c|}
\hline $\begin{array}{l}\text { Scenario } N \\
\text { Bed aggregate }\end{array}$ & $i$ & $i i$ & iii \\
\hline AMAU & 40 & 40 & 40 \\
\hline Spec] & 1 & 1 & 1 \\
\hline 5pec2 & 44 & 49 & 52 \\
\hline Spec3 & 74 & 82 & 87 \\
\hline Spec4 & 4 & 4 & 5 \\
\hline Spec5 & 12 & 13 & 14 \\
\hline Spect & 1 & 1 & 1 \\
\hline Spec7 & 38 & 42 & 45 \\
\hline Spec8 & 16 & 18 & 19 \\
\hline Spec9 & 4 & 4 & 5 \\
\hline Spec10 & 1 & 1 & 1 \\
\hline Spec11 & 1 & 1 & 1 \\
\hline Spec12 & 1 & 1 & 1 \\
\hline Spec 13 & 53 & 59 & 62 \\
\hline Spec 14 & 12 & 13 & 14 \\
\hline Spec15 & 29 & 32 & 34 \\
\hline Spec16 & 1 & 1 & 1 \\
\hline Spec 17 & 1 & 1 & 1 \\
\hline Spec18 & 25 & 28 & 29 \\
\hline Spec19 & 7 & 8 & 8 \\
\hline Spec20 & 2 & 2 & 2 \\
\hline Spec21 & 1 & 1 & 1 \\
\hline Spec22 & 21 & 23 & 25 \\
\hline Total & 389 & 425 & 449 \\
\hline
\end{tabular}

Table 4: Simulation experiments

\begin{tabular}{|c|c|c|c|}
\hline \multicolumn{2}{|c|}{ Experiments } & \multirow{2}{*}{$\frac{\text { Ward configuration }}{1}$} & \multirow{2}{*}{$\frac{\text { Size of the aggregates }}{i}$} \\
\hline 7 & 2 departments $\cdot 0 \%$ & & \\
\hline 2 & 2 departments - $90 \%$ & 1 & $\mathrm{ii}$ \\
\hline 3 & 2 departments $-85 \%$ & I & iii \\
\hline 4 & 3 departments - $0 \%$ & $\|$ & $i$ \\
\hline 5 & 3 departments - $90 \%$ & $\|$ & $\mathrm{ii}$ \\
\hline 6 & 3 departments - $85 \%$ & $\|$ & iii \\
\hline 7 & 5 departments $.0 \%$ & III & $i$ \\
\hline 8 & 5 departments - $90 \%$ & III & ii \\
\hline 9 & 5 departments $-85 \%$ & III & iii \\
\hline 10 & Specialty departments - $0 \%$ & IV & $\mathrm{i}$ \\
\hline 11 & Specialty departments - $90 \%$ & IV & ii \\
\hline 12 & Specialty departments - $85 \%$ & iv & iii \\
\hline
\end{tabular}




\section{CHAPTER 4}

\section{Results}

Table 5 displays the results of each of the experiments and table 6 , additionally, displays the results of the ANOVA analyses. Overall, the results show that grouping together beds in higher aggregates and offering more beds, decreases the waiting times of both acute and elective patients to be admitted to a bed as well as the time patients spent in bed unnecessarily ('wrong bed use'). Bed utilization is less when more beds are available. The configuration of the hospital in terms of bed aggregates as well as the size of the aggregates significantly affected patient waiting times for a bed in the AMAU and the ward as well as wrong bed use in the AMAU and the wards. When size was increased, waiting times and wrong bed times decreased. Bed utilization decreased as well, as more beds were available to the same number of patients. Regarding the ward configuration, the results show that increasing the aggregation level of beds decreased waiting times and wrong bed use. The Bonferroni post tests showed, however, no significant difference in performance between the scenarios with 2 bed aggregates and 3 bed aggregates. Further, the post-tests showed that only the configuration with specialty labeled beds significantly increases wrong bed use, compared to the three other configurations. The ANOVA analyses in table 6 additionally show that the waiting times for elective patients to be admitted to a ward bed as well as the wrong bed use at the wards were affected most by the configuration of the hospital. It needs to be noted here that the differences found amongst the experiments for performance indicator 'wrong bed use at the wards' seems of little practical relevance, as the differences are 0.1 to 0.2 hours, which corresponds to 6 to 12 minutes.

The ANOVA analyses also show that the size of the wards had the most impact on patient waiting time for the AMAU and wrong bed time of patients at the AMAU. Bonferroni post tests showed wrong bed time of patients at the AMAU is only different when the size of the bed aggregate was increased with either 10 percent or 15 percent. There was no difference between the $90 \%$ and $85 \%$ scenarios. With regard to the time patients spent waiting for AMAU admission, the post tests reported output differs significant amongst al three bed capacity scenarios.

Regarding the use of beds, we see in the results that the use of AMAU beds was significantly lower in the situation with more beds after the AMAU. However, the post-tests showed this only happened when bed capacity was increased with 10 or 15 percent. 
CREATING CROSS-FUNCTIONAL WARDS IN HOSPITALS

Table 5: Results simulation experiments

\begin{tabular}{|c|c|c|c|c|c|c|c|c|c|c|c|c|}
\hline & \multicolumn{6}{|c|}{ AMAU } & \multicolumn{6}{|c|}{ WARDS } \\
\hline & \multicolumn{2}{|c|}{ Wail time } & \multicolumn{2}{|c|}{$\begin{array}{c}\text { Wrong } \\
\text { bed }\end{array}$} & \multicolumn{2}{|c|}{ Bed use } & \multicolumn{2}{|c|}{ Wait time } & \multicolumn{2}{|c|}{$\begin{array}{c}\text { Wrong } \\
\text { bed }\end{array}$} & \multicolumn{2}{|c|}{ Bed use } \\
\hline & Avg & $C V$ & Avg & $\mathrm{CV}$ & Avg & $C V$ & Avg & $\mathrm{CV}$ & Avg & $C V$ & Avg & $C V$ \\
\hline 2 depts. $0 \%$ & 11.3 & 1.4 & 4.6 & 1.4 & 0.92 & 0.2 & 0.1 & 6.4 & 2.7 & 1.5 & 0.87 & 0.1 \\
\hline 2 depts.90\% & 4.0 & 1.5 & 3.5 & 1.1 & 0.89 & 0.2 & 0.0 & . & 2.6 & 1.5 & 0.79 & 0.1 \\
\hline 2 depts. $85 \%$ & 3.8 & 1.5 & 3.4 & 1.7 & 0.89 & 0.2 & 0.0 & . & 2.6 & 1.5 & 0.75 & 0.1 \\
\hline 3 depts. $0 \%$ & 11.1 & 1.3 & 4.8 & 1.2 & 0.93 & 0.1 & 1.0 & 5.5 & 2.7 & 1.5 & 0.87 & 0.1 \\
\hline 3 depts. $90 \%$ & 3.9 & 1.5 & 3.5 & 1.1 & 0.89 & 0.2 & 0.0 & 15.3 & 2.6 & 1.5 & 0.79 & 0.1 \\
\hline 3 depis. 85\% & 3.8 & 1.5 & 3.4 & 1.7 & 0.89 & 0.2 & 0.0 & . & 2.6 & 1.5 & 0.75 & 0.1 \\
\hline 5 depts. 0 & 14.5 & 1.4 & 5.4 & 1.5 & 0.94 & 0.1 & 2.0 & 5.1 & 2.7 & 1.4 & 0.87 & 0.1 \\
\hline 5 depis. $90 \%$ & 4.3 & 1.5 & 3.6 & 1.2 & 0.90 & 0.2 & 0.3 & 11.9 & 2.6 & 1.5 & 0.79 & 0.1 \\
\hline 5 depts. $85 \%$ & 3.8 & 1.5 & 3.4 & 1.1 & 0.89 & 0.2 & 0.1 & 17.5 & 2.6 & 1.5 & 0.75 & 0.1 \\
\hline Spec. $0 \%$ & 21.4 & 1.3 & 6.3 & 1.7 & 0.95 & 0.1 & 14.6 & 2.6 & 3.0 & 1.4 & 0.86 & 0.1 \\
\hline Spec. $90 \%$ & 7.0 & 1.2 & 4.3 & 1.3 & 0.91 & 0.2 & 6.1 & 4.0 & 2.8 & 1.4 & 0.78 & 0.1 \\
\hline Spec. 85\% & 4.9 & 1.4 & 3.8 & 1.2 & 0.90 & 0.2 & 4.1 & 5.6 & 2.7 & 1.5 & 0.74 & 0.1 \\
\hline
\end{tabular}

Table 6: ANOVA results

\begin{tabular}{lll}
\hline & Most impact on performance $\neq$ & Impact on performance \\
\hline Wait AMAU & Size & Configuration; Configuration*Size \\
Wrong bed AMAU & Size & Configuration; Configuration*Size† \\
Use beds AOA & Size & - \\
Wait wards & Configuration & Size; Configuration*Size \\
Wrong bed wards & Configuration & Size \\
Use beds wards & Size & $\cdot$ \\
\hline
\end{tabular}

F Most impact on performance implies highest $F$ ratio reported in ANOVA analysis

t Interaction term included in ANOVA analyses

There were no differences between the $90 \%$ and $85 \%$ aggregates. At the wards, beds were also less utilized when there were more of them. Significant differences were found amongst the three scenarios. Bed use at both the AMAU and the wards was not significantly affected by the configuration or an interaction term.

The experiments also brought about interaction effects that indicate significant differences resulting from relations between the hospital configuration and the size of the corresponding departments. This interaction effect was found to significantly influence the time acute patients spent waiting to be admitted to the AMAU, the time they unnecessarily spent in an AMAU bed waiting for a ward bed, and the time elective patients spent waiting to be admitted to a ward bed. 


\section{CHABDTER}

\section{Discussion and conclusions}

Taking into account the results of the simulation model and the experiment, some discussion points come to the fore. First of all, the increased bed, use that is reported when the size of the wards is decreased. This increased bed use, herewith, is not so much the result of efficiency in the AMAU, but more of the lack of transfer opportunities in the wards if fewer beds are available. With less transfer opportunities, more AMAU patients have to unnecessarily remain at the AMAU in a bed until a ward bed is free.

With regard to the interaction term found in the ANOVA analyses, we can say that the effect of the size of the aggregation depends on how beds are grouped in the configuration. The simulation results indeed show that the more ward-types exist, the more effect the size of the ward has on the throughput of patients. In other words, the bigger the ward, the less influence the configuration has on the results. This is in line with the statement Walley [1] makes concerning the importance of resource configuration compared to recourse capacity.

In the simulation experiments, it seems that as long as bed capacity is abundant the configuration is of less to none effect. However, as beds are limited in most hospitals and bed reductions have taken place the last decade [12], the configuration seems to provide the most opportunities for performance improvement. Especially, if we look at the relative effect of size combined with the configuration we can see that having fewer beds in a functional hospital with specialty labeled beds increases waiting time more than in a hospital with beds without specialty labels. This means that the flow and throughput of patients is more sensitive to changes and disturbances in a hospital with many different bed labels.

Further, based on the results, we can conclude that patients flow more easily through a system with less specific bed labels. This holds true for elective patients especially. Acute patients are given priority, and as such, their flows are less influenced by the ward-types that exist. Yet, the results show that this effect mainly exists if the bed capacity is increased with either 10 or 15 percent and that between 10 and 15 percent there is less significant difference. This implies that an increase of bed capacity of approximately 40 or 60 beds is needed in the hospital to improve performance. This will prove to be difficult, given the budgetary limitations healthcare and most hospitals have to deal with. Interesting to note in this respect is that redesigning the structure from functional to more cross-functional results in improved output with the same number of beds. Some differences are found between the three 
scenarios with cross-functional departments, however, the biggest differences are found between the functional and cross-functional departments.

Limitations of the study mainly centre on the input data. These data represent the situation in the past, without the AMAU. As there was no AMAU when this simulation study was carried out, there were no data available. Therefore, the simulation and its experiments were based on input data identical to the past situation. This results, e.g., in hardly any changes in the use of beds as the stay time of patients at the wards remained constant. A decrease in stay times of acute patients can be expected when an AMAU is introduced [12]. In the AMAU of the hospital under study, the acute patients are to be diagnosed and based on the diagnosis a complete treatment plan is set up. This is expected to make the rest of the patient's stay after the AMAU more predictable. Not having to transfer patients can also benefit their stay time, as transfers are associated with increased stay times due to complications [25]. Not taking into account such affects on stay time in the experiments can results in the simulation model given a underestimation (or overestimation) of reality. In fact, previous research on creating a process oriented acute stoke unit, by Vos et al. [31], also showed that through process redesign, the number of patients that can be directly admitted increased, which improved performance and reduced patient length of stay considerably.

Another limitation concerns the fact that skills and behavior of the professionals involved in the new situation were not simulated. Cross-functional wards will require staff, nurses especially, to be multi-skilled [1]. Not only clinical skills are required; skills related to process coordination are of the essence in crossfunctional structure [31]. Not having such skills, can impede a successful implementation. Second, physician behavior might change after implementation of an AMAU. For example, physicians can adapt how and when they admit elective patients at the wards. Because of an AMAU, acute patients are already admitted to the hospital and so there is less pressure of finding a regular bed for them, where in the situation without an AMAU pressure is on physicians to free beds for acute patients. With an AMAU, there is the opportunity to stretch the stay of acute patients at the AMAU so extra elective patients can be admitted. This affects not only the in-process waiting times of acute patients, but also the efficiency of beds utilization and the inflow of new acute patients.

Both limitations of the model plead for clear regulations for practice as to when and how patients should be admitted or transferred. Also, they indicate that 


\section{CHAPTER 4}

staff behavior in this respect needs to be monitored. Not transferring patients from the AMAU to the wards impedes the inflow of new acute patients to the AMAU. Such actions could undo the advantages of creating cross-functional wards.

In conclusion, the authors argue for evaluating the functional structure of most current hospitals, given the gain in efficiency resulting from redesigning the ward structure in the hospital under study. This chapter proves that breaking down some of the functional barriers can improve performance, without having to draw on limited budgets and bed pools. This holds true especially for the organization of care elective patients, as soon as an AMAU is introduced.

Elective patients and their flows often need to give way to acute patients. Introducing an AMAU can lessen this load; yet, without cross-functional regular wards, elective patients still face waiting times and other waste and AMAU beds are not optimally used. The simulation study discussed in this chapter shows that the inconsistencies between the AMAU and wards can be resolved by restructuring the current bed capacity

In a situation with cross-functional wards, acute patients disturb the flows of elective patients less and the probability of direct access for these patients increases. In such a situation, hospital managers might even consider removing such distinctions between acute and elective patient groups, as all patients can have direct access to the care they demand. 


\section{References}

1. Walley P. Designing the accident and emergency system: lessons from manufacturing. Emerg Med J. 2003;20(2): 126-30.

2. Plsek PE, Wilson T. Complexity science: Complexity, leadership, and management in healtheare organisations. BMJ. 2001;323(7315):746-9.

3. Parnaby J, Denis TR. Seamless healthcare delivery systems. International Journal of Health Care Quality Assurance. 2008;21(3):249-73.

4. Womack JP, Jones DT. Lean Thinking - Banish waste and create wealth in your corporation. Revised and Updated. New York: Free Press; 2003

5. Van Merode GG, Molema H, Goldschmidt H. GUM and six sigma approaches positioned as deterministic tools in quality target engineering. Accreditation and Quality Assurance. $2004 ; 10(1-2): 32-6$.

6. Van Merode GG, Groothuis S. Hospitals as complexes of queuing systems. In: Anderson JG, Katzper $M$, editors. Health Sciences Simulation 2003; 2003 January 19-23, 2003; Orlando FL: Society for Modeling and Simulation International (SCS); 2003. p. 39-44.

7. Noon CE, Hankins CT, Cote MJ. Understanding the impact of variation in the delivery of healthcare services. Journal of Healtheare Management. 2003;48(2):82.

8. Walley P, Silvester K, Steyn R. Managing Variation in Demand: Lessons from the UK National Health Service. Journal of Healthcare Management. 2006;51(5):309-20.

9. Institute for Healthcare Improvement. Optimizing Patient Flow: Moving Palients Smoothly Through Acute Care Settings. Boston: IHI; 2003,

10. Bagust $A$, Place $M$, Posnett JW. Dynamics of bed use in accommodating emergency admissions: stochastic simulation model. BMJ. 1999 July 17, 1999;319(7203):155-8.

11. Moloney ED, Bennett K, Silke B. Effect of an acute medical admission unit on key quality indicators assessed by funnel plots. Postgrad Med J. 2007;83(984):659-63.

12. Moloney ED, Smith D, Bennett K, O'Riordan D, Silke B. Impact of an acute medical admission unit on length of hospital stay, and emergency department 'wait times'. QJM. 2005;98(4):283-9.

13. Rooney T, Moloney ED, Bennett K, O'Riordan D, Silke B. Impact of an acute medical admission unit on hospital morlality: a 5-year prospective study. QJM. 2008;101(6):457-65.

14. Law AM, Kelton WD. Simulation Modeling and Analysis, Third ed. New York, USA: Tato McGraw.Hill; 2003.

15. Silvestro R. Positioning services along the volume-variety diagonal - The contingencies of service design, control and improvement. International Journal of Operations \& Production Management. 1999;19(4):399-420.

16. Silvestro R, Fitzgerald L, Johnston R, Voss C. Towards a classification of service processes. International Journal of Service Industry Management. 1992;3(3):62.75.

17. Armistead CG. Service operations strategy: framework for matching the service operations task and the service delivery system. International Journal of Service Indusiry Management. 1990;1(2):6-16.

18. Galbraith JR. Designing organizations: an executive guide to strategy, structure and process. New and Revised ed. San Fransico, USA: Jossey-Bass; 2002.

19. Tummers GER, van Merode GG, Landeweerd JA. Organizational Characteristics as Predictors of Nurses' Psychological Work Reactions. Organization Studies. 2006;27(4):559-84.

20. Mintzberg H. The structuring of organizations. Engelwood Cliffs, N.J.: Prentice-Hall, Inc.; 1979. 
21. Anthony RN. Planning and control systems - a framework for analysis. Boston, Massachusetts: Division of Research, Graduate School of Business Administration, Harvard University; 1965.

22. De Vries G, Bertrand JWM, Vissers JMH. Design requirements for health care production control systems. Production Planning \& Control. 1999;10(6):559-69.

23. Van Merode GG. A prelude to the 2004 Antwerp Quality Conference: Targets and target values - integrating quality management and costing. Accreditation and Quality Assurance. 2004;9:16877.

24. Maruster $L$, Weijters $T$, de Vries $G$, van den Bosch A, Daelemans W. Logistic-based patien grouping for multi-disciplinary treatment. Artificial Intelligence in Medicine. 2002;26(1-2):87 107.

25. Hendrich AL, Lee N. Intra-unit patient transports: Time, motion, and cost impact on hospital efficiency. Nurs Econ. 2005;23(4): 157-64.

26. Germain R, Claycomb C, Dröge C. Supply chain variability, organizational structure, and performance: The moderating effect of demand unpredictability. Journal of Operations Management. 2008;26(5):557-70

27. Van Merode GG, Oosten M, Vrieze OJ, Derks I, Hasman A. Optimisation of the structure of the clinical laboratory. European Journal of Operational Research. 1998; 105(2):308-16.

28. Van Merode GG, Groothuis S, Hasman A. Enterprise resource planning for hospitals. International Journal of Medical Informatics. 2004;73(6):493-501.

29. Santos Bernardes E, Hanna MD. A theorelical review of flexibility, agility and responsiveness in the operations management literature: toward a conceptual definition of customer responsiveness. International Journal of Operations \& Production Management. 2009;29(1):30-53.

30. Cousens $A$, Szwejczewski $M$, Sweeney M. A process for managing manufacturing flexibility. International journal of Operations \& Production Management. 2009;29(4):357-85.

31. Vos L, van Oostenbrugge RJ, Limburg M, van Merode GG, Groothuis S. How to implement process-oriented care, Accreditation and Quality Assurance: Journal for Quality, Comparability and Reliability in Chemical Measurement. 2009;14(1):5-13. 


\title{
CHAPTER 5
}

\author{
A vision on thospilloll system \\ design: Arovind Eye Hospiltal
}

Molema JJW, Van Merode, GG.

Submitted for publication 


\section{CHAPTER 5}

\section{Abstract}

The Aravind Eye Hospitals in South India prove that waiting is not inextricably bound to healthcare delivery and hospitals. Aravind patients can enter the hospital on day they want, to receive the care they demand, without waiting times. In a country like India where budgets are ever limited, it is notable that patients encounter higher service levels than in countries at the top of the pyramid. The present case study wanted to research what exactly it is in the hospital structure that enables Aravind to constantly minimize patient waiting times, given limited resources.

At Aravind, patient demands vary in terms of volume, mix and delivery, from day to day, from month to month, from year to year. Aravind's answer to this variability is reactive decision making. If demand for a specific task increases, staff is switched to that task from a task that is temporarily less demanded, or patients are rerouted to a unit where the same tasks is performed but where demand is temporarily less. This ability is based on the flexibility Aravind has created in system structure and workforce. Compared to more functionalistic hospital structures, Aravind organizes its structure not so much around medical specialties but around the tasks and patients. Further, staff are assigned to where the need for them exists, based on actual demand. Staff receive constant training and education, on both clinical tasks and ICT, and are taught to make the reactive decisions. Finally, Aravind emphasizes the use of lower educated staff to take over administrative and clinically less complex tasks.

The case study results of Aravind infer that the traditional interpretation of a hospital as a functionalistic stronghold focused on professional hierarchy and fragmented responsibility should be changed into hospitals that are directly accessible to patients, through flexible structures that can adapt supply to patients' demands.

\section{Acknowledgements}

This study could not have been done without the support of the Aravind staff. We are grateful to all, the sisters that participated in the interviews especially. We would like to thank Dr. S. Aravind, Dr. N. Ramakrishnan, Mr. S. Philip, and Mr. Rajakumar for their help, advice, and sincere interest in the project and for enabling the work to be carried out smoothly. Finally, the authors wish

to thank Dr. A. van Raak for his valuable comments and support. 
A VISION ON HOSPITAL SYSTEM DESIGN

\section{Introduction}

In hospitals, patients wait; this almost seems inevitable. If only there were enough resources, like doctors, nurses and beds, to offer patients the supply they want, at the moment they demand it. Yet, budgetary constraints face hospital managers, who constantly try to match demand and supply. In an emerging economy like India, budget is even more limiting. It is, however, in this country, at the bottom of the pyramid, where the poorest of patients in need of eye care face hardly any waiting time at all [1].

In Tamil Nadu, a state in South-India, one can find the Aravind Eye Care System, which consists of five hospitals and encompasses an extensive eye care network [1]. The biggest of the five hospitals is the Aravind Eye Hospital in Madurai. In this hospital, a patient in need of eye care can walk in for a direct outpatient consultation and a date for an eye surgery is scheduled at the patient's convenience. Patients decide what they pay, based on what they can afford: nothing at all (70\% of the patients), a small fee, or regular price, which is one USD for a comprehensive eye check up. At the hospital, there is hardly any waiting time for any type of patient and lead time, i.e. the time from when a patient expresses his demand until this demand is met, is low for all services offered at the hospital. Lead time is maximum 1 day for the outpatient process and 1 to 3 days for surgery, depending on the time needed for post-surgery care. The time in between the two activities depends on the patient, when he wants to receive the cataract surgery. Additionally, Aravind reports high resource utilization.

In other hospitals, lead times are high(er) and hospitals are characterized by waiting times for patients and inefficient use of resources. In the UK, for example, waiting time for cataract surgery is reported as ranging from 18 weeks to four months, from referral to treatment [2]. To study how Aravind achieves better results and exceeds others in terms of performance, a hierarchical planning and control framework for hospitals, introduced by Vissers et al. [3] (see also table 1), was used to build up explanations about what exactly it is in the hospital structure that enables Aravind to constantly minimize patient waiting times, given limited resources. 
Table 1: Hierarchical planning and control framework $[3,4]$

\begin{tabular}{|c|c|c|c|}
\hline & Purpose & Planning horizon & Scope \\
\hline $\begin{array}{l}\text { Strategic } \\
\text { planging }\end{array}$ & $\begin{array}{l}\text { Decide what services to offer } \\
\text { and in what form to offer } \\
\text { them (organizational } \\
\text { archetype) }\end{array}$ & Long-term & Hospital as a whole \\
\hline $\begin{array}{l}\text { Patient volume } \\
\text { planning \& } \\
\text { control }\end{array}$ & $\begin{array}{l}\text { Trade-off between service } \\
\text { level and resource utilization; } \\
\text { decisions are made regarding } \\
\text { patient mix }\end{array}$ & $\begin{array}{l}\text { Medium-term } \\
\text { (production period) }\end{array}$ & Hospital as a whole \\
\hline $\begin{array}{l}\text { Resource } \\
\text { planning \& } \\
\text { control }\end{array}$ & $\begin{array}{l}\text { Determine required resource } \\
\text { volume and skills }\end{array}$ & $\begin{array}{l}\text { Medium-term } \\
\text { (production period) }\end{array}$ & Each patient group \\
\hline $\begin{array}{l}\text { All patient } \\
\text { groups }\end{array}$ & $\begin{array}{l}\text { Define market performance } \\
\text { objectives; acquisition of } \\
\text { resources; control of patient } \\
\text { flow; utilization }\end{array}$ & $\begin{array}{l}\text { Medium-term } \\
\text { (production period) }\end{array}$ & Each patient group \\
\hline $\begin{array}{l}\text { Single patient } \\
\text { group }\end{array}$ & $\begin{array}{l}\text { Decouple production phases } \\
\text { that deal with different levels } \\
\text { of uncertainty }\end{array}$ & $\begin{array}{l}\text { Shortterm (day-to } \\
\text { day) }\end{array}$ & $\begin{array}{l}\text { Processes used in } \\
\text { facilitating day-to- } \\
\text { day patient } \\
\text { activities }\end{array}$ \\
\hline
\end{tabular}

1.7 Planning and control

Through planning and control decisions organizations try to fit their system's structure to the strategy [3-6]. The framework in table 1 is based on the assumption that production control in a hospital concerns, within the boundaries set by evidence based medicine, the design, planning, implementation, and control of coordination mechanisms between patient flows and workflows, to maximize output with available resources and minimize waiting times and costs, while ensuring delivery flexibility [7]. The framework can be applied to production systems that are characterized by a homogeneous product range and a primary process that is geared to this product range [4]. The latter is the case at Aravind, which can be considered a focused eye hospital.

Following the framework, the trade-off between patient service levels and resource utilization is made for the hospital as a whole as well as for each of the departments and patient groups the hospital aims to serve [7]. This implies that planning and control takes place on different levels. In fact, it varies from strategic planning, to medium-term planning, and day-to-day decisions [3-6]. The hierarchical planning framework is used top-down, as the long-term strategy is defined first, after which decisions are made with regard to the volume and skill mix of resources required to perform the services. According to the framework, resources and patient groups are placed in the system. Based on their locations and the transfers between resources and patients, 
relations and interdependencies exist amongst them. The whole of these relations represents the structure of the system. Also, it determines which shortterm decisions still need to and can be made to, e.g., define the daily allocation of resources to single patient groups.

\subsection{Methodology}

A case study was set up and aligned to the hierarchical framework. The unit of analysis was the Aravind Eye Hospital in Madurai. During three months, interviews were held with Aravind staff and leaders, (participating) observations were made, data sets as well as documents were analyzed, and several artifacts, like the hospital lay-out, were studied.

For data triangulation, different methods for data collection were used and their results were compared. The interview respondents were staff working at the various units and departments of the hospital. Of each unit, at least one senior nurse and/or manager was interviewed about the unit's planning and control, patient flows, and staff flows. Observations were made at the units and participation observations were made at various hospital management meetings. Hospital data from the hospital information system were analyzed, planning and control information of patients at the outpatient department especially. Additionally, on the results of the interviews, observations, and data analyses, feedback was given by the interviewees as well as Aravind management.

Below, the results of the case study are described. In section 2, this is done following the levels of the hierarchical framework. Section 3 continues the discussion on the Aravind structure, yet introduces aspects that are beyond the hierarchical framework. Section 4 relates the framework, the aspects beyond the framework and the performance at Aravind to current hospital design in the Netherlands. Section 5, finally, summarizes the main findings of the chapter and concludes what can be learned from the case of Aravind.

\section{Aravind}

Worldwide, 37 million people are blind. Cataract is the leading cause of blindness but can be cured by a simple surgery and a sight test [8]. Of the 12 million blind living in India, most cannot afford such surgeries. In 1976, after his retirement as government ophthalmologist, Dr. Govindappa Venkataswamy wanted to do something about this. He opened a small community hospital in the south Indian town Madurai and ran and financed it with his family [9]. 


\section{CHAPTER 5}

Since 1976, this first 'Aravind Eye Hospital' has developed into five hospitals that encompass over 4000 beds. Over 3.4 million eye surgeries have been performed within what is now a registered non-governmental organization called 'Aravind Eye Care System' (AECS). Today, AECS is the largest and most productive eye care system and trainer of ophthalmic personnel in the world. AECS mission is to "eliminate needless blindness by providing high quality, high volume, compassionate eye care to all". In 2008-2009, over 2.7 million outpatients were seen and more than 300,000 surgeries and laser procedures were performed. The average annual AECS surgeon's productivity is 2000 cataracts, compared to the Indian national average of 250 [9]. Comparing Aravind to the research of Norregaard [10] shows that in other countries, surgical productivity is also lower. The work of Prahalad [1] shows that Aravind's high volume surgery is performed at a surgical quality at least comparable to others. Finally, costs are low at Aravind. The average price for cataract surgery for paying patients is 6,550 Indian Rupees (= 130USD), while $60 \%$ of AECS patients pay nothing or almost nothing. AECS' financial system is self-supporting and yields gross margins of $35 \%$.

\section{1 Strategic planning}

Aravind has designed its system to offer care to those patients that need it most. That is, patients that cannot afford eye care in regular hospitals, yet, without it go blind or remain blind. To make the care delivery affordable, Aravind has created a network in which all services are delivered and controlled by Aravind. Through both national and international partnerships, Aravind offers not only eye care services but a wide range of services related to eye care, including a pharmacy, production of eye care products, staff training, and research. Without offering this variety of services and keeping up the network, the care would become too expensive for the Aravind customers. In this respect, Aravind also depends on funds generated from patient care. Within the network Aravind strives to keep its services efficient for its own sustainability, In terms of performance measures, Aravind strives to minimize costs and maximize patient throughput to provide eye care to all at a cost patients can afford. When Aravind started, intra ocular lenses (IOL) for cataract surgery were bought from external producers. These lenses were expensive and made it difficult to offer free surgeries. Dr. Venkataswamy decided that the only way to make surgery affordable was to self-produce the lenses. He founded Aurolab in 1992, which started the AECS network. Aurolab brought the $\mathrm{IOL}$ price down from 100 USD to 2 USD. Today, Aurolab 
not only produces lenses but also suture needles, and pharmaceuticals. It sells its products worldwide.

Next to an internal supply chain, AECS also maintains partnerships within India and outside to help other hospitals in developing and maintaining sustainable business models. The Aravind Managed Eye Care Hospitals are a good example. Aravind sends some of its people to existing or newly built hospitals that lack the knowledge to use resources optimally for the community. Currently, Aravind has helped set up four such hospitals and hopes to set up more managed care hospitals in the future. Aravind additionally maintains partnerships with global health organizations like WHO and Vision2020. Further, Aravind welcomes all that want to learn at Aravind. For instance, surgical trainees from internationally renowned university training programs visit Aravind every year to do part of their training program at Aravind. Particularly inside its hospitals, Aravind has created a layout that virtually, through IT, and physically, because all hospital services are within walking distance, supports the mission.

2.2 Patient volume planning \& control

Flows arise as a result of transfers of patients, tasks, information, or materials, from one location or person to another [11]. Creating continuous flow for patients requires that only value added activities are performed in and nonvalue added time is minimized. To identify the flow of patients, Aravind identifies their 'value stream' [12]. That is, for all types of patients, Aravind specifies which activities need to be performed. Together, these activities map the flow of patients through Aravind and activities that do not add value are precluded [12]. For all value adding activities, Aravind identifies who can best perform them at a high service level and at the same time at minimum cost.

For patients, Aravind values the principle of flow and is especially aware of the fact that variability in the aggregated demand of the hospital depends on variations in demand at the various units. So, the accuracy in the forecast of aggregated demand depends on the covariations between demands in the subsystems [13]. As variations exist between subsystems, Aravind tries to flexibly organize demand and supply across subsystems. This flexibility is needed to enable responsiveness to variations and ensure continuous patient flows and efficient resource use throughout the hospital.

For patient demand, decisions regarding patient mix are made. For example, the major part of the OPD is not specialty labeled; rather, it is a general OPD servicing a range of patients. Patients can be rerouted between general units 


\section{CHAPTER 5}

to even out variations in the aggregate demand. For specialized demands, Aravind has distinguished patient types as well as specific subsystems. These are the retina, vitreous, cataract, neuro-ophthalmology, pediatric ophthalmology, orbit and oculoplasty, glaucoma, uvea, cornea, and vision rehabilitation units. To even out flow at these units, the resources within these units are switched between surgery and diagnostic tasks, depending on the overall demand at the specialty unit.

\subsection{Resource planning and control}

Aravind uses doctors, both junior and senior, only where they are needed in the process and has transferred many tasks to technicians but especially to Mid Level Ophthalmic Personnel (MLOP). The MLOPs are called sisters, instead of nurses. Their level of education is school completion and an in house training program certified by the government. The MLOPs perform medical registration tasks, counseling, diagnostic tests, support surgeries, housekeeping tasks, and support research. Regardless of the unit or tasks where they are deployed each MLOP is identifiable by her sari the color of which varies according to the job profile.

To plan and control all resources, staff as well as apparatus, amongst units within the hospital, Aravind uses custom-made information systems. Aravind's own IT-department has developed these information systems not only to register data for feedback information, but also to enable feedforward loops for sending patients to certain departments. One part of the system encompasses all general patient information concerning the date of OPD visits and surgeries The other part comprises treatment details of patients who have visited the OPD specialty clinics. With the information systems Aravind sets up yearly calendars for each hospizal and its units. These calendars predict the expected patient load for each day of the year for, e.g., the whole outpatient department or a specific outpatient specialty clinic. Based on the predictions, resources are allocated to the units. If the actual demand is different from the predictions, resources can be switched to ensure that resources are allocated to the unit or task where they are most needed. The information systems are also used to route patients to the OPD units with the shortest queves. This not only reduces patient waiting times but also levels out the patient load over the units. 


\subsection{All patient groups}

Aravind's objective with regard to patient flow is to see and treat all patients that present themselves at the hospital on the day they express their demand. For outpatients, this means their lead time should be one day maximum. For surgery patients, lead time objectives depend on the medical evidence for the duration of post-surgical care. To achieve this objective resources are acquired from the overall pool of resources. Depending on the demand of patients, the required number of resources is determined. This number can vary over days, as demand can vary over days.

On an average day in Madurai, 1500 patients visit the OPD of the Aravind Eye Hospital; however, this number varies from 800 to 2000 patients. All patients start their OPD flow at the registration desks on the ground floor. From there, sisters literally take most patients by the hand, which the patients value very much as many are old and have poor vision. In all OPD units patients are first seen by a junior doctor, after which many receive a refraction test and/or some other tests, or dilatation drops. To set the final diagnosis, all patients consult a senior doctor. Every OPD visit ends with counseling sisters giving patients detailed instructions on medication, surgery, specialized treatments, glasses, eye drops, etc. Patients that need care from more than one unit are taken there the same day. Nearly all patients complete all necessary activities at the OPD in one day, mostly within one to two hours.

Patients that need to undergo surgery flow through a similar process. After a patient has been found eligible for surgery, a date is planned according to the patient's convenience. At the same time, the patient may select any type of available room. Aravind differentiates between the following room types: suite, special $A C$ and non $A C, A$ class, B class and $C$ class. Each room has specific rate. The patient may decide, after consultation with the doctor, how long the postoperative stay should be. This can be daycare or longer. The length varies according to the condition of the patient. The patient also has a say in the type of incision and lens (in case of cataract surgery) used during the operation. When the patient is ready to undergo surgery, he/she is counseled in the respective clinic or in the general counseling department. After counseling, the patient is directed to the admission counter where the full charge for the operation must be paid in advance. The patient gives consent for surgery at the time of admission. On the day of surgery the patient is taken to the preoperative ward within the OT complex. There, the patient awaits surgery. Once it is time for surgery, an MLOP will get the patient and accompany him to the specific OT. Aravind operates OTs for cataract, retina, cornea, 


\section{CHAPTER 5}

glaucoma, pediatrics, and orbit surgery. Dependent on the specialty, the OT either has 2 or 4 beds. After the surgery, the patient is taken back to the regular ward. A senior doctor decides about the moment of discharge. To give insight into the process organization of one of the OTs, the cataract OT is now described in more detail.

In the cataract OT, a sister places the patient on his bed together with the $10 \mathrm{~L}$ lens the patient has selected. Then the sister leaves and the OT sisters take over. They prepare the patient for surgery. Some of the patients have already been given certain anesthetics at the preoperative ward; some get (additional) anesthetics at the OT, for example eye drops. Each cataract surgeon operates on two beds simultaneously. Once a surgery is finished on the first, the next is started on the second bed. The surgeon only has to turn around and there he finds the new patient, prepared for surgery. The sister discusses the case sheet with the surgeon and the surgery begins. The time a cataract surgery takes depends highly on the surgeon and the type of cataract. Each surgeon uses two beds during 6 hours $(7 \mathrm{am} \cdot] \mathrm{pm})$ and is supported by a team of sisters for all pre-operative and post-operative tasks. Senior surgeons and their teams perform 6 surgeries on average per hour and thus 36 per morning; some even perform 80 [14]. In the four-bed cataract OT, up to 80 patients can receive sight restoring surgeries on an average morning. As soon as the surgeon's work is done, a sister is called in to help the patient sit up straight again and to bring the patient to the post operative ward.

\subsection{Single patient group}

To service single patient groups and ensure both continuous patient flow within and amongst groups and efficient resource utilization within and amongst units on a day-to-day basis, Aravind has decoupled tasks and the placement of resources in the framework and hospital structure. The decoupling makes resources flexible. For one, even though staff (sisters and doctors) are initially allocated to departments and tasks according to a schedule, this schedule is lapsed when major changes in daily demand occur. For example, after a very busy day at the outpatient department (OPD), a very busy day at the operating theatre (OT) is next. To enable continuous flow at the OT the next day, some workers are freed from their scheduled tasks for that day or for part of the day and appointed to the OT. Second, to ensure continuous flow at the OPD on very busy days, all staff members are encouraged to take over tasks for each other to level out the patient load. Thirdly, patients are in principle not allocated to one specific doctor; rather, they are treated by the first doctor 
available. Service quality is upheld through extensive use of the medical records of patients that fully document the patients' details. Finally, all staff members are continuously trained on their basic ophthalmology skills so they can (temporarily) help out in the basic ophthalmology units at the OPD when these get overcrowded. As staff members can be employed in multiple units and tasks, Aravind can ensure a high utilization of staff members which keeps cost minimized. At the same time, it keeps patients flowing because staff is allocated to the unit or task where they are most needed.

\section{Beyond the hierarchical planning and control framework}

The hierarchical planning and control framework assumes that a system designs its structure through a hierarchical set of decisions. Yet, while performing the case study at Aravind, we discovered it is not simply a one-time hierarchical process through which Aravind designs its structure. Rather, the structure and the people working in it are continuously evaluated and improved. In this, we recognized elements of the EFQM excellence model and the Model for Improvement [15-17]. Characterizing the EFQM excellence model [15] are a focus on people and development of people's skills. To enable excellence, people's knowledge and competencies should be identified, developed and sustained through training and education so that people are involved and empowered [15]. Additionally, the Model for Improvement, developed by the Associates in Process Improvement [16], defines and describes how organizations can continuously learn and improve themselves [17]. The Plan-Do-Study-Act (PDSA) cycle that is part of the model allows for knowledge to be built into the system while system changes are being tested [18]. These key points from both models were used to further explain what enables Aravind to achieve those excellent results. The emphasis is placed on people in paragraph 3.1, on education and training of people in paragraph 3.2 , and on continuous system evaluation and improvement in paragraph 3.3 .

3. 1 People

The workforce at Aravind is remarkably different from that of some other eye internationally acknowledged Eye hospitals (table 2). The number of doctors employed is smaller, whereas the size of the support staff is larger at Aravind. This support staff enables the high outpatient attendances as well as the high number of surgeries. Both are less at the other hospitals. 


\section{CHAPTE 5}

Table 2: Workforce at eye hospitals

\begin{tabular}{|c|c|c|c|c|c|}
\hline & $\begin{array}{r}\text { Moorfield } \\
\text { s Eye } \\
\text { Hospital } \\
{[19]}\end{array}$ & $\begin{array}{r}\text { Rotterdam } \\
\text { Eye } \\
\text { Hospital* } \\
{[20,21]}\end{array}$ & $\begin{array}{r}\text { Singapore } \\
\text { National } \\
\text { Eye Centre } \\
{[22]}\end{array}$ & $\begin{array}{r}\text { St. Erik Eye } \\
\text { Hospital } \\
\text { [23] }\end{array}$ & $\begin{array}{c}\text { Aravind } \\
\text { Eye } \\
\text { Hospital } \\
\text { Madurai } \\
\end{array}$ \\
\hline Total staff & 1350 & 313 & 465 & 355 & 983 \\
\hline Senior doctors & 220 & 29 & 82 & 90 & 46 \\
\hline Junior docto & & & & 20 & 94 \\
\hline $\begin{array}{l}\text { Nurses (incl. } \\
\text { trainees/assistants) }\end{array}$ & 299 & 194 & 13 & 180 & $\begin{array}{r}485 \\
\text { (MLOPs) }\end{array}$ \\
\hline Others & 831 & 111 & 250 & 65 & 358 \\
\hline $\begin{array}{l}\text { Total outpatient } \\
\text { attendances }\end{array}$ & 255,000 & 139,000 & 254,000 & 176,000 & 581,000 \\
\hline Surgeries & 27,185 & 12,600 & 14,000 & 10,000 & 91,000 \\
\hline
\end{tabular}

* Workforce reported in Full time equivalents (Fte)

Senior doctors at Aravind perform a limited set of tasks, only where they are needed; the other tasks are performed by the MLOPs and junior doctors. Nurses are the main professional component of the frontline staff in most hospitals [24]. Their wages make up the largest proportion of hospital costs [25]. Compared to other hospitals, Aravind deploys a very high proportion of nurses, whom Aravind calls 'sisters'.

Table 2 also lists 'other' employees, which represent a large proportion of the workforce in 'other' than doctors or nurses in the hospitals. For Aravind, this group includes technicians which probably also holds true in the other hospitals. However, it remains unclear from the studied hospitals' annual reports who belongs to the category others; probably, also administrative workers and other support staff like housekeeping and cleaning. At Aravind, part of the administrative tasks is carried out also by MLOPs, who are member of the medical registration department.

At Aravind, the MLOP sisters are considered the backbone of all activities. At the age of 18-20 these girls are recruited in villages where their future is not too bright. Aravind takes them in, provides them with food and lodging, and pays them a modest salary most of which is saved for the girls' wedding expenses. Staff turnover at Aravind is highest among the sisters because many of them are married off around the age of 22-25. This is around the time they complete their 5 -year training program. Aravind is aware of this outflow of junior sisters and therefore hires extra to ensure sufficient senior capacity for the future. The senior sisters are essential for training the junior sisters and managing the MLOP workforce at their departments. Because of the high case load at all Aravind departments, the sisters get very experienced in their tasks 
and perform them meticulously. More over, because the sisters take over a lot of work from the doctors, these doctors are more flexible as to when and where they can be deployed for certain tasks, which can increase their (surgery) productivity.

\subsection{Education and training}

To make use of the full potential of the MLOPs, Aravind identifies the girls' competencies upon their arrival and develops and sustains them through continuously offering all sisters educational programs. The MLOPs receive extensive on-the-job training on the set of tasks to perform and are deployed in a variety of departments where their tasks are similar. But it is not just the MLOPs that receive training. Everybody who works at Aravind receives continuous education and training. All employees receive hospitality lessons and are instructed with the Aravind mission. The lessons focus on creating a patient friendly environment and delivering compassionate care. Additionally, all employees are continuously educated on continuous improvement techniques.

Aravind uses education and training of staff not just for hospitality reasons but more to ensure cross-skillfulness, to a certain extent, as well as decision capability. Both provide Aravind with the flexibility it needs to respond to the demands of its patients. This cross-skillfulness of staff is fundamental at Aravind for a flexible reallocation of workers to tasks and processes. It allows staff members within a subgroup to be interchanged within and between hospital units.

At the same time, the continuous training at Aravind formalizes worker behavior in both job performance and patient flow management. Behavior formalization is there to minimize variation amongst staff when they interact with patients. The continuous training also controls for any variability in employee behavior when they make reactive decisions. Reactive decisions are often made at to even out patient flow, given day-to-day uncertainties. For example, staff itself can decide to re-route patients or change-over staff members if workload in one department is higher than in another. Another decision taken by staff itself to even out flow is to increase supply volume by shortening (not cancel) staff coffee and lunch breaks.

To make the reactive decisions when and where needed, Aravind frontline staff have been given decision power. To know when to make the reactive decision, employees can continuously access real time information in the IT system about patient volume at the various departments and the hospital in 


\section{CHAPTER 5}

general. To know how to make the decision and which decisions they can and should make, Aravind trains and educates staff, also in their use of the IT system. Herewith, staff has not only the power to make decisions, but also the information and self-efficacy to make them.

3.3 Continuous evaluation and improvement

Most processes and workflows at Aravind are standardized or being standardized. Through standardization and continuous learning cycles Aravind strives for excellence. Also, because of the high level of standardization, both patients and staff members can be interchanged between processes. Technicians or refraction sisters, e.g., can perform their tasks in various processes as these tasks are standardized.

Aravind continuously evaluates the planning and control policies in all processes and production systems and feeds the results of these assessments back into the system. The main tools for performance assessment are the selfdeveloped IT system and the active involvement of the people performing the processes. Not only the operational level is subject of improvement, but also more long term planning and control issues like building lay out, staff training programs, and IT networks are constantly being evaluated.

All staff members are actively involved in improving the department they work in as well as the overall hospital. They are encouraged to introduce ideas to improve the care delivery at Aravind. Management also sometimes awards prizes to staff members and the departments they work for when someone came up with a good idea. The prizes are never personal, but always for the gain of the department and its patients. For example, when one of the retina sisters came up with idea to make recovery after retina surgery more comfortable for patients, the sister was awarded a new water filter for the retina department because of her ingenuity. For the occasion, a small ceremony was held to give notice to this particular idea and encourage others to come up with other ideas.

\section{What can be learned from Aravind?}

The lack of efficiency in most hospitals seems to stem from a lack of fit between demand and supply. From the perspective of a hospital as a production system, patient demand can be defined as the care and quality of care patients ask for or need from a hospital system at a specific time and place. Hospital supply, in this respect, can be defined as the care and quality of care 
offered at a specific time and place and by the (human) resources in the hospital system. Patient demand is often characterized by variability and this variability is not always appreciated enough in how supply is offered [26, 27].

Even though the Aravind Eye Hospital in Madurai is a hospital of unprecedented patient volume, still it is faced with variability in patients demands. At Aravind, patient demands vary in terms of volume, mix and delivery, from day to day, from month to month, from year to year. Aravind's answer to this variability is reactive decision making. They respond to changes in demand by adapting their supply. If demand for a specific task increases, staff is switched to that task, from a task that is temporarily less demanded, or patients are rerouted to a unit where the same task is performed, but where demand is temporarily less. This ability is based on the flexibility Aravind has created in the system structure and workforce.

If the structure of the Aravind Eye Hospital is compared to the current, more functionalistic hospital structures [28], we can see that Aravind organizes its structure not so much around medical specialties but around the tasks patients demand from Aravind. Second, the placement of employees in the system is not fixed; rather, people are placed where the need for them exists, based on the demand for specific tasks. Third, the workforce at Aravind is empowered to perform a set of tasks and receives constant fraining and education for these tasks, and possibly new tasks to enrich jobs. Finally, staff is empowered to make the reactive decisions. Hereto, they receive training, on the IT system as well, and have been given decision power. All four decisions create the opportunity to respond to changes in demand.

Flexibility relates to the extent to whether a system is able to create variety in the mix and/or volume of resources in a system, like doctors or nurses in a hospital, so that the system state can be changed [29]. The hierarchical planning and control framework allows for creating flexibility. However, the framework takes structure more as a rigid element of a system as through hierarchical decisions a structure is formed. This structure can be flexible to some extent and, as such, enable responsiveness to demand fluctuations. Yet, the concept of structure in the framework depends on fixed locations and tasks, medical specialties and patient groups and the fixed placement of people and power within the structure. Changing the structure takes time.

At Aravind, people are not placed in a fixed position, which makes the structure seemingly more fluid. The structure is also under constant development as it is coupled to the tasks that patients demand. If demand 


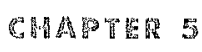

increases at a unit, the extra resources necessary to respond to this increase are instantly switched from other units where demand is less. Or, demand is rerouted to a less busy unit equipped with staff to perform the tasks demanded. The time Aravind allows it self to make changes to the structure is often less than a day, as the objective is to have a patient lead time of one day.

How Aravind deploys MLOPs gives new insights into how nursing activities might be structured. All over the world, healthcare systems are faced by a shortage of nurses. Buchan and Aiken [24] conclude this is not just the result of a lack of people but also of inadequate workforce planning and control. Nurse's time is not used efficiently due to mismatch between education supply and service based demand, inappropriate skill mix, underutilization due to non-value adding activities, and a lack of training opportunities [24, 25, 30]. Aravind trains its nurses to perform a specific set of skills and ufilizes the nurses where needed. Additionally, Aravind ensures nurses and other staff members can either perform more than one type of tasks or perform the same task in different processes.

That Aravind employs so many MLOP sisters is a strategic choice. As aforementioned, the MLOPs have taken over many of the doctors tasks. As MLOPs cost less than doctors, Aravind can hire more and, therewith, increase resource capacity. Also, delegating tasks of doctors that do not require their direct involvement to support staff like MLOPs is a form of system (re)design that can increase the patient centeredness of care [31].

Aravind staff, as in all other hospitals, deal with the actual processing of the patients. Herewith, they are the performers that mostly influence system performance [32]. To control for any unnecessary variation in this behavior, Aravind continuously trains staff to formalize their behavior. Behavior formalization is essential in bridging the gap between on the one hand system design and how managers plan that workers behave and on the other hand the actual operation performance of workers [32]. This gap is present is most organizations, even more in those that are faced with uncertainty resulfing from random variability in demand. Additionally, system structures in most haspitals are characterized by a variety of specialty departments each focusing on their own optimization. This local optimization further limits staf utilization because changing over staff or other resources is time consuming and costly. It requires staff retraining or complicated budgetary clearances. Transfers that do take place amongst departments are those of patients. These 
cannot be avoided, as patients often require care from more than one department.

At Aravind, formalized, cross-skilled staff allows for successful changeovers of staff amongst departments and tasks. Furthermore, as processes are standardized, Aravind can reroute patients to other departments to level demand. All this creates opportunities to absorb variations in patient mix.

For its planning and control system, Aravind uses information about customer demand in the past to predict future demand. These predictions are used to set up schedules. In many hospitals, fixed (appointment) schedules are the leitmotiv for running the day-to-day operations. In Aravind they are not; actual demand is. Whoever comes in is treated. Additionally, whereas hospitals sometimes cream-skim their patients to level demand [33], Aravind proves that with cross-skilled staff that can be changed over, standardized processes that allow for patient rerouting, continuous training, and staff with decision power, patient skimming is not necessary. More than that, it ensures that there is no real need to distinguish between emergency and elective patients at Aravind as every patient receives eye care the moment he demands it. The case of Aravind stipulates flexibility in supply is vital to enable excellent results and sustain direct patient access to a hospital and continuous flow within the hospital.

The hierarchical pianning and control framework was used to build up explanations for the results Aravind achieves, yet the framework does not seem to fully explain why Aravind is considered excellent. Elements from the EFQM model and the Model for Improvement were additionally used to describe several elements of the Aravind structure, namely people, education and training, and continuous improvement. The complete description of Aravind provides a new vision on hospital system design.

A question that remains is, whether Aravind, that can be considered a focused factory [34], focusing on eye care, can serve as an example to functional, general hospitals? Can these hospitals introduce 'Aravind elements' in their work and structure? Or are they too different in terms of complexity stemming from the patient types and number of medical specialties involved?

In functional hospitals resources are often fixed and patient demands follow these fixed placements [7]. At Aravind, patient demand takes the lead and resources follow the demand. Would it create chaos in other hospitals if resources, doctors too, might be switched between processes and tasks to create a system for patients in which direct access to care is possible? looking 
CMAPTER 5

at the case of Aravind it most likely would not. But it will require more flexibility in terms of multi-skilled staff and workforce availability. Opportunities to this end exist, yet are not often made use of. For example, departments could decide to no longer focus on medical specialties but on tasks and assemble all resources necessary to perform these tasks within departments or subsystems [7, 28]. Employing more cross-skilled staff creates the ability to switch staff between tasks within departments and also between departments [35]. Further, staff flexibility can be achieved through the introduction of more parttime jobs in the medical profession [36]. All people working in the hospital should additionally be actively involved in continuously improving the structure as well as the performance of the hospital.

In conclusion, based on the case of Aravind, we propose that the structure of functional general hospitals should be re-evaluated. As far as a model as the hierarchical framework is structurally used for actual planning and control in these hospitals, Aravind's interpretation of the model in terms of planning and control and system structure is far different from that of functional hospitals. Aravind's results teach us that this interpretation can create hospitals that are directly accessible to patients for care delivery of high quality. 


\section{References}

1. Prahalad CK. The Aravind Eye Care System: delivering the most precious giff. In: Prahalad CK, editor. The fortune at the bottom of the pyramid. Upper Saddle River, NJ: Pearson Eduation, Inc.; 2005. p. 265-86

2. Godden S, Pollock AM. Waiting list and waiting time statistics in Britain: A critical review. Public Health, 2009;123(1):47-51.

3. Vissers JMH, Bertrand JWM, De Vries G. A framework for production control in health care organizations. Production Planning \& Control. 2001;12(6):591-604.

4. Van Merode GG, Groothuis S, Hasman A. Enterprise resource planning for hospitals. Infernational Journal of Medical Informatics. 2004;73(6):493-501.

5. Armistead CG. Service operations strategy: framework for matching the service operations task and the service delivery system. International Journal of Service Industry Management. 1990;1(2):6-16.

6. Anthony RN. Planning and control systems - a framework for analysis. Boston, Massachuselts Division of Research, Graduate School of Business Administration, Harvard University; 1965.

7. De Vries G, Bertrand JWM, Vissers JMH. Design requirements for health care production control systems. Production Planning \& Control. 1999; 10(6):559-69.

8. Editorial. Blindness in the elderly. The Lancet. 2008(372):1273.

9. Bhandari A, Dratler S, Raube K, Thulasiraj RD. Specially Care Systems: A Pioneering Vision For Global Health. Health Aff. 2008;27(4):964.76.

10. Norregaard JC. Results from the International Cataract Surgery Outcomes Study. Acla Ophthalmol Scand. 2007;85(thesis):5-32.

11. Hopp WJ, Spearman ML. Factory Physics: foundations of manufacturing management. Second ed. New York: Irwin/McGraw-Hill; 2001

12. Womack JP, Jones DT. Lean Thinking - Banish waste and create wealth in your corporation. Revised and Updated. New York: Free Press; 2003.

13. Van Merode GG, Oosten M, Vrieze OJ, Derks J, Hasman A. Optimisation of the structure of the clinical laboratory. European Journal of Operational Research. 1998;105(2):308-16.

14. Venkatesh R, Muralikrishnan R, Balent LC, Prakash SK, Prajna NV. Outcomes of high volume cataract surgeries in a developing country. $\mathrm{Br}$ J Ophthalmol. 2005;89(9):1079-83

15. European Foundation of Quality Management. Introducing Excellence. Brussels, Belgium: EFQM; 2003,

16. Associates in Process Improvement. [Accessed on: 29-04-2009]; Available from: hitp://www.apiweb.org/.

17. Berwick DM. Improvement, trust, and the healthcare workforce. Qual Saf Health Care 2003; 12(6):448-52.

18. Berwick DM. Developing and Testing Changes in Delivery of Care. Ann Intern Med. 1998; 128(8):651-6.

19. Moorfields Eye Hospital, NHS foundation trust (2008). Annual report and accounts 2007/08 [Accessed on: 03-12-2008]; Available from: hitp://www.moorfields.nhs.uk

20. Rotterdam Eye Hospital (2007). Annual Report 2007 [in Dutch - Jaarbericht Oogziekenhuis Rotterdam]. [Accessed on: 03-12-2008]; Available from: hitp://www.oogziekenhuis.nl

21. Rotterdam Eye Hospital (2006). Annual Report 2006 [In Dutch - Jaarbericht Oogziekenhuis Rotterdam]. [Accessed on: 03-12-2008]; Available from: hitp://www.oogziekenhuis.nl

22. Singapore National Eye Centre (2006). Annual report 2006. [Accessed on: 03-12-2008]i Available from: http://www.snec.com.ss 


\section{GHAPTER 5}

23. St. Erik Eye Hospital (2008). An introduction to St. Erik Eye Hospital. [Accessed on: 03-12. 2008]; Available from: hitp://www.sankterik.se

24. Buchan J, Aiken L. Solving nursing shortages: a common priority. I Clin Nurs. 2008; 17(24):3262-8

25. Storfiell JL, Omoike O, Ohlson S. The balancing act: Patient care time versus cost. Journal of Nursing Administration. 2008;38(5):244.9.

26. Bagust $A$, Place $M$, Posnett JW. Dynamics of bed use in accommodating emergency admissions: stochastic simulation model. BMJ. 1999;319(7203):155-8.

27. Noon CE, Hankins CT, Cote MJ. Understanding the impact of variation in the delivery of healthcare services. Journal of Healtheare Management. 2003;48(2):82.

28. Van Merode GG, Molema H, Goldschmidt H. GUM and six sigma approaches positioned as deterministic tools in quality target engineering. Accreditation and Quality Assurance. 2004; 10(1-2):32-6.

29. Santos Bernardes E, Hanna MD. A theoretical review of flexibility, agility and responsiveness in the operations management literature: toward a conceptual definition of customer responsiveness. International Journal of Operations \& Production Management. 2009:29(1):30-53

30. Czuber-Dochan WJ, Waterman CG, Waterman HA. Trends in the nature of provision in ophthalmology services and resources and barriers to education in ophthalmic nursing: 3 rd national UK survey. Nurse Educ Today. 2006;26(3):191-9.

31. Bergeson SC, Dean JD. A Systems Approach to Patient-Centered Care. JAMA. 2006;296(23):2848-51.

32. Wiingaard J, de Vries J, Nauta A. Performers and performance - How to investigate the contribution of the operational network to operational performance. International Journal of Operations \& Production Management. 2006;26(3-4):394-411.

33. Richman BD, Udayakumar K, Mitchell W, Schulman KA. Lessons From India In Organizational Innovation: A Tale Of Two Heart Hospitals. Health Aff. 2008;27(5):1260-70

34. Skinner W. The focused faclory. Harvard Business Review. 1974;52(3):113-21.

35. Cousens $A$, Szwejczewski $M$, Sweeney $M$. A process for managing manufacturing flexibility. International Journal of Operations \& Production Management. 2009;29(4):357-85.

36. Molema JJW, Groothuis S, Baars IJ, Kleinschiphorst M, Leers EGE, Hasman A, ef al. Healthcare system design and partime working doctors. Health Care Management Science. 2007; 10(4):365.71. 


\title{
CHAPTER 6
}

\author{
Mralyzing hospirtal system \\ design -How supply fexibility \\ coun improve pertormonce
}

Molema JJW, Van Merode, GG.

Submitted for publication 


\section{GHAPTER 6}

\section{Abstract}

Creating and maintaining direct access is a challenge of continuously matching demand and supply. This match not only minimizes waiting times, but also ensures that resources are efficiently used. The Aravind Eye Hospitals in South India aim to approximate the match by constantly responding to changes in patient demand. They can make reactive decisions because of the supply flexibility in the system. In the present research, we study in what sense supply at Aravind is flexible and how this affects output. Hereto, a case description of the outpatient department (OPD) of one of the Aravind hospitals was set up and a simulation model developed. We simulated the structure at Aravind and several alternative experiments, each representing a configuration of resources which structure is influenced by planning and control decisions.

The results show the lowest throughput time for patients and lowest waiting time for the final consultation in the Aravind configuration. This configuration has cross-skilled staff and standardized processes so that between OPD units staff can be switched and patient rerouted. Not having this flexibility resulted in increased throughput and waiting times. Results at Aravind also excelled other configurations because frontline staff was able to decide, based on real time information, whether extra staff was needed. At Aravind the average utilization of doctor-time was $80 \%$. This rate is higher in the other configurations, mainly because there is less flexibility to pull in an extra doctor. The higher utilization causes more queuing of patients than it is efficient.

Overall, we conclude that Aravind does not hierarchically plan and control its resources. Rather, planning and control is part of a continuous improvement cycle. Comparing the results of Aravind to other experimental structures, opportunities can be inferred of how other hospitals can face the challenge of minimizing patient waiting times while maximizing resource utilization. The opportunities are in the flexibility Aravind has created in its system structure increasing skill variely and process standardization especially.

\section{Acknowledgements}

This study could not have been done without the support of the Aravind staff. We are grateful to all, the sisters that participated in the interviews especially. We would like to thank Dr. S. Aravind, Dr. N. Ramakrishnan, Mr. S. Philip, and Mr. Rajakumar for their help, advice, and sincere interest in the project and for enabling the work to be carried out smoothly. 


\section{Introduction}

Hospital managers are continuously challenged to maximize patient throughput, while minimizing costs; also the managers at the Aravind Eye Care System (AECS) in Southern India. At the outpatient department (OPD) of the Aravind Eye Hospital in Madurai demand volume and mix are stable over time but they fluctuate over the days of the week and during the day. For example, in May 2008, the OPD registered over 42,000 patients, with a daily average of 1500 visits but a range of 800 to 2000 visits per day. Despite this variability in demand, patients can enter the OPD at the hospital directly, without any appointments, and lead time, i.e. the time from when a patient expresses his demand until this demand is met, is low for all services offered at the hospital.

Creating and maintaining direct access is a challenge of continuously matching demand and supply and planning for any contingencies [1]. AECS, or simply 'Aravind', achieves this by having a clear structure for its patients and staff and making small changes to this structure if patient demands vary. Aravind hospitals constantly respond to changes in the environment through what is called 'reactive decision making' [2]. Reactive decision making requires a certain flexibility of the system, i.e. to respond the system must be able to change as timely as possible [3.5]. Responsiveness is needed especially in a system that is often confronted with demand changes caused by variability. By responding to the variability in patient demands in hospitals, hospitals could minimize patient waiting times and maximize patien throughput capacity.

Reactive decision making includes more short term planning and control [2] Which decisions are possible depends on the relations between the elements that comprise a system as well as the overall structure of the system $[2,6-8]$. Most hospitals decide to plan and control resources into subsystems or configurations. In a hospital, a configuration can be a set of doctors, medical assistants, nurses, beds, equipment, and rooms [9], that are grouped based on medical specialty, diseases, treatment programs, or other grouping variables. How resources are grouped into a configuration determines the flow of both work and customers within the configuration and throughout the system. It also determines if and how fluctuations in demand can be absorbed [8] Subsequently, the attractiveness of a particular configuration depends entirely on what is important to the organization [10].

Aravind has created a system structure in which the match between demand and supply is regarded important. In this structure, supply flexibility is assumed 


\section{CAMATER 6}

as an enabler for adequate reactive decision making [2]. In this chapter, we study how Aravind's system configuration enables supply flexibility, which on its turn enables Aravind to respond to changes in demand. To gain insight into how other hospitals can face the challenge of minimizing patient waiting times while maximizing resource utilization, we studied which planning and control decisions that shape the structure at the Aravind outpatient department contribute most to supply flexibility and the ability to respond to changes in demand. First, a case description of the Aravind Madurai OPD was set up based on interviews, observations and data of the Aravind patient population. Based on the case description, a conceptual model was designed that portrayed the structure of the Aravind OPD. To study whether this structure was really most enabling minimal waiting fimes and maximal resource utilization, a simulation study was set up. In this simulation study, scenarios for the planning and control decisions were simulated and compared to the Aravind situation.

\section{Planning, control, and flexibility}

It takes several planning and control decisions on different levels to define and structure a configuration $[2,8,11,12]$. Planning determines what services to offer, who to offer them to, and in what way to ensure that processes run timely and smoothly at the required level [13-15]. Important decisions are how resources are grouped into subsystems, how labor is divided into distinct tasks, how coordination is achieved amongst the tasks and subsystems, and where power and authority are placed in the system [16-21]. Control, additionally, focuses on assuring that the right resources are obtained and used effectively and efficiently as well as on assuring that tasks are carried out effectively and efficiently [8].

\section{1 Planning and control on different levels}

Planning and control levels vary from a long-term strategic level, to a mediumterm level, to a short-term day-to-day level $[2,12,18,22]$. Table 1 displays a hierarchical framework of planning and control in hospitals. Table 1 underlines that planning and control is a hierarchical process [2, 8, 11, 12], where higher-level decisions determine the degrees of freedom for lower-level decisions. 
ANAEYZING HOSPITAL SYSTEM DESIGN

Table 1: Hierarchical planning and control framework $[2,12]$

\begin{tabular}{llll}
\hline & Purpose & Planning horizon & Scope \\
\hline $\begin{array}{l}\text { Strategic } \\
\text { planning }\end{array}$ & $\begin{array}{l}\text { Decide what services to offer } \\
\text { and in what form to offer them } \\
\text { (organizational archetype) }\end{array}$ & long-term & Hospital as a whole \\
$\begin{array}{l}\text { Patient volume } \\
\text { planning \& } \\
\text { control }\end{array}$ & $\begin{array}{l}\text { Trade-off between service level } \\
\text { and resource utilization; } \\
\text { decisions are made regarding } \\
\text { patient mix }\end{array}$ & $\begin{array}{l}\text { Medium-term } \\
\text { (production period) }\end{array}$ & Hospital as a whole \\
$\begin{array}{l}\text { Resource } \\
\text { planning \& } \\
\text { control }\end{array}$ & $\begin{array}{l}\text { Determine required resource } \\
\text { volume and skills }\end{array}$ & $\begin{array}{l}\text { Medium-term } \\
\text { (production period) }\end{array}$ & Each patient group \\
$\begin{array}{l}\text { All patient } \\
\text { groups }\end{array}$ & $\begin{array}{l}\text { Define market performance } \\
\text { objectives; acquisition of } \\
\text { resurces; control of patient } \\
\text { flow; utilization }\end{array}$ & $\begin{array}{l}\text { Medium-term } \\
\text { (production period) }\end{array}$ & Each patient group \\
$\begin{array}{l}\text { Decouple production phases } \\
\text { thale patient dal with different levels } \\
\text { group }\end{array}$ & $\begin{array}{l}\text { Shortterm (day-to- } \\
\text { day) uncertainty }\end{array}$ & $\begin{array}{l}\text { Pracesses used in } \\
\text { facilitating day-to- } \\
\text { day patient activities }\end{array}$ \\
\hline
\end{tabular}

Dependent on the strategy, managers determine patient volume and, subsequently, resource volume. Resource volume depends also on the tradeoff between service level and ufilization strived for. Next, the tasks and required skills have to be divided over the different patient groups. Finally, on a daily basis, production within each of the groups is managed. This final step in the framework is bounded by the earlier decisions. For example, if the system encompasses functional subsystems, the flow of patients amongst the subsystem is bounded by local optimization objectives per subsystem [23].

Planning and control decisions, as said, define and structure a configuration or system. To quantify the system, the state can be described, i.e. the relations amongst the resources as well as between the resources and demand at a particular point in time [24]. System performance depends on the system state and to improve performance the state needs to be changed. The decisions in the planning and control framework define to a large extent the opportunities to do so. The must leave room in the structure for a certain flexibility in supply [5].

\subsection{Flexibility}

Figure 1 displays a model of system $S$ that consists of two production lines. Per production line, the servers $(\mu \mathrm{i})$ and the demand arrivals per server $(\lambda i)$ determine the state of each server and the overall system. Demand in system $\mathrm{S}$ and its production lines is likely to be variable. Variability related to demand volume, mix and delivery uncertainty are three main drivers for requiring flexibility [3]. Figure 2 displays reactive decision making in system $\mathrm{S}$. 


\section{CHAPTER 6}

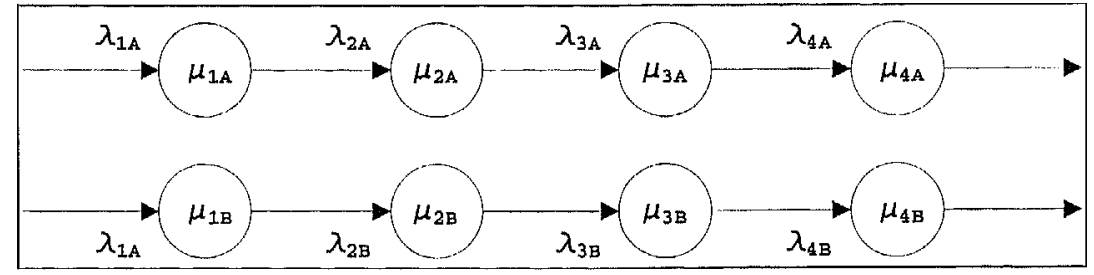

Figure 1: Schematic display of system $S$

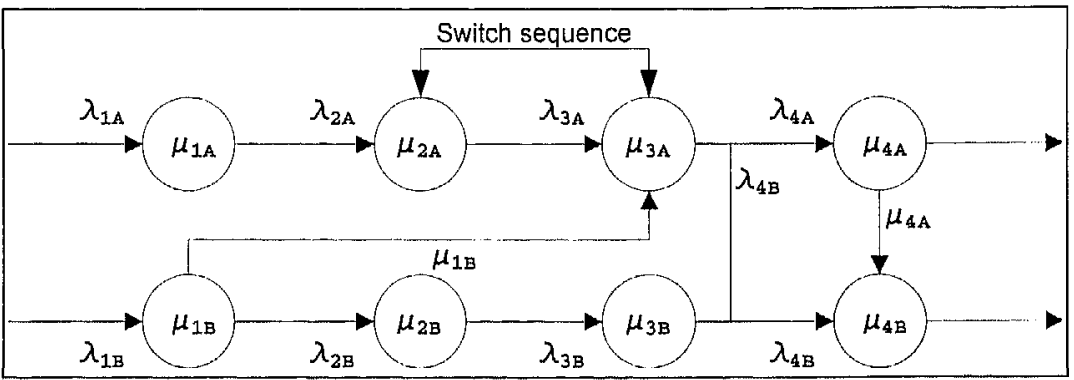

Figure 2: Reactive decision making in system $S$

To generate responses in figure 2, the servers in system $S$ can send out messages. When demand increases or the mix changes and sufficient resources are lacking at a server, this server can turn to other servers for switching the service sequence of (temporarily) increasing capacity at the server to increase the service rate. Alternatively, demand can decrease to a level where the available resources at a server are hardly utilized anymore. Then the server can either inform other servers that resrouces are available for use elsewhere in the system or increase demand at the server by re-routing it from other production lines.

The extent to whether system $\mathrm{S}$ can actually be defined as flexible depends on whether variety can be generated in the system [5]. Variety implies that options are available to change the system state as a response to the uncertainty. Gerwin [25] and Schmenner \& Tatikonda [26] discuss in what ways supply can be flexible in manufacturing processes and thus in what way variety can be generated. Some supply flexibility types mentioned by them are $[25,26]$ :

- Mix: ability to produce different products at the same point in time;

- Changeover: ability to deal with changes in the product mix over time;

- Rerouting: ability to change the operating sequence through which the parts flow;

- Volume: ability to easily make changes in the aggregate production amount;

- Sequencing: ability to reorganize the procesing of different kinds of parts; 
The capability of generating variety depends on the degrees of freedom set by the hierarchical planning and control decisions. For example, if workers can perform more than one job, they can be switched between jobs. Supply flexibility is determined by the degree of task specialization of workers, the planning responsibilities possessed by workers, and the degree of specialization and level of aggregation of non-human resources, especially [25]. The latter relates to the aggregate label or tasks assigned to resources. If this label is highly specialized, the flexibility of resources is limited. If the label is more general, flexibility increases as the resources can be used to deliver a variety of services.

\section{Aravind's OPD configuration}

As mentioned, this chapter focuses on the OPD at the Aravind Eye Hospital in Madurai, India. The OPD consists of several units; three are general ophthalmology units. Of these units, the configuration of 'unit $3^{\prime}$ was studied. Below, the flow of patients through unit 3 is described. Subsequently, planning and control at the unit is specified. To summarize unit 3 , its configuration is depicted in a conceptual model.

\subsection{Unit patient flow}

For the description of unit 3 , interviews and observations were held and data concerning patient arrivals were extracted from the hospital information system. Data concerning service times and patient types were based on estimates of the professionals involved in the process at the unit, as Aravind does not yet register such data in its information systems. Figures $3 a$ and $3 b$ display the flow of these patients. All percentages and service times in the figures are estimates of the sisters, doctors and managers involved in the process at the unit.

Unit 3 opens at $7 \mathrm{am}$ and remains opened until $5 \mathrm{pm}$. On average, 180 patients visit the unit; with a minimum of 120 and a maximum of 250 patients per day. Peak hours in ferms of patients visiting at the unit are from 1 lam till $1 \mathrm{pm}$. The unit comprises four servers: preliminary examinations, refraction tests, dilatation, and final examinations. The preliminaries are carried out by junior doctors, the refractions by the refraction sisters, and the finals by medical officers. At the unit, both new and review patients visit and undergo the same process. However, the division of patients over the servers slightly differs between the groups. 


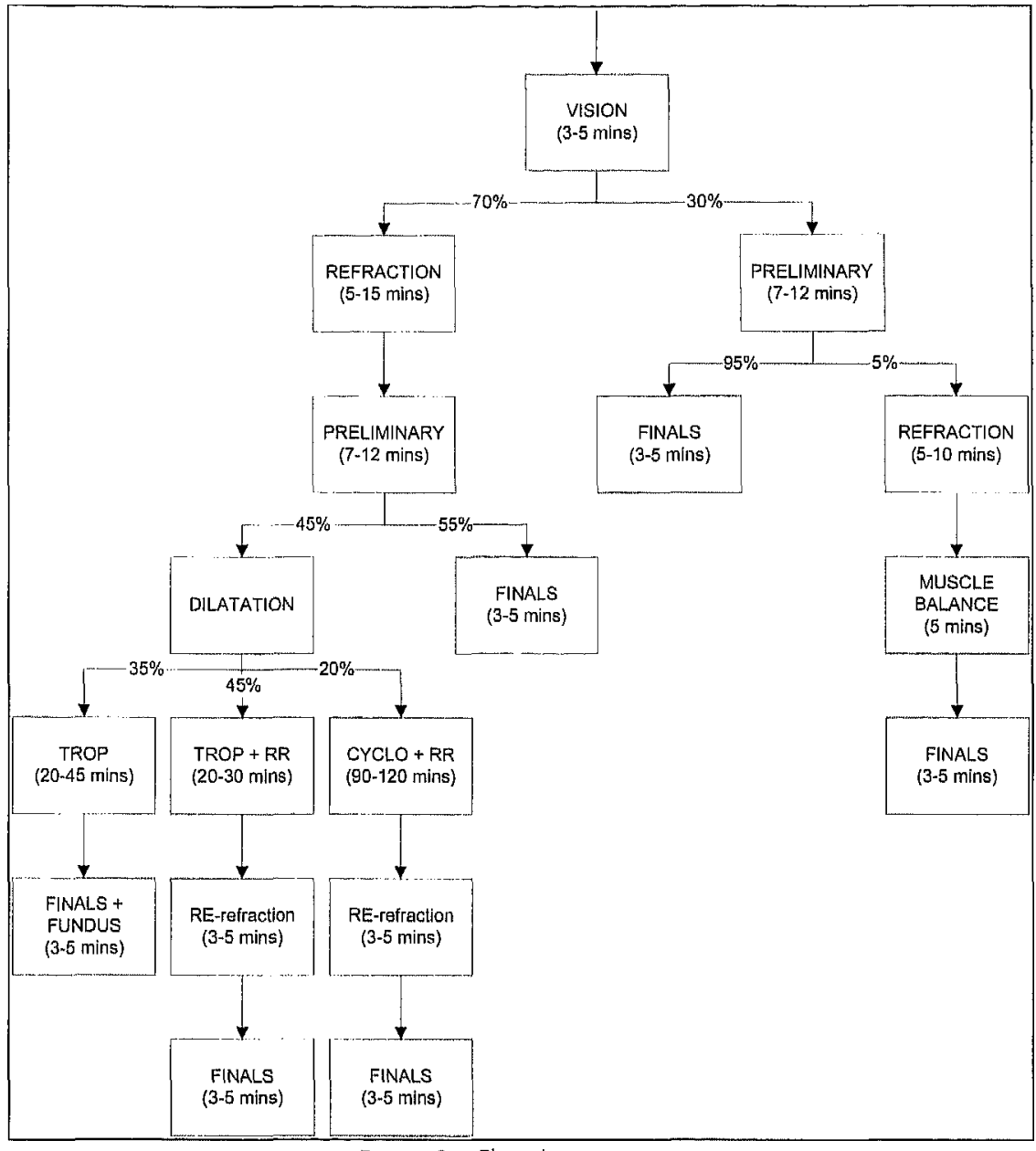

Figure 3a: Flowchart new patients

3.2 Unit planning and control

Planning and control at the unit is done on different levels and with different decision centrality. The long and medium term planning is done by the hospital management. Mainly, management decides which sisters, junior doctors, and medical officers are placed at the unit. This decision is based on the volume per resource type as well as the skills available. At Aravind, staff is crossskilled such that, e.g., all junior doctors and medical officers can treat patients at the three OPD general ophthalmology units. Senior staff at the unit is given the power to make changes to the process as long as they are improving patient flows. 
ANALYUNG HOSBTAL SYSTEM DESIGN

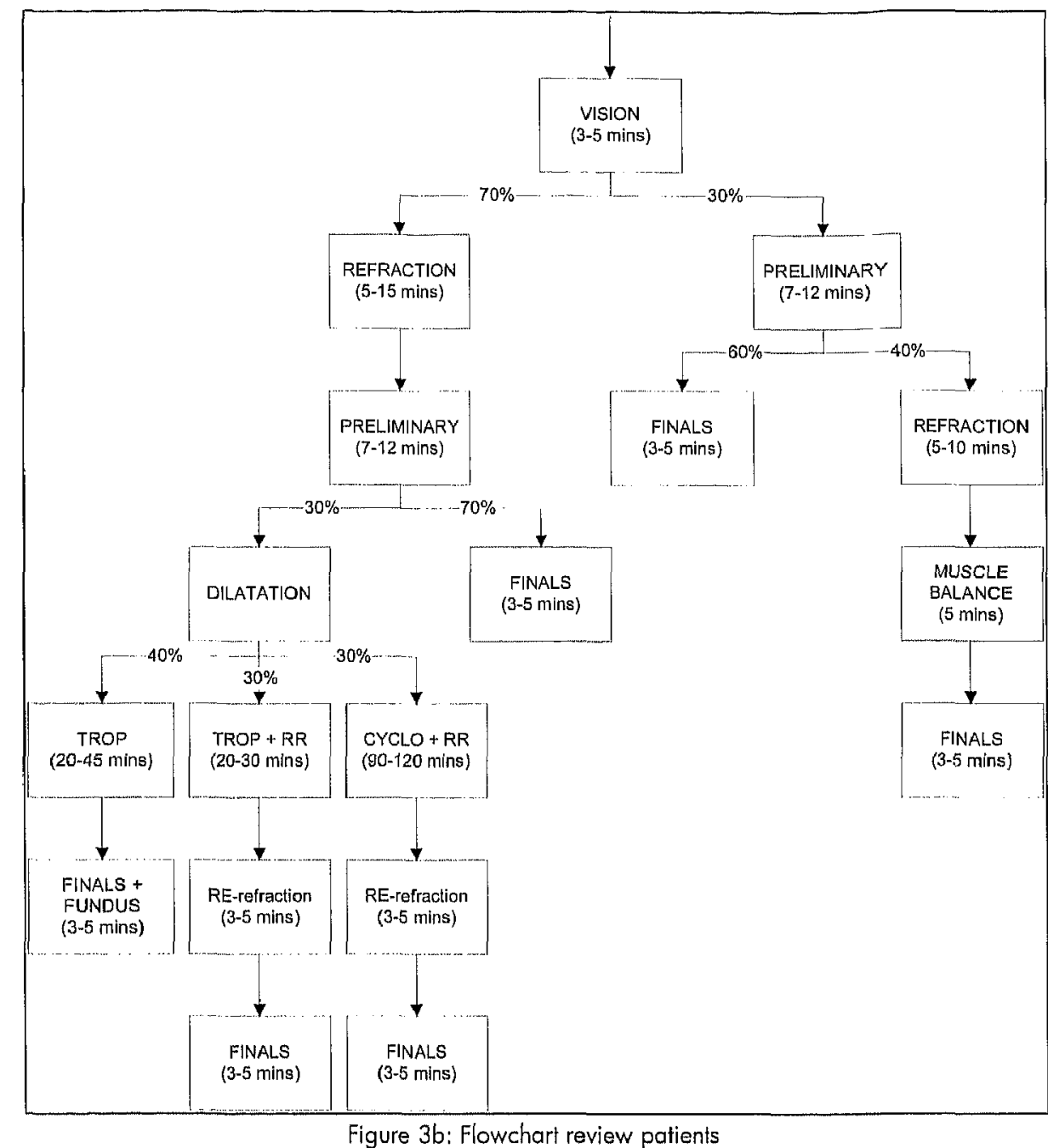

Because of the long and medium term decisions, the empowered unit staff can make several changes to the unit process, when patient flow continuity is endangered. If patient waiting times for finals build up, an extra medical officer is pulled into the department. If patients arrive after $5 \mathrm{pm}$, the time unit 3 closes, these patients are sent to another general OPD unit in the hospital that has extended opening hours. Also, if unit 3 expects a high patient load, a senior sister can reroute some patients to one of the other OPD units. Another measure that can be taken when the unit is faced with a high patient load is that staff lunch breaks can be shortened.

To make these decisions at the right time, the system state and performance at the unit are constantly assessed. Also, staff members at the unit have been 


\section{CHAPTER 6}

given the power to decide when responsiveness is called for. This power comes with some rules though. For instance, an extra medical officer can only be pulled into a process during the peak hours. Also, the responses are not endless; only one extra doctor can be pulled in and lunch breaks are only shortened by half an hour.

\subsection{Conceptual model}

Figure 4 displays a conceptual model that summarizes the planning and control decisions at the OPD unit studied and the effect the corresponding configuration has on the system state and the performance.

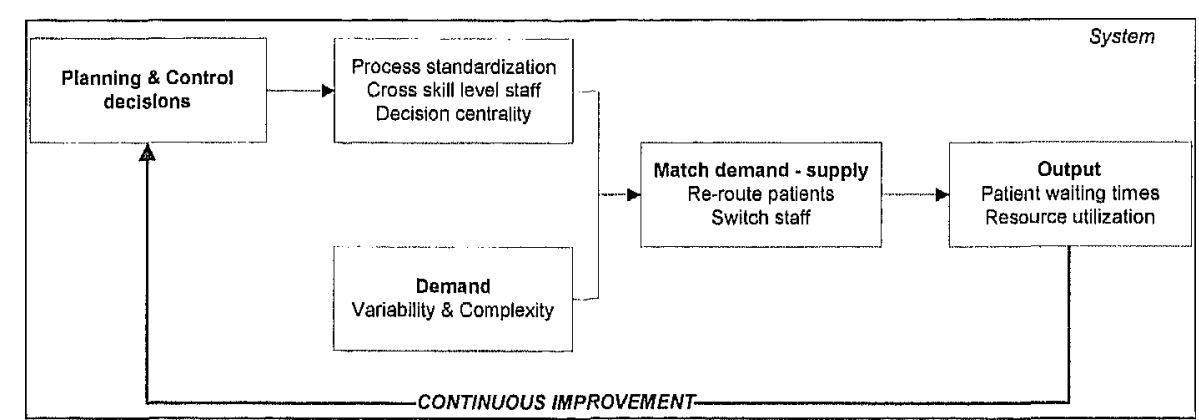

Figure 4: Conceptual model of unit 3 at Aravind Eye Hospital Madurai

Through planning and control, Aravind continuously tries to minimize patient waiting times and maximize resource utilization. If patient waiting times are minimized, patient throughput can be increased. This enables Aravind to attract more patients in need of eye care which they can only treat by constantly improving resource utilization. When resource utilization is maximized, more patients can be treated.

Waiting times are only minimal and resource utilization only maximal when demand and supply are equal in the system [27]. To constantly match supply to demand and keep up performance two reactive decisions are made at Aravind, to re-route patients and/or switch staff. Staff is initially appointed to a schedule and specific tasks; however, if demand changes, these schedules are open to changes. The same holds true for the allocation of patient(types) to the OPD units. The reactive decisions can be made, because supply is flexible. This flexibility results from standardized processes and cross-skilled workers, 
especially. Additionally, there is flexibility to make the reactive decisions by the front-line staff, as they have been given the decision authority.

\section{Simulation study}

Through computer simulation we studied the effect of Aravind's planning and control decisions on the system's ability to respond to changes in demand. Herewith, the simulation study aims to analyze how exactly Aravind matches demand and supply by enabling supply flexibility. This information can help other hospitals in deciding how to structure a system that creates opportunities for better absorbing demand fluctuations.

\section{1 Simulation model}

The simulation model was based on the description of unit 3 given in paragraph 3. The model was structured by means of an event list that comprised all events (activities) for patients. The list contained the information that defined and grouped patients, like the type of activities that patients undergo and service times. Also, information about arrival times was included. To determine service times for refraction, dilatation, and doctor consultations in the model, truncated exponential distributions were set up [24]. These were based on the estimations by staff about patient's minimum, maximum, and average service times for the different activities in the unit (see also the flowcharts in figures $3 a$ and $3 b$ ). Estimations of staff were also used to define rules in the model concerning when to pull in a doctor or when to shorten lunch breaks.

The model starts with determining the patient load for the day, If this number exceeds 220 patients, $10 \%$ of the patients is rerouted to one of the other units. Also, patients that arrive after $5 \mathrm{pm}$ are rerouted to another unit, as unit 3 closes at that time. If the patient load exceeds 200, lunch breaks of staff members are shorted with half an hour. In the model, the event list is checked and updated every minute to check whether new patients have arrived and where these new patients need to go. To handle the events in the event list, an event handler was designed. This event handler is a server and can be a refraction sister, a junior doctor, or a medical officer. Each event handler is preceded by a queue. The waiting time in the queve depends on the capacity of the event handler and arrival pattern of patients in the queve. Based on the FIFO rule (first in- first out) the first patient to arrive in a queue is treated at the corresponding server. Only for the refraction queve, a rule was made that 


\section{CHATR 6}

gave patients that were dilated for the so-called second refraction preference over the regular refraction patients. The pupil stays only dilated for a while and the doctor needs the pupil fully dilated for the examination.

Based on the actions of the event handler, the event list, waiting lists, and lists containing information on the availability of the servers are updated every minute. During the simulation, the decision can be made to pull in an extra medical officer for final examinations. This is done only during the peak hours and only when at least 10 patients are waiting more than 20 minutes. The extra doctors will leave the unit at the end of the peak hours. When the simulation ends, i.e. when all patients have been served at the unit, the throughput times of patients and waiting times per workstation are determined.

\subsection{Experimenting with the structure}

Tables 2 and 3 give an overview of the reactive decisions that can be taken in the simulation model. These decisions are bounded by rules, resulting from the structure of the unit. Following the conceptual model, two decisions are possible, namely to re-route patients upon arrival (table 2) and to add a medical officer to the workforce (table 3).

Regarding the first decision, patients at the unit are re-routed if either the overall patient load for a workday is high or if a patient arrives after $5 \mathrm{pm}$. These decisions can be taken at Aravind because processes are standardized. For a scenario with non-standardized processes it was assumed that patients cannot be rerouted to other units. Not standardizing processes implies that processes are different amongst units. Patients can also be rerouted if they receive the same care at the different units.

Regarding the second decision, a medical officer can only be added to the workforce at the unit because doctors at Aravind are trained to be able to perform tasks for various patient types. This cross-skillness enables them to be switched among processes or among tasks within a process. A second constraint for adding a medical officer to the workforce is related to the centralization of decision making. At unit 3, the decision has been decentralized which means staff themselves can take the decision, only during the peak hours though, if the need arises. The need arises if over 10 patients wait at least 20 minutes for a consultation with the medical officer. As this information is not monitored in the information system it is only visible to the people at the unit. 
Table 2: Action "Re-route patients upon arrival" if

\begin{tabular}{lll}
\hline Condition "IF" & Constraint \#I I "ANDIF" & Action "THEN" \\
\hline Work process is standardized & Patient load $>220$ & Re-route $10 \%$ of patients \\
Work process is standardized & Patient arrives after $5 \mathrm{pm}$ & Re-route this patient \\
Work process is not standardized & Re-route no one
\end{tabular}

Work process is not standardized Re-route no one

Table 3: Action during peak hours "Add medical officer during peak hours" if..

\begin{tabular}{|c|c|c|c|c|}
\hline Condition "IF" & $\begin{array}{l}\text { Constraint \#1 } \\
\text { "AND IF" }\end{array}$ & $\begin{array}{l}\text { Constraint \#2 } \\
\text { "AND IF" }\end{array}$ & $\begin{array}{l}\text { Constraint \#3 } \\
\text { "AND IF" }\end{array}$ & Action "THEN" \\
\hline Staff is cross-skilled & $\begin{array}{l}\text { Decision making } \\
\text { is decentralized }\end{array}$ & $\begin{array}{l}\text { Start peak hours } \\
\leq t \geq \text { end peak } \\
\text { hours }\end{array}$ & $\begin{array}{l}\text { over } 10 \text { patients } \\
\text { wait } \geq 20 \text { mins }\end{array}$ & $\begin{array}{l}\text { Add medical } \\
\text { officer }\end{array}$ \\
\hline Staff is cross-skilled & $\begin{array}{l}\text { Decision making } \\
\text { is centralized }\end{array}$ & $\begin{array}{l}\text { Expected patient } \\
\text { load } \geq 200\end{array}$ & & $\begin{array}{l}\text { Add medical } \\
\text { officer }\end{array}$ \\
\hline Staff is mono-skilled & & & & Do nothing \\
\hline
\end{tabular}

If the decision would be centralized and, as such, taken by someone outside the unit, different information would have to be used. For the centralized scenario, the rule was set up that a doctor is appointed to the unit to help out during the peak hours only when the expected patient load for a day is high, i.e. over 200 patients. This centralized decision is taken at the start of the workday.

Table 4 gives a schematic overview, of the attributes of the enabling factors and the decision possible. The reactive decisions combined with the factors lead to the experimental design displayed in table 5 .

By setting up an experimental design, we were not only able to study the effect of other planning and control decisions on system performance. Also, we could study if Aravind indeed has created a configuration that responds best to patient demands or that another configuration might lead to better results.

We defined performance in terms of patient waiting times for refraction, preliminary, re-refraction and final consultation, patient throughput time, measured from when patients enter the unit until they leave, and utilization of the medical officers working at the unit, measured by dividing the time the medical officers were treating patients by the time medical officers were available at the unit. Further, the effect flexibility had on the system state was measured by counting the number of patients re-routed during the day as well as the number of patients waiting for more than 20 minutes for a final consultation with a medical officer.

All six experiments in table 5 were replicated 250 times. In all six experiments identical patients arrive in the same sequence, resulting from the use of the same pseudo-random number stream in each experiment. 
CHAPTER 6

Table 4: Experimental variables

\begin{tabular}{|c|c|c|}
\hline Factor & & Value \\
\hline \multicolumn{3}{|c|}{ 1) skill level of staff } \\
\hline & Cross-skilled: extra worker can be pulled into process & + \\
\hline & Mono-skilled: extra worker cannot be pulled into process & - \\
\hline \multicolumn{3}{|c|}{ 2) decision centrality } \\
\hline & $\begin{array}{l}\text { Decentralized: unit staff can decide to pull in extra worker if at least } \\
10 \text { patients are waiting for }>20 \text { minutes during peak hours }\end{array}$ & + \\
\hline & $\begin{array}{r}\text { Centralized: management can appoint extra worker if expected } \\
\text { patient load is }>200 \text { at the start of the workday }\end{array}$ & - \\
\hline \multicolumn{3}{|c|}{ 3) level of workflow standardization } \\
\hline & $\begin{array}{r}\text { Standardized: demand can be re-routed to other process in case } \\
\text { of patient load }>220 \text { or if patients arrive after } 5 \mathrm{pm}\end{array}$ & + \\
\hline & Not standardized: demand cannot be re-routed to other process & - \\
\hline
\end{tabular}

Table 5: Experimental design

\begin{tabular}{llll}
\hline Experiment & Factor 1 & Factor 2 & Factor 3 \\
\hline Aravind & + & + & + \\
1 & + & + & - \\
2 & + & - & + \\
3 & + & - & - \\
4 & - & - & + \\
5 & - & - & - \\
\hline
\end{tabular}

\subsection{Results}

Table 7 displays the average results per experiment as well as the dispersion within each performance indicator. The latter is expressed by the coefficient of variation, which displays the ratio of standard deviation to the mean. To determine whether differences between the simulated configuration experiments were significant, ANOVA analyses were applied $(a=0.01)$. Table 8 shows the results of these analyses. In table 8 a distinction is made between the factor with the highest impact on performance, i.e. with the highest $F$ ratio, and the other factors with significant effects yet lower $F$ ratios. Each experiment simulated represents a configuration of resources of which the structure is influenced by three planning and control decisions. The results show that the Aravind configuration has the lowest throughput time for patients and lowest waiting time for the final consultation and that the highest throughput time and waiting times are reported in experiment 6 , the configuration with mono-skilled staff and non-standardized processes. The Aravind model results in an average patient throughput time at the unit of 2 hours. This average throughout time found in the model corresponds to average patient throughput times in reality. In the model, as in reality, some 
patients are ready at the unit in a matter of 10 to 15 minutes, where others undergo dilatation procedures and more extensive consultations. Patients in the latter group can end up staying at the unit for several hours; if they arrive during the busier peak hours especially.

Waiting times for the refraction and preliminary changed under the influence of the level of process standardization. The commonest waiting time for patients was zero, however, waiting time for a single patient could increase up to one hour for refraction and more than 2 hours for preliminary. The rule in the model was that $10 \%$ of the patients could be re-routed to another unit if patient load exceeded 220. On 49 days, the patient load was higher and so in the experiments in which patients could be rerouted, $10 \%$ of the patients were rerouted 49 times. Next to rerouting patients because of a high load, patients also could be rerouted within standardized processes when they arrived at the unit after $5 \mathrm{pm}$. Together with the patients that were rerouted on very busy days, the average number of patients rerouted over the 250 days simulated was five.

Practically, the opportunity to reroute patients meant an average decrease in waiting times of approximately two minutes for refraction and nearly five minutes for preliminary. So, re-routing patients can benefit the overall flow of patients. At the same time, however, it can create discontinuity in flows as patients are not allocated to a specific doctor. Instead, patients are treated by the first doctor to become available, even if this doctor is in another unit, unless an explicit comment is made on their medical record.

Waiting times for second refraction (after receiving dilation drops) did not differ over the experiments. For the second refraction average waiting time was practically zero, as these patients were given priority in the queve over the regular refraction patients. This was done similarly over the six experiments.

Waiting times for final consultations did differ amongst the experiments. This was mainly due to changes in the skill levels of doctors, which determined whether doctors could be switched between processes. Waiting times for finals were lowest in the Aravind configuration, where cross-skilled doctors could be pulled into the unit during peak hours, when patient demand was high. Crossskillness of staff also has the most influence on the number of patients waiting for finals, the overall patient throughput times, and utilization of staff. 
CHA

\begin{tabular}{|c|c|c|c|c|c|c|c|c|c|c|c|c|}
\hline \multirow[t]{2}{*}{ Experiment } & \multicolumn{2}{|c|}{ Aravind } & \multicolumn{2}{|c|}{7} & \multicolumn{2}{|c|}{2} & \multicolumn{2}{|c|}{$\overline{3}$} & \multicolumn{2}{|c|}{4} & \multicolumn{2}{|l|}{ 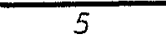 } \\
\hline & Mean & CV & Mean & $C V$ & Mean & $C V$ & Mean & $C V$ & Mean & $\mathrm{CV}$ & Mean & $C V$ \\
\hline \multicolumn{13}{|c|}{ Waiting time (minutes) } \\
\hline Refraction & 10.2 & 2.1 & 12.4 & 2.1 & 10.2 & 2.1 & 12.4 & 2.1 & 10.2 & 2.1 & 12.4 & 2.1 \\
\hline Preliminary & 65.0 & 1.0 & 69.5 & 1.1 & 65.0 & 1.0 & 69.5 & 1.1 & 65.0 & 1.0 & 69.5 & 1.1 \\
\hline 2nd refraction & 0.3 & 5.1 & 0.3 & 5.1 & 0.3 & 5.1 & 0.3 & 5.1 & 0.3 & 5.1 & 0.3 & 5.1 \\
\hline Finals & 14.3 & 1.4 & 15.5 & 1.5 & 41.0 & 1.2 & 37.5 & 1.2 & 50.6 & 1.0 & 50.3 & 1.0 \\
\hline \multicolumn{13}{|c|}{ Throughput time (minutes) } \\
\hline $\begin{array}{l}\text { Throughput } \\
\text { time }\end{array}$ & 121.1 & 0.7 & 129.1 & 0.7 & 147.8 & 0.6 & 151.1 & 0.7 & 157.4 & 0.6 & 163.9 & 0.7 \\
\hline \multicolumn{13}{|l|}{ Percentage } \\
\hline $\begin{array}{l}\text { Utilization } \\
\text { Count }\end{array}$ & \multicolumn{6}{|c|}{ Count } & 86.5 & 0.1 & 91.4 & 0.1 & 90.0 & 0.1 \\
\hline $\begin{array}{l}\text { Patients } \\
\text { re-rouled }\end{array}$ & 4.8 & 1.8 & 0.0 & - & 4.8 & 1.8 & 0.0 & 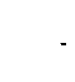 & 4.8 & 1.8 & 0.0 & . \\
\hline $\begin{array}{l}\text { Waiting final } \\
>20 \text { ins }\end{array}$ & 40.7 & 0.5 & 44.3 & 0.6 & 83.7 & 0.3 & 81.8 & 0.3 & 99.2 & 0.3 & 101.8 & 0.3 \\
\hline Extra doctor & 250 & - & 250 & - & 63 & - & 82 & - & . & . & - & \\
\hline
\end{tabular}

Table 8: ANOVA analyses $(a=0.01) 250$ replications

\begin{tabular}{lll}
\hline & Most impact on performance $\neq$ & Impact on performance \\
\hline Wait refraction & Process standardization & \\
Wait preliminary & Process standardization & \\
Wait 2nd refraction & - & - \\
Waiting for final >2Omins & Skill level & Decision centrality \\
Wait final & Skill level & Decision centrality; \\
Throughput time & Skill level & Process standardization; D*Pt \\
& Skill level & Pecision centrality; \\
Utilization & Drocess standardization; D*Pt \\
\hline
\end{tabular}

F Most impact on performance implies highest $F$ ratio reported in ANOVA analysis

t Interaction term included in ANOVA analyses

Utilization at Aravind is around $80 \%$. This is lower than in the experiments with centralized decision making or with mono-skilled staff. In the latter experiments (4 and 5) no extra doctors can be used in the unit. So, there is only one medical officer to perform the final consultations. The average probability that this doctor is busy with a patient is around $90 \%$. So, $90 \%$ of the patients will find the doctor busy and have to queve. Because service times are exponentially distributed, an increased utilization is likely to increase throughput time in a non-linear fashion [15]. The results in table 7 underpin this. A $10 \%$ increase in utilization causes a 35 -minute increase in waiting time for final consultations. Even though the dispersion in patient waiting times for 
finals is higher in the Aravind configuration, the overall waiting times are much higher in the experiments without the flexibility the Aravind configuration introduces. The higher dispersion does show that for patients, the flexibility at Aravind can lead to some more variation in output.

In experiments 2 and 3 decision making is centralized and staff cross-skilled. Here, we see that utilization is higher than in the experiments with decentralized decision making. In experiments 2 and 3 an extra doctor is appointed to the unit during peak hours when the daily patient load exceeds 200. This decision is made at the start of the day when there is no information available concerning patient waiting times. The results of experiments 2 and 3 show an extra doctor is appointed to the unit 63 times in experiment 2 where patients can be rerouted (because of standardized processes) and 82 times in experiment 3 where processes are not standardized. In the Aravind model and experiment 1 resource utilization is lower because in all 250 experiments an extra doctor was pulled in. The average time the doctor helped out in both scenarios was 110 minutes, with a standard deviation of 21 minutes. This implies a doctor was not always called in at the start of the peak hours, but also somewhere during the peak hours. In the Aravind model, the latter happened 61 times and in experiment 1 it happened 59 times.

\section{General discussion and conclusions}

The OPD of the Aravind Eye Hospital in Madurai dealt with over 550,000 patients last year and the surgeons performed over 90,000 surgeries [28]. Over two million patients visit the AECS per year and while $70 \%$ of them pay nothing or almost nothing, AECS' financial system is self-supporting and yields gross margins of $35 \%$ [29]. Continuously, hospital managers further increase patient throughput capacity at Aravind by minimizing patient waiting times and maximizing resource utilization. This chapter focuses on how Aravind's system is structured such that it enables to respond to (changes in) the patient demands.

Aravind indeed has surgeons that seem to operate almost perfectly, at very high volume [30]. Further, support staff at Aravind seems endless in numbers and culture is such that people never stop working; they all want to serve the patients [28]. These two characteristics may not be so easily replicated in other, Western hospitals. What is replicable and provides opportunities for patient flow improvement is the high level of supply flexibility that Aravind creates. At Aravind, the rule is that whenever someone is needed for a patient, 


\section{CHAPTER 6}

he is located and sent to that patient to serve the patient's demands. The flexibility in the workforce at Aravind highly contributes to the quality of care delivered. This flexibility was simulated in a study where experiments were set up with other rules for flexibility than the ones at Aravind. Even though the experiments are not comprehensive and based on the input values estimated by Aravind staff, they do provide insight into the effects of flexibility.

Every day, Aravind is faced with changes in input, in demand volume and mix. In other hospitals, such fluctuations in demand are likely to cause discontinuities in flows. At Aravind, though, a structure has been created that promotes responsiveness to patients and their demands. We might say that at hospitals characterized by high waiting times, the capability to respond to changes in input is rather limited. In this respect, changing the structure following the hierarchical planning and control framework in table 1 does not provide hospitals sufficient insight in to how Aravind increases flexibility to enable excellence.

Compared to this framework, Aravind does not just hierarchically plan and control its resources. Rather, planning and control is part of a continuous improvement cycle. Aravind has created flexibility by increasing the variety in workers skills while standardizing its processes. This has not only made supply flexible for patients, but also makes the work more attractive for the people doing it [31]. Further, Aravind frontline staff has been given decision power; an intervention that can improve performance as well as work motivation [20]. Also, Aravind ensures workers are cross-skilled and continuously educated. Additionally, Aravind tries to formalize staff behavior in different processes to minimize inter-staff variance. The latter benefits patient outcomes and contributes to process standardization. Finally, system performance is constantly fed back into the system and planning and control is adjusted if either performance is unsatisfactory or when demand changes. This is done through the use of an integrated information system, developed by Aravind. The extensive information system is used by staff, who are trained to do so. In the system, staff of all units both enter and access patient information regarding the location of patients in the system, previous visits of the patient and patient general information. Additionally, medical registration sisters are posted at all hospital units to keep up the units' clinical registrations too so that the patient's diagnostic and medical history is available throughout the hospital.

The supply flexibility Aravind creates does not come without costs, both direct and indirect. First of all, cross-skilled staff costs money due to training and time 
spent on training. Second, each staff transfer is associated to cost related to worker time and lost productivity [32]. Aravind minimizes these effects by offering all tasks within the same building [33]. Walking distances are minimized and mainly apply to staff. Aravind does not transfer patients once they are within a particular process at a unit. Patients, however, can be rerouted to another unit upon arrival in the hospital. The flexibility further requires that staff members are willing to be cross-skilled as well as transferred. Also, they have to cut their lunch breaks short if patient load high. This is possible and accepted at Aravind, yet may not be as easily implemented in Western hospitals, where work culture is often different and law may be limiting such flexibility.

In the simulation model, following the daily performance at Aravind, the opportunity to transfer staff results in system performance improvement. In the experiment simulating Aravind, an extra doctor was pulled in every day the model was simulated. This shows a structural need for this doctor during the peak hours. In the model, transfers took place only during peak hours based on the patient waiting times during these hours. Aravind staff could monitor waiting times throughout the day to see if extra staff is required at a unit other than during the peak hours. This could further improve patient flow as well as resource utilization. However, transferring staff more often will of course multiply transfer cost. Also, it can cause uncertainty in staffing at other units and for other tasks.

Now, it is common knowledge at Aravind that during peak hours staff can be pulled out of some tasks to help out at other tasks. If this can be done any time of day, patient flows at the unit that is temporarily understaffed could temporarily benefit. Yet, it introduces an optimization issue. Because of staff flows back and forth between units, variability in the aggregated supply of the whole hospital depends on variations in supply at the various units [34]. In other words, patient flows at some units might worsen, where flows at other units improve. Additionally, staff transfers affect resource utilization as they take time which makes the staff in transfer temporarily unavailable. These influences of transfers and flows require information systems that can track not only patient flows through the system but also resource flows. Further, they require an optimization study matching demand and supply by searching for a fit between maximum patient waiting times and minimum resource utilization throughout the hospital and at each subsystem. 


\section{CHAPTE G}

In most hospitals, power is decentralized to the frontline staff. Professional autonomy is high in hospitals, for doctors especially. However, having the power to make a decision does not provide the information to make it [21]. In many healthcare systems, hospitals included, a lack of adequate and timely information obstructs the process of reactive decision making [2]. Information systems are often segmented in hospitals. As a consequence, patient flows cannot be completely and actively evaluated. Previous research also showed that, even though some may implement more integrated information systems to plan and control patients, the system do not automatically work [35]. The professionals involved, like the doctors, need to agree with how their activities are entered in the system and need to accept that their performance is so actively monitored [35].

Furthermore, in most hospitals resources are specialty labeled and subsystems focus on their own optimization [23]. This creates sub-optimization and impedes the coordination of activities and processes amongst subsystems and departments. Additionally, a lack of process standardization further increases the burden of coordination as well as variability in performance [23] Regarding workforce flexibility, legislation often limits shifts and changes in work hours and leave time. However, opportunities like parttime work contracts to introduce workforce flexibility are currently underappreciated [36] Overall, the focus on highly specialized resources, an inflexible workforce, segmented flows and processes, and segmented tools for planning and coordination limit supply flexibility, which limits opportunities for excellent performance.

\section{Limitations}

The chapter is not comprehensive, rather, indicates opportunities and enablers of supply flexibility. Additionally, the simulation study is limited as it only provides insight in part of the hardware of the Aravind system structure and focuses on just one unit. It does not simulate staff behavior neither does it simulate the interaction between units or subsystems. The fact that most of he input of the model was estimated by Aravind staff also limits the generalizability of the results to other hospital structures. That is to say, in other structures, with other input values and rules as when to transfer staff or reroute patients, results regarding waiting times and resource utilization would be different, yet without counteracting the overall effect that more flexibility improves performance. That is, despite the limitations of the study, the 
simulation results show that the planning and control decisions taken by Aravind have enabled a situation in which demand fluctuations can be absorbed by staff flexibility, for the benefit of patient flows as well as efficient resource utilization.

This chapter highlights three of Aravind's central elements in system design that have increased this flexibility and supports this with a simulation model. The results indicate that the hierarchical planning and control framework from Vissers et al. [12] needs to be extended with respect to opportunities to switch workers, continuous staff training, performance monitoring and information systems, and continuous process improvement. Further research is required to study the optimization issue of matching demand and supply throughout the hospital, taking into account covariations amongst the subsystems. 


\section{CHAPTER 6}

\section{References}

1. Bergeson SC, Dean ID. A Systems Approach to Patient-Centered Care. JAMA. 2006;296(23):2848-51.

2. Van Merode GG, Groothuis S, Hasman A. Enterprise resource planning for hospitals. International Journal of Medical Informatics. 2004;73(6):493-501.

3. Tachizawa EM, Thomsen CG. Drivers and sources flexibility: an exploratory study. International Journal of Operations \& Production Management. 2007;27(9-10):1115-36.

4. Cuatrecasas Arbós L. Design of a rapid response and high efficiency service by lean production principles: Methodology and evaluation of variability of performance. Internationa Journal of Production Economics. 2002;80(2):169-83.

5. Santos Bernardes E, Hanna MD. A theoretical review of flexibility, agility and responsiveness in the operations management literature: toward a conceptual definition of customer responsiveness, International Journal of Operations \& Production Management. 2009;29(1):30-53.

6. Van Merode GG, Hasman A, Derks J, Goldschmidt HMJ, Schoenmaker B, Oosten M. Decision support for clinical laboratory capacity planning. International Journal of Bio-Medical Computing. 1995;38(1):75-87.

7. Van Merode GG, Hasman A, Derks J, Schoenmaker B, Goldschmidt HMJ. Advanced management facilities for clinical laboratories. Computer Methods and Programs in Biomedicine. 1996;50(2):195-205

8. Hax AC, Candea D. Production and inventory management. Englewood Cliffs, New Jersey: Prentice-Hall, Inc.; 1984

9. Swisher JR, Jacobson SH. Evaluating the Design of a Family Practice Healthcare Clinic Using Discrete-Event Simulation. Health Care Management Science. 2002:5(2):75-88.

10. Hyer NL, Brown KA, Zimmerman S. A socio-technical systems approach to cell design: case study and analysis, Journal of Operations Management. 1999;17(2):179.203.

11. Krajewski L, Ritzman LP. Operations Management. 6th Edition ed. Upper Saddle River, NJ: Prentice Hall; 2002.

12. Vissers JMH, Bertrand JWM, De Vries G. A framework for production control in health care organizations. Production Planning \& Control. 2001;12(6):591.604.

13. Encyclopædia Britannica Online (2006). Production management. [Accessed on: 21.082006]; Available from: http://www.search.eb.com.

14. Prajogo D. The implementation of operations management techniques in service organisations - an Australian perspective. International Journal of Operations \& Production Management. 2006;26(12):1374-90

15. Hopp WJ, Spearman ML. Factory Physics: foundations of manufacturing management. Second ed. New York: Irwin/McGraw-Hill; 2001.

16. Silvestro R. Positioning services along the volume-variety diagonal - The contingencies of service design, control and improvement. International Journal of Operations \& Production Management. 1999;19(4):399-420.

17. Silvestro R, Fitzgerald $L$, Johnston R, Voss $C$. Towards a classification of service processes International Journal of Service Industry Management. 1992;3(3):62.75.

18. Armistead CG. Service operations strategy: framework for matching the service operation task and the service delivery system. International Journal of Service Industry Management. $1990 ; 7(2): 6-16$.

19. Galbraith JR. Designing organizations: an executive guide to strategy, structure and process. New and Revised ed. San Fransico, USA: Jossey-Bass; 2002. 
20. Tummers GER, van Merode GG, Landeweerd JA. Organizational Characteristics as Predictors of Nurses' Psychological Work Reactions. Organization Studies. 2006 April 1 2006;27(4):559-84

21. Mintzberg H. The structuring of organizations. Engelwood Cliffs, N.J.: Prentice-Hall, Inc; 1979

22. Anthony RN. Planning and control systems - a framework for analysis. Boston, Massachusetts Division of Research, Graduate School of Business Administration, Harvard University; 1965.

23. Van Merode GG, Molema H, Goldschmidt H. GUM and six sigma approaches positioned as deterministic tools in quality target engineering. Accreditation and Quality Assurance. 2004 Dec; 10(1-2):32-6.

24. Law AM, Kelton WD. Simulation Modeling and Analysis. Third ed. New York, USA: Tato McGraw-Hill; 2003.

25. Gerwin $D$. An agenda for research on the flexibility of manufacturing processes. International Journal of Operations \& Production Management. 2005;25(12):1 171-82.

26. Schmenner RW, Tatikonda MV. Manufacturing process flexibility revisited. International Journal of Operations \& Production Management. 2005;25(12): 1 183-9.

27. Arnold D, Furmans K. Materialfluss in Logistiksystemen. Berlin Heidelberg: Springer-Verlag; 2007.

28. Aravind Eye Care System (2007). Activity Report 2006-2007. [Accessed on: 03-12-2008] Available from: hHtp://www.aravind.org

29.Aravind Eye Hospitals, India. [Accessed on: 26-09-2008]; Available from: http://www.aravind.org

30. Prahalad CK. The Aravind Eye Care System: delivering the most precious giff. In: Prahalad CK, editor. The fortune at the bottom of the pyramid. Upper Saddle River, NJ: Pearson Eduation, Inc.; 2005. p. 265-86.

31. Adler PS, Goldoflas B, Levine DI. Flexibility versus efficiency? A case study of mode changeovers in the Toyota Production System. Organization Science. 1999;10(1):43-68

32. Hendrich $\mathrm{AL}$, Lee $\mathrm{N}$. Intra-unit patient transports: Time, motion, and cost impact on hospital efficiency. Nurs Econ. 2005;23(4):157-64.

33. The Center for Health Design. The Role of the Physical Environment in the Hospital of the $21 \mathrm{~s}$ Century: A Once-in-a-Lifetime Opportunity: Ulrich R, Quan X, Zimring C, Joseph A, Choudhary R; 2004,

34. Van Merode GG, Oosten M, Vrieze OJ, Derks 」, Hasman A. Optimisation of the structure of the clinical laboratory. European Journal of Operational Research. 1998;105(2):308-16.

35. Baars IJ, van Merode GG. A planning tool for multidisciplinary youth care evaluated: A case study. International Journal of Medical Informatics. 2008;77(5):315.23.

36. Molema JJW, Groothuis $S$, Baars II, Kleinschiphorst $M$, Leers EGE, Hasman A, et al. Healthcare system design and parttime working doclors. Health Care Management Science. 2007;10(4):365-71. 


\section{CHAPTER 7}

Canerolliscussion and condlusions 


\section{CHAPTER Y}

\section{Introduction}

This thesis aimed to explicate the relations amongst some planning and control decisions, system structure, supply flexibility, and system performance in hospitals. Structure was defined as the relations amongst entities in a system, if and how they are divided into subsystems, how coordination amongst them is achieved, and how the system functions [1-6]. Supply flexibility was defined as the variety in the mix and/or volume of resources in a system, so that the system state can be changed [7].

The central research question was "given the variability and complexity of demand in a hospital, how should planning and control be organized so that the system structure enables a match between supply and demand, resulting in low patient waiting times and high resource utilization?" In the various chapters, opportunities for better matching supply to demand in hospitals have been studied, under the assumption that increased supply flexibility provides opportunities for this. In the present chapter, first the main findings of the thesis are presented. Subsequently, these findings are taken into consideration and some of the limitations of the conducted research are reviewed. This chapter ends with summarizing recommendations for the future following on the conclusion.

\section{Main findings}

All studies performed as part of this thesis were case studies in which hospital structure was analyzed with the aim of building evidence for the conceptual model introduced in the first chapter of this thesis. Next, the main findings regarding ways to create flexibility in (human) resource volume and mix within hospitals and the effects of such flexibility on patient waiting times and resource utilization, are discussed. Additionally, the findings from analyzing the Aravind eye hospital are described, where supply flexibility is considered of paramount importance to their excellent service delivery.

2.1 Flexibility and work contracts

In chapter 2 we studied how a parttime contract can be an intermediate variable between work design, supply flexibility, system efficiency, and quality of work. Based on the results it can be concluded that, from a logistical viewpoint, creating opportunities for working parttime seems very well possible in hospitals and sometimes even advisable. Parttime contracts can ensure a 
certain variety in when employees are available, how long they are available and for which tasks. Herewith, offering parttime jobs can introduce workforce flexibility and even improve performance.

In structures where demand fluctuates, having disposal of a more flexible workforce can enable the opportunity to temporarily increase or decrease staff or the work hours of individuals at a department or for a task. The type of demand variability should determine the type of parttime contract. Although offering parttime contracts with fixed work hours and days to mono-skilled workers might fit in highly standardized processes; if demand varies highly, offering such contracts will not improve performance, more likely diminish it. Thus, in systems characterized by large variability, either the structure should be redesigned or parttime work should not be enabled. Overall, the decision to introduce parttime contracts should be accompanied by an evaluation of current work processes. The latter also enables a reduction of wasteful activities and preventable variability.

\subsection{Flexibility and resource aggregation}

In chapters 3 and 4 the relations between the level of resource aggregation in a system and system performance were studied. In these chapters, resource aggregation was interpreted as how hospital beds are grouped. Beds grouped to medical specialties were considered of a lower aggregation level than beds grouped to more general demand characteristics, like demand for surgery, complex care process or acute care. The more general the bed label, the more patient types can be admitted to the bed, so the more flexible the bed is.

To study how specialty labeling limits patients flow continuity and what opportunities are available for performance improvement, a case study was performed. Qualitative and quantitative analyses were performed and two simulation models were designed. The results show a considerable opportunity to reduce the number of queves and improve patient flow continuity by increasing the level of resource aggregation.

Introducing an acute care medical admission unit (AMAU) aggregates acute beds to a general label, whereas these are often scattered in hospitals. This increase in acute bed aggregation level streamlines acute care processes and also regulates the admission process of acute patients at wards. However, if the functional structure at wards remains, the analyses show that elective patients will still face waiting times for admission when only an AMAU is introduced. The research shows that the flow of elective patients only improves if, next to the AMAU, cross-functional wards are created. Furthermore, this 


\section{C}

reduces in-process congestions which acute patients face when they are transferred from the AMAU to specialty labeled wards.

Overall, patients flow more easily through a hospital with less specific bed labels. Notwithstanding the significant performance improvements that were found when bed capacity was increased, the analyses showed real efficiency gains when the bed structure was redesigned from functional to more crossfunctional. Given the budgetary limitations hospitals face, such gains in efficiency resulting from increased supply flexibility seem promising. Unclear, however, is the effect the cross-functional wards have on the organization of staff and their quality of work. Both paragraph 3.2 .2 and 3.3 elaborate on this issue.

\subsection{Flexibility to enable excellence}

In chapters 5 and 6 of this thesis, resource planning and control at one of the Aravind Eye Hospitals was analyzed to identify how supply flexibility is enabled and how this affects output. Whereas in most hospitals lead times are high(er) and patients wait while resources are not efficiently used, in South India, the Aravind Eye Hospitals distinguish themselves by their excellence and efficiency. The Aravind Eye Care System operates five hospitals in which remarkable results are achieved: there are no waiting lists for patients, who receive all necessary care on the day they want. The hospital ufilizes its resources very efficiently and reports service quality similar to other internationally renowned hospitals, yet for a fraction of the costs.

The results show that all employees are cross-skilled and continuously educated at Aravind. Processes and tasks are standardized through protocols and front line staff have been given decision power. These decisions create a flexible workforce and a set of non-human resources that are put to use at different locations in the hospital, for different patient types, and based on the actual demand of patients. To enable the reactive decision making as well as monitor its effects, Aravind tracks activities and output with ICT. Its information system is easily accessible by all employees in the hospital, who are continuously trained to work with it.

Overall, Aravind places patients' demands and the tasks required to serve them at the hart of its structure. Through a more general label on resources and a flexible workforce, staff and resources are controlled following on demand. Central in its planning and control is the ICT system of Aravind, which provides both historic and real time patient data concerning patient arrivals, demand 
specifications, and patient volume per unit. These data are required to respond adequately to demand changes.

2.4 General conclusions

In the chapters of this thesis, several possible redesigns in hospitals were studied to contribute to the current knowledge on hospital structure and how can be used to respond to demand. It leads to the conclusion that the functional structure in hospitals needs to be evaluated and that more flexibility is needed.

Healthcare should not only be redefined [8], but also redesigned, following on the credo that a system is more than the sum of its parts. Stemming from the traditional functional structure and specialty labeling of resources is a certain inflexibility in supply that makes hospitals unable to adequately respond to patients' demands. Also, it causes complexity in flows for patients as well as (non) human resources. If hospitals want to create direct access for patients and support collaboration and cooperation among its resources they must ensure a structure where demand generates supply through a planning and control system that takes into account demand complexity and variability and does justice to quality of work preferences. This structure needs variety in resources. Further, it should not fix people and label resource to too many specialty locations, but assign people and labels more flexibly, when and where these are needed. Having partime work contracts can introduce flexibility for employees in hours and/or days to work and tasks to perform. Ensuring that staff is cross-skilled, in addition, enables that staff can be switched between tasks and even subsystems. Increasing the level of resource aggregation, furthermore, provides freedom in scheduling patients and streamlining their flow through the hospital

\section{Considerations}

The main findings support the conceptual model introduced in chapter 1 that assumes that supply flexibility provides opportunities for better matching demand and supply in hospitals. Additionally, they provide insights into what these opportunities are. However, the conclusions of the research performed cannot simply be transferred to practice. To make well informed decisions, some aspects of the research are now taken into deeper consideration. 


\section{CHAPTER 7}

\subsection{Study limitations}

Hospitals are very complex systems in which many elements interact. Trying to stay close to reality in modeling hospitals could lead to highly complicated mathematical models of which it is questionable whether they will result in the optimal solution [9].

In the various chapters of this thesis, only simple queuing models were developed, with simplifications and constraints with regard to the real world. Particularly, the 'human' aspect was not input into the models of this thesis more than it is in most other models [10, 11], although this factor is likely to be of influence in reality. For example, chapter 2 dealt with work contracts and shifts, which are likely to affect staff performance [10]. The success of parttime work will be influenced by aspects like inter-doctor agreements and understandings concerning tasks shared by or split between doctors. Also, the results in chapters 3 and 4 might be influenced by the behavior of doctors. If they start admitting or discharging patients differently when an AMAU is implemented and wards are restructured, patient flows as well as utilization of beds might be affected [12]. At Aravind, in chapters 5 and 6, staff clearly affected system performance. However, their behavior in the model was based on explicit rules without room for negotiation within or between staff and departments. Previous research has already shown how actual behavior can undo advantages of an innovation or counteract their effects [13].

Not having included the human factor in the models need not be a limitation per se. Following Burton and Obel [14], the computational validity of a model is a balance of the question studied, the experimental design and the computational model. The question studied in this thesis aimed to provide insights into the potentional benefits that supply flexibility can bring to hospitals. That this issue was considered on its own merits, without including the human factor, enabled us to study the effects of the proposed changes without being inhibited by possible behavioral barriers. The insights and results this thesis yielded can provide arguments for implementing these changes, and give direction to the human factor in reality.

The models were based on historic registered data, interviews, observations, document analyses, and estimations. Part of the study limitations lies within a lack of complete historic data registration in the hospitals studied. Sometimes, data were not registered or, when they were, the registrations did not prove to be reliable (enough). Here, assumptions were made always in close consultation with hospital management and staff. To further ensure reliability of input and model validity, input in all models was based on data triangulation 
and both the model structure and results were evaluated with hospital management.

3.2 Supply flexibility to respond to demand variability

According to a recent paper by Rogers et al [15], healthcare (re)design could benefit from a set of simple rules, where rule number four dictates that 'demand is finite and predictable, supply is flexible and manageable; capacity and demand can be matched and queves are not necessary'. Primarily, the findings in this thesis support the proposition that, to prevent for queues and create continuous patient flows, hospital structures need to be viewed upon as systems of interacting subsystems [16, 17]. A different configuration of the currently fragmented subsystems and resources is necessary to respond to the increasing variefy in demand [18]. Primarily, the subsystems should collaborate [19]. To be able to collaborate, they must be flexible enough to respond to each other and demand [20]. The need for flexibility is expected to increase even more owing to the influx of demand for care from multiple medical specialties or disciplines [21].

\subsubsection{Workforce flexibility}

The research in this thesis supports earlier findings $[22,23]$ that if workload can be balanced and shared, because staff can be switched, performance improves. In this thesis, supply flexibility was increased through cross-skilled staff and by introducing variety in work contracts.

Sources of supply flexibility in hospitals have not before been searched in the structure of parttime work contracts and jobs. Additionally parttime work opportunities are not yet offered sufficiently in healthcare because of attitudes of doctors themselves [24, 25]. Further, even if attitudes are positive, it is unclear to doctors which type of work contract they should choose [26]. The research in this thesis showed, however, that parttime work should not merely be a matter of personal taste, but the contracts should be aligned to the structure of the hospital. If this is achieved, these can increase flexibility and improve performance. Having a cross-skilled workforce also improves performance. At Aravind, it enables staff to be switched to where they are needed and, as such, reduce waiting times for patients.

In many hospitals staff is structurally assigned to one department [20]. Staff switching in these hospitals, if at all, takes place within these departments. The results of the simulation study at Aravind show the benefits of losing the focus on departments and expanding the view to the whole hospital. At Aravind staff 


\section{CHADCR}

can be switched between departments, just as long as they are qualified to perform the task demanded. In lean thinking this switching of staff is coupled to what is called 'Takt time' [27]. A lean system is one in which only value is added to demand $[28,29]$. Takt time is one of the basic concepts of the 'value stream principle' and in Takt systems demand is met at any point in the system $[28,30]$. Takt time can be defined as "the cycle time allowing production attuned to demand to be carried out in the time available. (...) Takt time will vary according to demand" [31]. In lean systems, Takt time is used to coordinate staff scheduling with the objective to prevent buffering of demand as well as over or under production. Hospitals too could follow on the principles of Takt time and determine what lead time they want to offer patients for various services. This sets a quality standard in terms of lead time and enables goal-oriented staff scheduling. Moreover, through a flexible workforce, it creates opportunities for aligning the interacting subsystems.

Workforce flexibility as well as performance might be further increased if staff is not only switched within one hospital, but also between hospitals. This enables hospitals to improve efficiency within their own walls and beyond those walls and optimize care in a region. Already, doctors sometimes work in two hospitals within relatively close range. By creating a flexible allocation of capacity and skills between hospitals, hospitals are able to opt for a specific set of processes and treatments and doctors can remain working on an attractive skill level by working in both hospitals. This of course automatically implies that hospitals should offer parttime work contracts.

Overall, supply flexibility increases with a flexible workforce. Although previous research also reported the benefits of having a flexible pool of employees $[23,27,32]$, research has all the same shown that without decision authority and good cooperation, quality of work might decrease [5]. The latter underlines that preconditions for increasing workforce flexibility need to be set. Paragraph 3.3 pursues some of these boundaries and side-effects.

\subsubsection{Non-human resource flexibility}

The findings of this thesis support a hospital structure that switches in focus from labeling resources to medical specialties to labeling resources to specific processes and patient demands. An example of grouping resources following a process orientation is the AMAU. In such a department, all acute patients are admitted, diagnosed, and treated. Previous research has already proved the benefits of such a department, in terms of increased performance [17, 33-35]. This thesis underlines these findings and adds to them that not only length of 
stay of acute patients decreases, but also the constitution of a patients' stay can change. With an AMAU or within a process oriented configuration in general, patients are less transferred [36]. This increases flow continuity and decreases the chance of errors or complications [37]. It also decreases length of stay [34]. Whereas the AMAU thus clearly provides improvements for acute patients, previous research, however, has not before placed the AMAU in the context of the hospital subsystems with which it interacts.

The research in this thesis proves that when an AMAU is implemented, while nothing else in the hospital structure changes, processes remain fragmented and suboptimal results are achieved, particularly for elective patients. Because the nature of elective patients' demand is perceived as less urgent, they have to wait in hospitals and acute patients are given priority. Having an AMAU does not solve this matter; it only partly streamlines the flow of acute patients and makes it easier to plan out their flow after the AMAU. To improve performance for elective patients too, cross-functional wards are required. These results imply a diminished need for complex admission scheduling systems via waiting lists. Waiting lists are used for scheduling elective patients as they increase the degrees of freedom in planning these patients [12]. Creating a cross-functional ward does not create such planning freedom however, creates another freedom, namely that beds can be more freely used for the admission of various patient types. This not only decreases the waiting times for elective patients, but can also decrease the probability of a mismatch between the patient and the department he is assigned to [36].

Notwithstanding the fact that cross-functional wards can improve patient flow continuity, they might also create a new problem of staff flow discontinuity. Cross-functional wards could become complex to manage, if many different types of patients would be admitted to the ward and many different functionalities would be required in a relatively small space. For patients, this might be disturbing and some streamlining could be assured through ensuring that patients of similar diagnostic groups or that demand similar service characteristics are grouped $[8,38]$. Caution is needed, as categorization of patients into too many different queues again disrupts the patient flows [39]. The problem of chaotic wards and patient categorization could be overcome through a different layout in hospitals. A trend in healthcare is to develop more single patient rooms [40]. These rooms provide an opportunity to flexibly admit patients of a different type to various locations in the hospital, without other patients being disturbed too much. 


\section{CHAPTER 7}

\subsubsection{Supply flexibility in planning and control}

The research in this thesis was based on the hierarchical planning and control model by Vissers et al. [41]. The results from the various chapters in this thesis indicate that this framework needs to be extended with respect to opportunities to switch workers, enable continuous staff training, performance monitoring and continuous process improvement, and integrate information systems. Next, the focus and position of the framework should be placed differently when using it to enable supply flexibility.

The current focus of the framework is on assigning people and resources to fixed locations in a system [20]. The results from Aravind prove the focus should be more on the tasks patients demand. This creates a structure with opportunities to flexibly allocate staff in a response to patients' demands, instead of molding patients' demands into a more rigid structure. This focus at Aravind seems to conflict with the rather strong, traditional control of the professional hierarchy and departmental rigidity [42, 43]. Moses et al. [43] discussed the fragmentation in responsibility for care in hospitals as a serious barrier to advancing the quality of care. Although individual decision authority improves quality of work [5], shared responsibilities and decision authority are needed.

Further, the framework focuses not so much on reactive decisions and has an unclear time horizon. According to the framework, staff can also be switched; however, the time horizon for this is very different from Aravind. At Aravind, monthly staff schedules are made to initially allocate staff to tasks and departments, yet the time horizon for changes in supply is one day or even less. What is seen in most hospitals is that the time horizon for planning is several weeks for outpatient appointments and sometimes even several months for surgery scheduling and/or resources like an MRI. This type of planning does not take into account the actual demand of patients or short-term changes herein; it only takes into account long-term forecasts and professional hierarchy. Smaller time horizons for planning and controlling staff and nonhuman resources at hospitals would create more flexibility to respond adequately to demand and better uphold a match between supply and demand.

Most design oriented models and operations research models in healthcare, also the hierarchical framework, are positioned within a design space for experiments that is within the current, somewhat conservative model of onesize-fits-all hospitals. Instead, hospitals could choose to construct hybrid organizations [20] in which supply flexibility is introduced in (sub)systems. A 
hybrid construction introduces flexibility to cluster or categorize queues and servers on different aggregation levels and reorganize the workforce into, e.g., multi-skilled teams [44]. In such a system, patients and resources are grouped within a structure to the type of care they need. An example of a hybrid construction in a hospital would be if one part of the hospital deals with more complex, chronic patients and another with patients that have more standardized mono-disciplinary demands. The hybrid subsystems should be controlled both individually and as part of the overall hybrid organization. The hierarchical framework certainly leaves room for this more innovalive approach.

\subsection{Contingencies}

Following Sousa and Voss [45], contingency theory in relation to $O M$ practices explains that several contingency factors may contribute to the success of a certain $O M$ intervention. What is best for one organization may not necessarily be so for another organization. Subsequently, according to Natarajan [46] several factors inhibit the transfer of best practices and insights from industry to healthcare. So, whereas increasing supply flexibility seems promising to hospitals in general, and the results Aravind achieves are excellent, the question is how sustainable and replicable the main findings of this thesis are across the rather varied collection of hospitals?

First, several elements can place constraints on the feasibility of supply flexibility. For one, increased supply flexibility is likely to induce extra cost, next to increasing performance. If staff is switched between departments and processes, staff time is consumed which will cost money. Moreover, it may create a situation where the hospital is constantly responding and creating chaotic transfers of staff. This will probably affect the quality of jobs and perception of work for staff $[5,47,48]$. Supply flexibility, therefore, will have a certain practical maximum. Constraints need to be set, e.g., like Aravind has done when they decided to only switch staff during peak hours.

Further, flexibility will be limited due to constraints that cannot be changed easily. For one, legal and policy issues like collective labor agreements and work hour legislation will limit the freedom to experiment with work contracts and flexible shifts [49]. Also, the opening hours of departments and resources like operating rooms will set boundaries for departments to cooperate, if these hours are not aligned [50]. Another constraint is the layout of the hospital [51]. There is a limit to the number of beds that can be grouped into a single ward. The more limited the space of wards, the more staff transfers are likely 


\section{CHAPTER 7}

to take place. Information systems of hospitals will also limit the scope of supply flexibility. Information systems need to be integrated so they too support cross-functionality and shared responsibility. If they do not or are not supported by staff that is supposed to use them, supply flexibility is hard to achieve and secure [52]. A lack of information integration will limit the responsiveness of a system as information is less easily available across departments and at all times. Further, the teaching responsibility of a hospital can be conflicting with increased supply flexibility. Where flexible collaboration is always needed across functionalities and specialties, some of the traditional boundaries between departments and specialties will be needed for external requirements like credentialing educational programs [43].

From the contingency point of view, effective organizations have structures that both support the unique nature of their own production processes and are customized to complement their environment [53]. In other words, organizational effectiveness results from a match between situation and structure and is defined as the ability of the organization to achieve its objectives $[5,6]$. Consequently, according to contingency theorists there is not one most effective structure for different organizations [53]; which structure is effective depends on characteristics of the environment and the organization and the fit that can be reached between them. The challenge is to find the best match.

The hierarchical planning and control framework used in this thesis could be interpreted as a universal tool that hospitals can use to create a structure that enables responsiveness to the environment and takes into account its disparities. The disparities and variability in both the environment and the organization itself might even lead to the decision to split up a hospital into a few more or less independent subsystems, as not all hospitals should strive to deliver all services. From this latter viewpoint, different structures will remain to exist amongst hospitals and there will not be a 'one-size-fits-all' hospital. For different patient groups the environment is not likely to be uniformly dynamic, complex, or diverse across its entire range [54]. Additionally, disparities in the environment are likely to call for different responses in the design of structure [6].

\section{Recommendations}

Organizations that, in the past, found a structure that worked well tend to stick to it and only make small, incremental changes [18]; the same seems to hold true for hospitals. Historically, the structure of functionalities and professional hierarchy may be well explained and justifiable; however, it no longer seems 
sustainable and hospitals have come to the point where they should restructure. Already, there is a growing awareness that increased flexibility is needed in healthcare to respond to variability in demand $[20,38,55]$. The main findings of this thesis provide insight into the opportunities for increasing flexibility and by changing the structure of hospitals. Based on the research and findings, several recommendations can be made with regard to (re)designing hospitals as well as with regard to future research on the design of hospitals.

\section{7 Hospital system design}

It seems obvious that not all hospitals will do equally well with the exact same planning and control structure [20] nor with the same level of supply flexibility, as different hospitals will strive for different results for different patient groups. Moreover, patients and doctors are humans and will always vary among each other and amongst systems. Even though this can not be prevented, this thesis clearly shows that managers can proactively design a system such that even inherent variability can be better dealt with [56]. The choice for a particular structure, be it hybrid or not, determines the performance achievable, as "every system is perfectly designed to achieve the results it achieves" [57] Different opportunities are available that can benefit performance for patients, staff, and managements.

More attention is needed for parttime contracts for staff. Doctors, especially, are not given enough opportunity to work parttime [25]. Previous research found their attitudes toward it to be the reason for this. The attitudes could be changed with the insights from the present research that showed the benefit of parttime work contracts in terms of increased workforce flexibility. This increased flexibility can enable a better response to demand fluctuations and improve performance. Parttime jobs and flexible work contracts are also needed to retain as well as attract physicians as they make the medical profession more alluring [58].

Not only to improve flow continuity for patients but also to improve the utilization of resources should hospitals search more for opportunities to create cross-functional wards. Such wards are better accessible for patients. They can even make a distinction among patient types, like elective and acute, redundant. Implementing cross-functional wards requires new design of work and a new distribution of skills amongst staff and teams [39]. Further, not only clinical skills are required; skills related to process coordination are of the essence in cross-functional structures [36]. A mix of skills should be represented 


\section{CHAPTER 7}

at wards. This can be either because most staff is multi-skilled or because differently skilled staff members form a multi-skilled team at a ward. The latter creates flexibility within departments, whereas the first also creates the opportunity for flexibility across departments.

If the structural redesign will take place, also decision authority issues need to be taken into account. For example, doctors, who have long had authority about their placement in the hospital structure, cannot be expected to suddenly give up this authority for the benefit of creating flexibility. This takes time and doctors, just as all other staff, should be involved in creating the new structure of shared responsibility and authority.

Finally, the research in this thesis focused on minimizing patient waiting times and throughput times. One of the benefits of this is an increased throughput capacity. That is, if patients are treated more efficiently, they flow through the system faster, and so more patients can flow through the system. However, in healthcare, faster care is not always better. Patients may actually want extra time in between tests or a diagnosis and treatment or surgery. Also, direct accessibility in terms of waiting times should not supersede accessibility in terms of travel times and physical accessibility, especially for the elderly. Such preferences need to be taken into account. Increasing flexibility with the aim of optimizing throughput should not entail that patients feel rushed and less inclined to ask for (more) time.

4. 2 Further research

The research in this thesis was mainly focused on individual cases. Further research could focus on comparing cases with the same clinical function, the same patient mix, but with a different structure. Alternatively, it would be interesting to compare cases with the same structure, yet of different patient mix and/or clinical function. Such research is needed to gain insight into the relations between clinic function, patient mix, system structure and performance. Additionally, it would be interesting to apply the new insights for supply flexibility to an entire hospital. This would provide the opportunity to study the optimization issue of matching demand and supply throughout a hospital, taking into account variations amongst all subsystems. In such research, the concept of hybrid organizations should also be incorporated as well as how such a structure affects covariation.

Furthermore, it would be interesting to study opportunities for developing a more general model that healthcare practice can use for supply flexibility optimization. Practice is more and more interested in a tool like simulation, yet 
GENERAL DISCUSSION AND CONELUSIONS

lack the knowledge to develop tailored tools for specific situations. As such tools not only demand certain knowledge but also time and are, herewith, rather expensive, it seems promising to perform research on a more generic planning and control tool for supply flexibility. Generic models require straightforward and relatively easy to grasp measures that can explain some issues hospital managers face when dealing with supply (in)flexibility.

Also, insights related to human behavior in the proposed changes in structure is needed. Initially, these insights should be more qualitative and relate to how doctors and nurses perceive themselves working in a structure where their dayto-day allocations are part of reactive decision making processes. Also, the effect of cross-skillfulness and cross-functional wards on the quality of work should be evaluated $[6,47]$. The overall question to study in this respect is: What level of supply flexibility would still be perceived attractive by the workforce? 


\section{References}

1. Silvestro R. Posifioning services along the volume-variety diagonal . The contingencies of service design, control and improvement. International Journal of Operations \& Production Management. 1999;19(4):399-420.

2. Silvestro $R_{r}$ Fitzgerald $L$, Johnston $R_{r}$ Voss $C$. Towards a classification of service processes. International Journal of Service Industry Management. 1992;3(3):62-75.

3. Armistead CG. Service operations strategy: framework for matching the service operation task and the service delivery system. International Journal of Service Industry Management. 1990; 1(2):6-16.

4. Galbraith JR. Designing organizations: an executive guide to strategy, structure and process. New and Revised ed. San Fransico, USA: Jossey-Bass; 2002.

5. Tummers GER, van Merode GG, Landeweerd JA. Organizational Characteristics as Predictors of Nurses' Psychological Work Reactions. Organizalion Studies. 2006;27(4):559-84.

6. Mintzberg H. The structuring of organizations. Engelwood Cliffs, N.J.: Prentice-Hall, Inc.; 1979.

7. Santos Bernardes E, Hanna MD. A theoretical review of flexibility, agility and responsiveness in the operations management literature: toward a conceptual definition of customer responsiveness. International Jaurnal of Operations \& Production Management. 2009;29(1):30-53.

8. Porter ME, Teisberg EO. Redefining health care: creating value-based competition on results. Boston, Massachuselts: Harvard Business School Press; 2006

9. van de Klundert J, Muls $P$, schadd M. Optimizing sterilization logistics in hospitals. Health Care Management Science. 2008; 11(1):23-33.

10. Baines TS, Asch R, Hadfield L, Mason JP, Fletcher S, Kay JM. Towards a theoretical framework for human performance modelling within manufacturing systems design. Simulation Modelling Practice and Theory. 2005; 13(6):486-504.

11. Shub AN, Stonebraker PW. The human impact on supply chains: evaluating the importance of "soff" areas on integration and performance. Supply Chain Management. 2009;14(1):3 1-40.

12. Gemmel P, Van Dierdonck R. Admission scheduling in acute care hospitals: does the practice fit with the theory? International Journal of Operations and Production Management. $1999 ; 19(9): 863-78$

13. Van Merode GG, Groothuis S, Schoenmakers $M$, Boersma HH. Simulation Studies and the Alignment of Interests. Health Care Management Science. 2002;V5(2):97-102.

14. Burton RM, Obel B. The validity of computational models in organization science: From model realism to purpose of the model. Computational \& Mathematical Organization Theory. $1995 ; 1(1): 57.71$

15. Rogers $H$, Maher $L$, Plsek PE. New design rules for driving innovation in access to secondary care in the NHS. BMJ. 2008;337(dec15_2):a2321-

16. Hopp WJ, Spearman ML. Factory Physics: foundations of manufacturing management. Second ed. New York: Irwin/McGraw.Hill; 2001

17. IHI. Optimizing Patient Flow: Moving Patients Smoothly Through Acute Care Settings. Boston Institute for Healthcare Improvement; 2003

18. Van Asseldonk AGM, Den Hartigh E. Economic productivity and value creation under various organizational configurations of business processes: A toolkit for phase transitions. In: Van Eijnatten FM, Den Hartigh E, editors. ECCON 2008 Annual Meeting; 2008; Veldhoven; 2008. p. 1-26. 
19. Mintzberg H. Toward healthier hospitals. Health Care Management Review. 1997;22(4):9. 18.

20. Van Merode GG, Groothuis $S$, Hasman A. Enterprise resource planning for hospitals. International Journal of Medical Informatics. 2004;73(6):493-501.

21. van Bussel B, Piipers E, Ferreira I, Castermans P, Nieuwenhuijzen-Kruseman A. Polymorbidity in diabetes in older people: consequences for care and vocational training. Postgrad Med J. 2007;83(986):763-7.

22. Cesani VI, Steudel HJ. A study of labor assignment flexibility in cellular manufacturing systems. Computers \& Industrial Engineering. 2005;48(3):571-91.

23. Li LLX, King BE. A healthcare staff decision model considering the effects of staff cross-training Health Care Management Science. 1999;2(1):53-61.

24. de Jong J, Heiligers P, Groenewegen P, Hingstman L. Part-time and full-time medical specialists, are there differences in allocation of time? BMC Health Services Research 2006;6(1):26.

25. Lugtenberg $M$, Heiligers $P$, de Jong J, Hingstman L. Internal medicine specialists' altitudes towards working parttime: a comparison between 1996 and 2004. BMC Health Services Research. 2006;6(1):126.

26. Heiligers P. Werken in deeltijd; slechts weinig specialisten kiezen de beste variant. Medisch Contact. 2001;56(47):1739-41.

27. Liker JK. The Toyola Way. New York: McGraw-Hill; 2004.

28. Womack JP, Jones DT. Lean Thinking - Banish waste and create wealth in your corporation. Revised and Updated. New York: Free Press; 2003.

29. Young T, Brailsford S, Connell C, Davies R, Harper P, Klein JH. Using industrial processes to improve patient care. BMJ. 2004;328(7432); 162-4.

30. Schroer BJ. Simulation as a tool in understanding the concepts of lean manufacturing Simulation-Transactions of the Sociely for Modeling and Simulation International. 2004;80(3): 171-5.

31. Cuatrecasas Arbós L. Design of a rapid response and high efficiency service by lean production principles: Methodology and evaluation of variability of performance. International Journal of Production Economics. 2002;80(2): 169-83.

32. Tummers GER, Landeweerd JA, Van Merode GG. Work organisation, work characteristics and the psychological effects on nurses in the Netherlands. International Journal of Stress Management. 2002;9(3): 183-206.

33. Moloney ED, Bennett K, Silke B. Effect of an acute medical admission unit on key quality indicators assessed by funnel plots. Postgraduate Medical Journal. 2007;83(984):659-63.

34. Moloney ED, Smith D, Bennett K, O'Riordan D, Silke B. Impact of an acute medical admission unit on length of hospital stay, and emergency department 'wait limes'. Qjm. 2005;98(4):283-9.

35. Rooney $T$, Moloney ED, Bennett $K$, O'Riordan D, Silke B. Impact of an acute medical admission unit on hospital mortality; a 5-year prospective study. QJM. 2008;101(6):457-65.

36. Vos $L$, van Oostenbrugge RJ, Limburg M, van Merode GG, Groothuis $S$. How to implemon process-oriented care. Accreditation and Quality Assurance, 2009;14(1):5.13.

37. Hendrich At, Lee N. Intra-unit patient transports: Time, motion, and cost impact on hospita efficiency. Nursing Economics. 2005;23(4):157.64.

38. Walley P, Silvester K, Steyn R. Managing Variation in Demand: Lessons from the UK National Health Service. Journal of Healtheare Management, 2006;51(5):309.20.

39. Walley P. Designing the accident and emergency system: lessons from manufacturing. Emerg Med J. 2003;20(2):126-30. 


\section{CHAPTER 7}

40. Leers EGE, Molema JJW, G.G. VM. De inrichting en functie van éénpersoonskamers in ziekenhuizen. Maastricht: Universiteit Maastricht; 2005.

41. Vissers JMH, Bertrand JWM, De Vries G. A framework for production control in health care organizations. Production Planning \& Control. 2001;12(6):591-604.

42. Kollberg B, Dahlgaard JJ, Brehmer P.O. Measuring lean initiatives in health care services: issues and findings. International Journal of Productivity and Performance Management. 2007;56(1):7-24.

43. Moses H, III, Thier SO, Matheson DHM. Why Have Academic Medical Centers Survived? JAMA. 2005;293(12): 1495-500.

44. Bohmer RMJ. Medicine's Service Challenge: Blending Custom and Standard Care. Health Care Management Review. 2005;30(4):322-30.

45. Sousa $R$, Voss CA. Contingency research in operations management practices. Journal of Operations Management. 2008;26(6):697-713.

46. Natarajan RN. Transferring best practices to healthcare: opportunities and challenges. The TQM Magazine. 2006; 18(6):572-82.

47. Adler PS, Goldoflas B, Levine DI. Flexibility versus efficiency? A case study of model changeovers in the Toyota Production System. Organization Science. 1999;10(1):43-68.

48. De Treville S, Antonakis J. Could lean production job design be intrinsically motivating? Contextual, configurational, and levels-of-analysis issues. Journal of Operations Management. 2006;24(2):99-123.

49. Baars IJ, Molema JJW, Groothuis S, van Merode GG. Programma deeltiidwerken medisch specialisten : computer simulatie onderzoek. Maastricht: Universiteit Maastricht; 2004.

50. Molema JJW, Kleinschiphorst M, Groothuis S, Pavlova MI, Groot WNJ, Van Merode GG. The effects of lengthening planned working hours in hospitals. A study on request of the Nethderlands board for hospital facilities. (in Dutch; summary in English). Utrecht; 2004.

51. Vos L, Groothuis S, van Merode G. Evaluating hospital design from an operations management perspective. Health Care Management Science. 2007;10(4):357.64.

52. Baars IJ, van Merode GG. A planning tool for multidisciplinary youth care evaluated; A case study. International Journal of Medical Informatics. 2008;77(5):315-23.

53. Zinn JS, Mor V. Organizational structures and the delivery of primary care to older Americans. Health Services Research. 1998;33(2):354-80.

54. Kast FE, Rosenzweig JE. Organization and management: a systems and contingency approach. 3rd ed. ed. New York: McGraw-Hill; 1979.

55. Murray $M$, Berwick DM. Advanced Access: Reducing Waiting and Delays in Primary Care. JAMA. 2003;289(8):1035-40.

56. Noon CE, Hankins CT, Cote MJ. Understanding the impact of variation in the delivery of healthcare services. Journal of Healthcare Management. 2003;48(2):82.

57. Berwick DM. A primer on leading the improvement of systems. BMJ. 1996;312(7031):619

58. Editorial. Keeping women in hospital and academic medicine. The Lancet. $2001 ; 358(9276): 83$ 
Summory

Someruvahing 


\section{Summary}

Most hospitals do not seem able to adequately match demand and supply. This can be derived from the fact that most hospitals are characterized by waiting lists and in-process waiting times as well as inefficient use of (human) resources. By improving the match between demand and supply, better access to healthcare in terms of reduced waiting times and better use of resources can be achieved. Such an improved match is important; especially, since demand on healthcare by the ageing population as well as demand complexity are currently increasing.

This thesis aims to study opportunities for matching supply to demand in hospitals. The central research question studied is: "given the variability and complexity of demand in a hospital, how should planning and control be organized so that the system structure enables a match between supply and demand, resulting in low patient waiting times and high resource utilization?" The main assumption for the research performed is that flexibility in supply provides opportunities for matching supply to demand. To ground this assumption, the various chapters of the thesis introduce studies on how flexibility in resource volume and mix can be created in hospitals and how this affects patient waiting times and resource utilization.

In chapter 2 supply flexibility is studied from the perspective of creating partime jobs. Sources of supply flexibility in hospitals have not before been searched in the structure of jobs. The results in chapter 2 provide evidence that partime work contracts can increase the opportunity for both doctors and patients to improve output. A prerequisite for this is that work contracts selected fit with the characteristics of the process they are to be implemented in

Chapters 3 and 4 bring the issue of specialty labeling of hospital beds up for discussion. A case is discussed of a general hospital that wants to omit most of these labels. Chapter 3 focuses on labels for acute care beds especially, whereas chapter 4 takes into account the interrelations between the organization of acute and elective care beds. The results show that when beds are no longer specialty labeled a new structure arises. This structure consists of larger bed aggregates that are more flexible as they can admit different patient types. The new structure creates opportunities for streamlining patient flows and minimizing queves and patient transfers. Overall, the results of chapters 3 and 4 infer that breaking down some of the functional barriers in 
hospitals can improve performance, without having to draw on limited budgets and bed pools.

Chapters 5 and 6 discuss the Aravind Eye Hospitals in South India. At Aravind, patients have direct access to both outpatient and inpatient services, at a fraction of the costs in Western hospitals. To study the enabling factors in the structure of an Aravind Eye Hospital, in chapter 5 a case study is discussed and in chapter 6 a simulation study. The results show that Aravind's answer to demand variability is reactive decision making. Aravind has created variability in its resource mix and volume to increase its responsiveness to actual demand. On a daily basis, decisions can be made to switch staff between units or tasks, adapt staff working hours, and/or reroute patients between units. The structural factors creating the variety are cross-skillfulness of staff, decentralized decision authority, and process standardization. Experimenting with these three factors shows that the structure at Aravind is indeed most enabling supply flexibility and results in the best output.

Hospitals should ensure a structure where demand generates supply through a planning and control system that takes into account the complexity and variability of demand and does justice to quality of work preferences. The research in this thesis proves that increased supply flexibility creates opportunities for this. Variety in resources creates room for reactive decision making to match supply to actual demand especially.

Opportunities for creating variety in resources can be found in work contracts, staff skills and education, resource labeling, and the placement of staff and their decision authority in the structure. A hospital that ensures that it has at its disposal more generally labeled resources and cross-skilled staff with varying work contracts and who share decision authority can create a structure where supply is matched to demand. Such a structure exceeds the current more functionalistic and rigid structures in hospitals. Also, it this structure the time window for reactive decisions can be narrowed from months or weeks to days, so that all patients can have direct access to hospitals and the care they demand. 


\section{Samenvatting}

Veel van de huidige ziekenhuizen lijken niet in staat tot het creëren van een goed evenwicht tussen de zorgvraag en het zorgaanbod. De huidige wachttijden voor toegang to ziekenhuizen en binnen ziekenhuizen enerzijds en inefficiënt gebruik van mensen en middelen anderzijds getuigen hiervan. Door te streven naar meer afstemming fussen vraag en aanbod kunnen de resultaten worden verbeterd. Het feit dat sprake is van een toename in de vraag naar zorg en dat ook de complexiteit van de zorgvraag toeneemt, maken deze verbeteringen hoogst noodzakelijk.

Dit proefschrift heeft tot doel na te gaan hoe, gegeven de variabiliteit en complexiteit van de zorgvraag, planning en control in ziekenhuizen georganiseerd kan worden, zodanig dat de systeemstructuur een evenwicht tussen vraag en aanbod waarborgt en resulteert in lage wachttijden voor patiënten en efficiënt gebruik van mensen en middelen. Hierbij is aangenomen dat flexibiliteit in aanbod mogelijkheden geeft voor het streven naar dit evenwicht. Om deze aanname te verantwoorden wordt in de verscheidene hoofdstukken van dit proefschrift onderzocht hoe aanbodflexibiliteit in mix en volume kan worden gecreëerd en wat de effecten hiervan zijn op wachttijden en utiliteit.

Hoofdstuk 2 bespreekt een onderzoek naar de mogelijkheden en effecten van deeltijwwerken door medisch specialisten. Niet eerder is onderzoek gedaan naar bronnen voor aanbodflexibiliteit in ziekenhuizen vanuit het perspectief van werkcontracten. De resultaten van het onderzoek maken inzichtelijk dat deeltijdwerken niet alleen voor specialisten, maar ook voor patiënten een verbetering van resultaten kan opleveren. Voorwaarde hierbij is dat de werkcontracten zijn afgestemd op het proces.

Hoofdstuk 3 en 4 stellen de wijze waarop bedden in ziekenhuizen worden gelabeld ter discussie. De hoofdstukken introduceren een casus van een algemeen ziekenhuis waar de beddentoewijzing niet meer zal plaatsvinden volgens de gebruikelijke labels van medische specialismen, maar waar meer algemene labels worden geïntroduceerd. De resultaten van de analyses in de hoofdstukken laten zien dat een dergelijke verhoging van het aggregatieniveau van bedden in het ziekenhuis leidt tot een nieuwe structuur. In deze structuur kunnen bedden flexibeler worden ingezet voor verschillende typen patiënten. Hierdoor kunnen patiënten beter doorstromen en zal ook het aantal wachtrijen en verplaatsingen afnemen. Uit de resultaten kan worden

\section{8}


afgeleid dat de huidige functionele schotten in ziekenhuizen moeten worden afgebroken. Dit verbetert de prestaties zonder extra inzet van de beperkte budgetten of beddencapaciteit.

Hoofdstuk 5 en 6 introduceren de Aravind oogziekenhuizen uit Zuid-India. Patiënten van Aravind hebben directe toegang tot zorg, voor een fractie van de kosten in Westerse ziekenhuizen. Om na te gaan welke factoren in de ziekenhuisstructuur deze resultaten mogelijk maken, zijn een casusonderzoek en simulatieonderzoek vitgevoerd. De resultaten tonen dat Aravind's oplossing voor variabiliteit in de vraag reactieve besluitvorming is. Om te kunnen reageren op de actuele zorgvraag heeft Aravind variëteit gecreëerd in zowel de mix als het volume van mensen en middelen. Dagelijks kan worden besloten om werknemers uit te wisselen tussen taken en processen, werktijden aan te passen en/of stromen van patiënten langs andere afdelingen te leiden. De structurele factoren die de variëteit creëren zijn multidisciplinaire vaardigheden van medewerkers, decentrale beslissingsautoriteit en gestandaardiseerde processen. Verschillende experimenten met deze drie factoren laten zien dat de flexibiliteit in aanbod bij Aravind leidt tot de laagste wacht- en doorlooptijden.

Ziekenhuizen zouden een structuur moeten waarborgen waarbinnen he aanbod zich kan aanpassen aan de actuele vraag. Het onderzoek in dit proefschrift toont aan dat aanbodflexibiliteit mogelijkheden hiervoor creëert. Aanbodflexibiliteit wordt vergroot door meer variëteit in werkcontracten en werknemervaardigheden, meer algemene labels voor middelen als bedden, gedeelde beslissingsautoriteit en een minder rigide plaatsing van mensen en middelen in de structuur. Voor een ziekenhuis, dat dergelijke variëteit kan waarborgen, kan een structuur worden ontworpen waarbinnen niet langer wordt gestreefd naar functionele schotten, maar naar een continu evenwicht tussen vraag en aanbod zonder beperking van schotten. In een dergelijke structuur kan de tijdshorizon voor het nemen van reactieve beslissingen worden teruggebracht van maanden en weken naar dagen, opdat alle patiënten directe toegang hebben tot het ziekenhuis. 


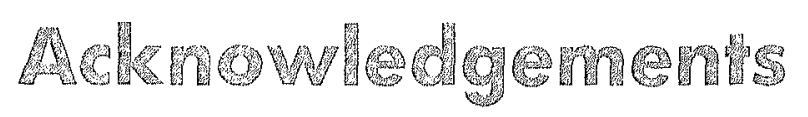

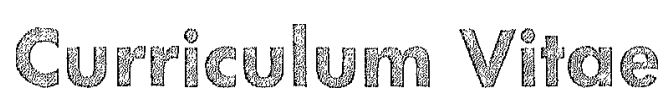

List: of Publicanions 


\section{Acknowledgements}

Flatter me and I may not believe you; Criticize me and I may not like you; Ignore me and I may not forgive you; Encourage me and I may not forget you. W. A. Ward

Voor de totstandkoming van dit proefschrift ben ik velen dank verschuldigd voor hun 'encouragement'. Niemand zal ik vergeten; enkelen in het bijzonder wil ik noemen.

Prof. Dr. G.G. Van Merode, Frits, als begeleider en promotor heb iii mii aangemoedigd mij te ontwikkelen in de wetenschap. Zes jaar lang heb ik prettig en goed met jou samengewerkt. Daarbij heb iii mij alle ruimte en kansen gegeven. Dank!

Dank ook aan de medewerkers van de verschillende ziekenhuizen waar ik de afgelopen jaren mijn onderzoeken heb vitgevoerd.

A special thanks to the people of the Aravind Eye Hospital in Madurai and Aravind Harmony Guesthouse for making me feel at home far away from home.

Al mijn oud-collega's van de Universiteit Maastricht wil ik danken voor hun dagelijkse collegialiteit, In het bijzonder wil ik bedanken: Lotte, voor jouw niet aflatende collegialiteit en vriendschap vanaf de eerste dag, ook buiten de UM en Maastricht, tot in Londen en Seatle; Irma, voor de leuke en ontspannen werksfeer; Janneke en Adrienne, voor de extra kleur aan mijn laatste maanden BEOZ en Maastricht; Cor Spreeuwenberg en Bert Vrijhoef, voor jullie aanmoediging om een carrière in de wetenschap te starten en jullie interesse in hoe ik na 2003 een vervolg hieraan gaf!

Catelijne en Fleur, jullie hebben mii als paranimfen en oud-collega's aangemoedigd te werken naar mijn doel: promoveren. Zowel de discussies hierover als over alles(!) wat daar de afgelopen jaren bij hoorde, waren waardevol. Ik ben dankbaar voor de vriendschap die er vit is voortgekomen.

Leanne, bedankt voor het prachtige ontwerp van de kaft! 
ACKNOWLEDGEMENTS

Mijn vrienden, familie en mijn schoonouders en schoonzus wil ik bedanken voor de interesse in mijn werk, de afleiding van dit werk, maar nog het meest voor de aanmoediging om mijn proefschrift af te ronden terwijl dit privé LATten betekende. Jullie hebben mij én Adriaan hier altijd in gesteund!

Mijn ouders en mijn broer ben ik oneindig dankbaar voor hun aanmoediging mezelf te ontwikkelen en de keuzes te maken waarin ik trouw kan blijven aan mijzelf.

Liefste Adriaan, aan aanmoediging van jouw kant geen gebrek! Je was en bent er altiid, ook op afstand. Het meest dankbaar ben ik voor wie iij bent, voor wie wij zijn en voor hoe ii mij laat stralen! "I love you not only for who you are, but also for who I am when I am with you". 


\section{Curriculum Vitae}

J.J.W. (Hanneke) Molema was born in Nijmegen, the Netherlands, on Augustus 2nd 1979. After finishing Grammar School in 1997, she started her studies in Health Sciences at Maastricht University in September 2007. In April 2003 Hanneke graduated on a research focused on quality of COPD care from the patient's perspective.

In February 2003, Hanneke had started working as a junior researcher at Maastricht University, at the faculty of Health, Medicine and Life sciences (until 2007 the faculty of Health Sciences). She first worked at the department of Nursing Science after which she joined the department of Health Organisation, Policy and Economics. In January 2005, Hanneke enrolled in a PhD track, under the supervision of Professor Frits van Merode, within the School for Public Health and Primary Care (CAPHRI) at Maastricht University. Hanneke's research focused on workflow and system design analysis in healthcare, in particular hospitals. As part of her research, Hanneke visited and studied a variety of hospitals and hospital departments within the Netherlands. In the summer of 2008, Hanneke spent three months in Madurai, India, to perform a workflow analysis at the local Aravind Eye Hospital. This hospital is part of the Aravind Eye Care system; the world's biggest eye care system.

During her time as a PhD student, Hanneke was a member of the project group "focused factories in Dutch healthcare". For two years, she also was PhD advisor of the scientific committee (COB) of the faculty of Health, Medicine and Life sciences. Additionally, she lectured within the Master of Health Policy, Economics and Management and the Master of Health Service Innovation and supervised students during the writing of their Master theses.

In June 2009, Hanneke started working as a researcher and consultant at TNO Quality of Life, department of Healthcare Innovation. 


\section{List of publications}

Articles

- Molema JJW, Groothuis S, Baars IJ, Kleinschiphorst M, Leers EGE, Hasman A, van Merode GG. Healtheare system design and parttime working doctors. Health Care Management Science. 2007;10(4):365.71.

- Steens L, Molema JJW, Meers E, van Merode GG. Meer ingrepen in minder tijd. Efficienter proces op de OK verkort de wachllijsten. Medisch Contact 2005;60(38):558-560.

- Molema JJW, Vrijhoef HJM, Bögels A, Spreeuwenberg C. Kwaliteit van zorg voor COPD patiënten: een verkennende studie. Tijdschrift voor Gezondheidswetenschappen (TSG) 2005(6):349-354

- Van Merode F, Molema H \& Goldschmit H. GUM and six sigma approaches positioned as deterministic tools in quality target engineering. Accreditation and Quality Assurance: 2004 Dec; 10(1-2):32-6.

- Baars IJ, Molema JJW, Groothuis S, Hasman A, Jacobs MJHM, Vermaeten GJ, Van Merode GG. Deeltiidwerk geen half werk, computer simulatie toont aan dat ook de chirurg partime kan werken. Medisch Contact 2004: 59(23):942-945.

Reports

- Leers E, Molema JJW, Van Merode GG. De inrichting en functie van éenpersoonskamers in ziekenhuizen. Maastricht; 2005. ISBN: 9085170478

- Kleinschiphorst M, Molema JJW, Groothuis S, van Merode GG. Deeltijdwerken Medisch Specialisten - Computer simulatie onderzoek II. Maastricht; 2005. ISBN: 9080871443

- Molema JJW, Kleinschiphorst M, Groothuis S, Pavlova MI, Groot WNJ, Van Merode GG. De effecten van bedriffstijdverlenging in ziekenhuizen. Utrecht; 2004. ISBN: 9080871427

- Baars IJ, Molema JJW, Groothuis S, van Merode GG. Programma deeltiidwerken medisch specialisten: computer simulatie onderzoek. Maastricht; 2004. ISBN: 9080871419

Presentations

- Baars IJ, Molema JJW, Van Merode GG, Arntz A, Evers SMAA. Care delivery system of mental healthcare: from concept to model. ORAHS 2008, Toronto, Canado.

- E Bredenhoff, WH van Harten, JJW Molema \& G.G. Van Merode. Focused factories in de Nederlandse Gezondheidszorg. 2e Kwaliteitsforum CBO/NVKZ, 2007 Nieuwegein.

Molema JJW, Groothuis S, Van Merode GG. Improving patient flow in a hospital. ORAHS 2007, Saint-Étienne, France

- Molema J.J.W., Groothuis S., Baars I.J., Kleinschiphorst M., Leers E.G.E., Hasman A., Van Merode G.G., Redesigning healthcare through simulation. International Conference on Health Sciences Simulation 2007; San Diego, USA

- Molema JJW, Groothuis S, Van Merode GG. Deeltijdwerken en logistiek. Najaarsconferentie Nederlandse Internisten Vereniging, 2005, Amersfoort

- Molema JJW, Groothuis S, Kleinschiphorst M, Pavlova MI, van Merode GG. Applying computer simulation to the method of target cosling. In: Anderson JG, Katzper $M$ (editors). International Conference on Health Sciences Simulation 2005, New Orleans, USA.

- Van Merode GG, Molema JJW, Kleinschophorst M, Groothuis S. Logistical perspective on hospital buildings. Symposium College Bouw Ziekenhuisvoorzieningen, 2004, Den Haag.

- Molema JJW, Vrijhoef HJM, Spreeuwenberg C. Kwaliteit van COPD zorg beoordeeld door de patiënt. CAHAG jaarconferentie 2004, Utrecht. 